\title{
Sucesión internacional y reenvío
}

\author{
Alfonso-Luis Calvo Caravaca \\ Catedrático de Derecho internacional privado \\ Universidad Carlos III de Madrid \\ $\mathrm{y}$ \\ Javier Carrascosa González
}

Profesor titular de Derecho internacional privado Universidad de Murcia

Recibido: 27.04 .07

Aceptado: 15.06 .07

\begin{abstract}
Resumen: Las recientes sentencias de los tribunales españoles en materia sucesoria han vuelto a cuestionar el papel del reenvío en dicho contexto. Una norma tan parca como el art. 12.2 Cc. ha sido objeto de un desarrollo judicial de alta calidad que ha llevado a cabo el Tribunal Supremo. En dicha línea, el reenvío confirma que puede ser empleado para potenciar la mejor localización de las sucesiones en los casos internacionales. En este trabajo se proporciona una visión sobre el reenvío en materia sucesoria que concilia las aparentemente contradictorias sentencias del Tribunal Supremo en la materia y que pone de relieve los aciertos y errores de la jurisprudencia de las Audiencias en torno a la cuestión. El debate sobre la intensidad con la que el reenvío puede y/o debe ser empleado está más abierto que nunca. Dicha situación no sólo no es perniciosa, sino que es saludable. En DIPr. las ideas fluyen, se intercambian, evolucionan. El dogmatismo no tiene sitio en el mundo de los conflictos de Leyes.
\end{abstract}

Palabras clave: Sucesión mortis causa. Reenvío. Testamentos. Conflicto de Leyes. Ley nacional.

Abstract: The last judgments of the Spanish Courts have given a relevant role to the so called renvoi. As an instrument of Justice in the world of Conflicts of Laws, renvoi can be used as legal device to improve localization of «international» successions. This essay shows how the three most remarkable decisions of the Spanish Supreme Court concerning renvoi in the field of succession can be listened like three different movements played by one single orchestra. Renvoi in favor of the Spanish Substantive Law may be accepted when the deceased's last domicile was in Spain and all the inmovables involved in the succession are situated in Spain. In any case, renvoi can not provoke the legal splitting of the succession, because under Spanish Law, succession must be governed by one single Law only.

Key words: Renvoi. Succession. Last domicile. Lex rei sitae. Testaments. National Law. Conflict of Laws.

Sumario: I. Introducción: los problemas de la sucesión internacional.- II. Ley aplicable a la sucesión en Derecho internacional privado español.-III. Sucesión internacional y reenvío en Derecho internacional privado español: antecedentes históricos. 1. El caso Forgo y el debate doc- 
trinal sobre el reenvío.2. El reenvío en Derecho internacional privado español antes de 1974. 3. El reenvío en Derecho internacional privado español desde 1974 a 1996.--IV. El reenvío de primer grado en materia sucesoria: los arts. 9.8 y 12.2 del Código Civil. 1. El reenvío como herramienta al servicio del art. 9.8 del Código Civil. 2. Supuestos en los que procede acoger el reenvío. A) Primera circunstancia: la unidad legal de la sucesión. B) Segunda circunstancia: un índice positivo de reenvío. a) Primer índice: el reenvío como mecanismo para resolver un «falso conflicto de leyes». b) Segundo índice: el reenvío como «ajuste de la localización». 3. Aspectos irrelevantes para aceptar o negar el reenvío. A) La «armonía internacional de soluciones» en sentido conflictual. B) El contenido material de las Leyes en conflicto. C) La voluntad del testador. D) El tipo de conexión empleado por la norma de conflicto extranjera. 4. Aplicación de las normas de conflicto extranjeras en materia de sucesión mortis causa. 5. Reenvío y conflicto de sistemas.-V. Los tribunales españoles y el reenvío en materia sucesoria desde 1996.1. Doctrina del Tribunal Supremo sobre el reenvío en materia sucesoria. 2. Los tribunales inferiores y el reenvío en materia sucesoria desde 1996.-VI. Conclusión.

\section{Introducción: Los problemas de la sucesión internacional}

1. Reflexionar sobre las relaciones entre el reenvío y las sucesiones en Derecho internacional privado (DIPr.) es pisar suelo sagrado en el templo de los conflictos de Leyes. El reenvío es un clásico de los conflictos de Leyes. Un clásico sobre el que los expertos debaten desde hace más de ciento cincuenta años. Por ello, toda reflexión que se realiza en este contexto debe estar presidida por la prudencia y el diálogo entre las propuestas jurídicas. Las páginas que siguen constituyen un conjunto de modestas observaciones sobre la operatividad del reenvío en materia sucesoria en DIPr. español.

2. Las sucesiones constituyen un sector eternamente controvertido del DIPr. Ya en el siglo XIX escribía el gran maestro francés A. LAINÉ, quien sintetizó en una obra clave la aportación del «movimiento estatutario» en DIPr., que las sucesiones conforman «una de las cuestiones más arduas del Derecho internacional privado» ${ }^{1}$. La complejidad de la regulación jurídica de las sucesiones en DIPr. deriva de varios factores: a) Las sucesiones se sitúan en la «intersección» entre el Derecho de la persona y de la familia, por un lado, $\mathrm{y}$ el derecho de los bienes por el otro, como ha puesto de relieve numerosa doctrina (M. Revillard, A. Rodríguez Benot, A. Miaja de la Muela,

${ }^{1}$ A. LAINÉ, Introduction au droit international privé, contenant une étude historique et critique de la théorie des status, (dos vols.), París, 1888, (reimpresión facsimil de Topos Verlag, Frankfurt am Main), 1970, p. 279. 
H. BATTifol, H. LeWALD, entre otros muchos ${ }^{2}$ ). Ello complica su régimen jurídico; b) Las sucesiones son el mejor banco de pruebas para observar todas las cuestiones clásicas del DIPr. En las sucesiones aparecen con extrema frecuencia problemas de calificación, reenvío, orden público internacional, fraude de Ley internacional, remisión a sistemas plurilegislativos ad extra y ad intra, prueba del Derecho extranjero, conflicto internacional transitorio, adaptación y cuestión previa internacional (A.-L. CALvo CARAVA$\left.\mathrm{CA}^{3}\right)$; c) Las sucesiones suscitan no sólo cuestiones de DIPr., sino también, en España, cuestiones de Derecho interregional.

3. A lo anterior se añade, en lo que atañe al Derecho español, un dato sociológico. La movilidad internacional de las personas, de los capitales y de las inversiones ha multiplicado el número y la complejidad de las sucesiones «internacionales». Y ha hecho del sector sucesorio, un sector del DIPr. español también profundamente «multicultural»(P. Diago DiAGO ${ }^{4}$ ). Por ello, cada vez es más frecuente que el patrimonio del causante se encuentre en Estados distintos, que el causante ostente nacionalidad extranjera o que tenga su residencia habitual en otro país, que el testamento se otorgue o redacte en país extranjero, y que existan herederos con residencia en diferentes países. Y cada vez es más frecuente la necesidad de ejecutar en España sentencias extranjeras en materia sucesoria y de hacer valer en España actos notariales extranjeros en materia sucesoria, y también es cada vez más frecuente la ejecución en el extranjero de sentencias y actos notariales españoles en materia sucesoria.

4. Una de las cuestiones más debatidas y más complejas que suscitan las sucesiones internacionales es el célebre fenómeno conocido como el «reen-

\footnotetext{
${ }^{2}$ M. Revillard, Droit international privé et communautaire: pratique notariale, Defrénois, 6. ${ }^{\text {a }}$ ed., Paris, 2006, pp. 301-425, esp. pp. 301-304; H. LEWALD, «Questions de droit international des successions», $R C A D I, 1925$, vol. 9, pp. 15-225, esp. pp. 21-22; A. RoDRíGUEZ BENOT, «Sucesión mortis causa y modelos de familia en el tráfico jurídico externo», en A.-L. Calvo Caravaca / E. Castellanos Ruiz (Dir.), El Derecho de Familia ante el siglo XXI: aspectos internacionales, Colex, Madrid, 2004, pp. 675-704; A. MiAJA DE LA Muela, Derecho internacional privado II, 1987, pp. 521-543 (revisado por N. BouZA VIDAL); H. BATIFFOL, «Réflexions sur la loi applicable aux successions», RabelsZ., 1958, pp. 791-801.

3 A.-L. Calvo Caravaca en J. D. González Campos y Otros, Derecho internacional privado parte especial, 6. ${ }^{a}$ ed., Eurolex, 1995, pp. 393-422; ID., «Art. 9.8 Cc.», Com.Cc. y Comp.For., 2. ${ }^{a}$ ed., 1995, pp. 350-391; ID., «La sucesión hereditaria en el Derecho internacional privado español», $R G D, 1986$, pp. 3103-3138.

${ }^{4}$ P. Diago Diago, «La sucesión y el fenómeno migratorio desde la perspectiva del Derecho internacional privado español», en J. L. Collantes González / F. SERRANo Migallón, El Derecho español y europeo, Derecho civil a 200 años del Código de Napoleón, Ed. Porrúa - UNAM, México, 2005, pp. 671-692.
} 
vío» ${ }^{5}$. Surge el reenvío, como es bien sabido, cuando la norma de conflicto del DIPr. del país cuyos tribunales conocen del asunto remite, para la regulación del caso, a un Derecho extranjero, ordenamiento que contiene una norma de conflicto que, a su vez, remite la regulación de la situación privada internacional al Derecho de otro país, que puede ser el Derecho del país cuyos tribunales conocen del asunto o el Derecho de un tercer país ${ }^{6}$.

5. Sobre la conveniencia de aceptar o rechazar el reenvío se han escrito auténticas montañas de libros, artículos doctrinales, estudios, trabajos, comentarios variopintos, tesis doctorales, notas de jurisprudencia y todo lo imaginable ${ }^{7}$. Esta situación se explica porque el reenvío presenta la virtud, o

\footnotetext{
${ }^{5}$ El más completo y profundo estudio sobre la cuestión del reenvío en materia sucesoria y su relación con los principios de universalidad y unidad de las sucesiones es, en la doctrina española, el firmado por E. CASTELlanos RuIZ, Unidad vs. pluralidad legal de la sucesión internacional, Granada, Comares, 2001. La autora ha actualizado este trabajo con estudios posteriores. Vid. ad ex.: E. CASTEllanos RuIZ, «Art. 9.8 Cc.», Legislación de Derecho internacional privado, comentada y con jurisprudencia, Madrid, Colex, 2002, pp. 57-69; ID., «Reenvío, unidad de la sucesión y armonía internacional de soluciones en el Derecho sucesorio», Internacional Law. Revista Colombiana de Derecho Internacional, diciembre2003, pp. 211-259; ID., «Reenvío, unidad de la sucesión y armonía internacional de soluciones en el Derecho sucesorio: antes y después de la STS de 23 septiembre 2002», en A.L. Calvo Caravaca/ E. Castellanos Ruiz (dirs.), El Derecho de familia ante el siglo XXI: aspectos internacionales, Madrid, Colex, 2004, pp. 239-269.

${ }^{6}$ El status quaestionis actual sobre el reenvío puede seguirse en A.-L. CALvo CARAVACA / J. Carrascosa GonzÁlez, Derecho internacional privado, vol. I, Granada, Comares, 8. ${ }^{a}$ ed., 2007, pp. 240-250.
}

${ }^{7}$ La bibliografía sobre el reenvío es inmensa y completamente inabarcable. Todos los manuales y tratados generales sobre el DIPr., antiguos y modernos, dedican unas páginas, con frecuencia muy sugestivas, al reenvío. Por lo que se refiere a los estudios específicos sobre el reenvío, puede verse, en la doctrina española: M. Aguilar Navarro, «De nuevo sobre el reenvío», REDI, vol. III, 1950, pp. 803-838; P. BLANCO-MORALES LIMONES, «¿Existe en nuestro Derecho una acción para pedir la declaración de la aplicación de la Ley española a la sucesión de un inglés fallecido en España?», $R G D$, núms. 613-614, oct.-nov. 1995, pp. 11341-11347; A. BorRás RodrígueZ, «Art. 12.2 Cc.», Com.Cc. Min. Justicia, 1991, pp. 140-142; ID., Calificación, reenvío y orden público en el Derecho interregional español, Bellaterra, UAB, 1984, pp. 55-68; N. BouZA VIDAL, «Art.12.2 Cc.», Com.Cc. y Comp.For., 2. ${ }^{a}$ ed., 1995, pp. 880-894; J. CARRASCOSA GONZÁLEZ, «Nota a la SAP Badajoz 11 julio 1995 (sucesión hereditaria)», REDI, vol. XLVIII, 1996, pp. 312-321; J. A. CARRILlo SALCEDO, «Art. 12.2 Cc.», Com.Cc. y Comp.For., 1978, pp. 433-437; L. Gestoso TudelA, «La teoría de la referencia en Derecho internacional privado», Anales de la Universidad de Murcia, Curso 1946-1947, pp. 193-203; J. L. IRIARTE ÁNGEL, «Doble reenvío y unidad de tratamiento de las sucesiones», $R G D, 1989$, núm. 537, pp. 3561-3580; A. MARíN LóPEZ, «El reenvío en el Derecho español», REDI, 1956, vol. IX, pp. 677-687; ID., «Las cuestiones generales de Derecho internacional privado en las recientes codificaciones europeas, el reenvío», $A C$, núm. 47, 18-24 diciembre 1995, pp. 941-957; A. MiAJA DE LA MuELA, «Un caso de aplicación de reenvío de primer grado en España», REDI, 1958, vol. XI, pp. 573-585; ID., «Cuestiones referentes a la norma de conflicto. El reenvío», Estudios sobre el Titulo Preliminar 
el pecado, según se mire, de «desactivar» todo el sistema de normas de conflicto. En efecto, si opera el reenvío, la Ley reguladora de una sucesión inter-

del Código civil, vol. II, Jaén, Edersa, 1977, pp. 307-366, concr. pp. 339-439; J. PÉREZ MoNTERO, «Consideraciones sobre el reenvío», Anuario AIHLADI, 1959, pp. 183-200; ID., «La contribución del profesor Maridakis a la doctrina sobre el reenvío en el Derecho internacional privado», Eranion en honor Prof. Maridakis, vol. III, Atenas, 1964, pp. 247-321; ID., «Art. 12.2 Cc.», Com.Ref.Cc., 1977, pp. 592-638; E. PÉrez VERA, «Un caso reciente de Derecho internacional privado, la sucesión de un argentino domiciliado en España. Nota sobre la sentencia del Tribunal Supremo de 27 de mayo de 1968», REDI, 1968, vol. XXII, pp. 561-570; A. PÉREZ VoITURIEZ, «El reenvío en el Derecho internacional privado español: una interpretación actualizada», Revista Jurídica del Notariado, núm.13, enero-marzo 1995, pp. 257-337; M. SÁINZ LóPEZ NEGRETE, «Problemas de reenvío en la sucesión de inmuebles de extranjeros en España», Boletín Ilustre Colegio Notarial de Granada, abril 1993, pp. 879-893; S. SÁNCHEZ LORENZO, «Reenvío», EJB, 1995, pp. 5645-5646; J. SuAY Milio, «Una solución jurisprudencial inglesa: el doble reenvío», REDI, 1956, vol. IX, pp. 87-122; E. THOMAS DE MAURICE, «El heredero inglés. El proceso sucesorio inglés y los problemas de las normas de conflicto de la ley inglesa», Boletín Ilustre Colegio Notarial de Granada, noviembre 1993, pp. 2651-2655; J. D. TRIAS GIRÓ, «De la théorie du renvoi devant les tribunaux espagnols», JDI Clunet, 1901, pp. 905-921; ID., «La solución de retorno (Renvoi) ante los Tribunales de España», RJC, 1901, pp. 173-189. En la doctrina extranjera, pueden consultarse, entre otros muchos, los siguientes estudios: E. H. Аввот, «Is the Renvoi a Part of the Common Law?», The Law Quarterly Review, 1908, pp. 133-146; P. ARMINJon, «Le Renvoi», RCDIP, 1922/1923, pp. 565-587; T.M.C. AsSER, «Quelques observations concernant la théorie ou le système du renvoi», JDI Clunet, 1905, pp. 40-43; J.-F. AuBERT, «Renvoi in Swiss Law», AJCL, 1956, pp. 478-486; ID., «Une révision du droit international privé: la 'Théorie du renvoi' de M. Francescakis», Schweizerisches Jahrbuch für internationales Recht, 15, 1958, pp. 187-214; G. BALLADORE-PALLIERI, «Il concetto di rinvio formale e il problema del diritto internazionale privato», Rivista di Diritto civile, 1929, pp. 413-425; T. BAllarino, «Rinvio (Diritto internazionale privato)», EdD, 1989, vol. XL, pp. 10051113; C. L. VON BAR, «Die Rückverweisung im internationalen Privatrecht», Zeitschrift für internationales Privat- und Strafrecht mit besonderer Berücksichtigung der Rechtshilfe, 8 , 1898, pp. 177-188; G. BARILE, «In tema di rinvio di diritto internazionale privato», RDI, 1964, pp. 489-494; E. BARTIN, «Les conflits entre dispositions législatives de droit international privé. Théorie du renvoi», RDILC, 1898, pp. 129-159; G. BEITZKE, «Zuständigkeitsrückverweisung und verstecke Rückverweisung in Adoptionssachen», RabelsZ., 37, 1973, pp. 380-393; ID., «Rück- und Weiterverweisung im Internationalen Deliktsrecht», Walter Wilburg zum 70 Geburstag, 1975, pp. 31-39; N. BENTwICH, «De la théorie du renvoi dans la jurisprudence anglaise», JDI Clunet, 1912, pp. 716-727; A. BERNARDINI, Produzione di norme giuridiche mediante rinvio, Milan, Giuffre, 1966; E. BORIOLI, La notion du renvoi en droit positif suisse, Genève, 1967; A. BRIGGS, «ln Praise and Defence of renvoi», ICLQ, 1998, pp. 877-884; A. BUCHER, «Über die räumlichen Grenzen der Kollisionsnormen», en Festchrift Frank Vischer, Zürich, 1983, pp. 93-105; W. CHEN, Rück- und Weiterverweisung (Renvoi) in staatsvertraglichen Kollisionsnormen, Frankfurt am Main, Lang, 2004; J. DERRUPPÉ, «Plaidoyer pour le renvoi», TCFDIP, 1964-1966, pp. 181-107; C. T. EBENROTH Y U. EYLES, «Der Renvoi nach der Novellierung des deutschen Internationalen Privatrechts», IPrax, 1989, pp. 1-12; A. ELKIM, «La doctrine du renvoi en droit anglais», JDI Clunet, 1934, pp. 577-601; J. D. FALCONBRIDGE, «Le renvoi et la loi du domicile», RCDIP, 1948, pp. 45-71; J. D. FALCONBRIDGE, «Renvoi, Characterisation and Acquired Rights», Canadian Bar Review, 1939, vol. 17, pp. 379-ss.; A. FERRER-CORREIA, «La question du renvoi 
nacional no será ya la Ley nacional del causante, como indica el art. 9.8 Cc., sino otra Ley, la Ley que señalen las normas de conflicto del país del que es

dans le nouveau code civil portugais», Miscellany in honor of Ch. Fragistas, vol. II, Tesalónica, 1967, pp. 337-368; P. FIORE, «Du conflit entre les dispositions législatives de droit international privé. Théorie du renvoi», JDI Clunet, 1901, pp. 424-439 y 681-698; L. J. FOYER, «Requiem pour le renvoi?», TCFDIP, 1980-1981, pp. 105-120; P. FRANCESCAKIS, La théorie du renvoi et les conflits de systemes en droit international privé, París, Sirey, 1958; ID., «Renvoi», E. Dalloz DI, vol. II, 1969, pp. 751-759; C. GRASSETTI, «La dottrina del rinvio in diritto internazionale privato e la common law anglo-americana», RDI, 1934, pp. 141, 233-261 y 350-375; ID., «Questione pregiudiziale e dottrina del rinvio», RDIPP, 1965, pp. 87-107; E.D. GRAUE, Internationales Privatrecht Rück- und Weiterverweisung, Berlín, Schweitzer, 1981; ID., «Rück- und Weiterverweisung (renvoi) in den Haager Abkommen, Grandeur et déclin du renvoi dans les Conventions de Haye», RabelsZ., 1993, pp. 26-62; R. H. GRAVESON, «Le renvoi dans le droit anglais actuel», RCDIP, 57, 1968, pp. 259-265; E. N. GRISWOLD, «Renvoi revisited», Harvard Law Review, 1938, pp. 388-426; O. HARTwIEG, Der Renvoi im deutschen Internationalen Vertragsrecht, Frankfurt a.M., Berlín, 1967; W. HöHN, Die Frage der Rückverweisung im internationalen Privatrecht, Diss. Bern, 1944; M. A. JAGMETTI, Die Anwendung fremden Kollisionsrechtes durch den inländischen Richter, Zürich, 1961; E. JAYME, «Zur 'versteckten' Rück- und Weiterverweisung im IPR», Zeitschrift für Rechtsvergleichung, 1970, pp. 253-269; ID., «Zur Rückverweisung durch staatsvertragliche Kollisionsnormen», IPrax, 1981, pp. 17-29; F. KAHN, «Der Grundsatz der Rückverweisung im deutschen bürgerlichen Gesetzbuch und auf dem Haager Kongress fur internationales Privatrecht», Jherings Jahrbücher, 1896, pp. 366-392; U. KARTZKE, «Renvoi und Sinn der Verweisung», IPrax, 1988, pp. 8-13; W. J. KASSIR, Réflexions sur le renvoi en droit international privé comparé (contribution au dialogue des cultures juridiques nationales à l'aube du XXI'me siècle), Bruylant-Delta-LGDJ, 2002; G. KegEL, Die Grenze von Qualifikation und Renvoi im Internationalen Verjährungsrecht, Köln, Opladen, 1962; L. KRAMER, «Return of the Renvoi», New York University Law Review, 1991, pp. 979-1044; G. KuHNE, «Der Anwendungsbereich des Renvoi im Lichte der Entwicklung des internationales Privatrecht», Festschrift für Murad Ferid, 1988, pp. 251-267; A. LAINÉ, «La théorie du renvoi en droit international privé», RCDIP, 1906, pp. 605-643, 1907, pp. 313-339, 1908, pp. 661-674, 1908, pp. 729-758 y 1909, pp. 12-40; Y. LEQUETTE, «Le renvoi de qualifications», Mélanges dédiées a Dominique Holleaux, París, Litec, 1990, pp. 249-262; P. LeREBOURS-PIGGEONNIÈRE, «Observations sur la question du renvoi», JDI Clunet, 1924, pp. 877903; H. LEWALD, «La théorie du renvoi», RCADI, 1929-IV, vol. 29, pp. 519-616; ID., «Renvoi Revisited?», en Fragen des Verfahrens- und Kollisionsrechtes, Festschrift Hans Fritzsche, Zürich, 1952, pp. 165-180; M. LigeoIX, «La théorie du renvoi et la nature juridique du droit international privé», JDI Clunet, 1903, pp. 481-498, y 1904, pp. 551-567; E.G. Lorenzen, «The Renvoi Doctrine in the Conflict of Laws - Meaning of 'the Law of a Country'», Yale Law Journal, 1917/18, pp. 509-534 (también en ID., Selected Articles on the Conflict of Laws, New Haven, 1947, pp. 54-79); P. Louis-LuCAS, «Vue simplifiée du renvoi», RCDIP, 53, 1964, pp. 1-14; G. S. MARIDAKIS, «Le renvoi en droit international privé (Rapports provisoire, definitif et supplementaire)», Annuaire IDI, 1957, vol. II, pp. 17-53, 1-16, 54-125, y vol. I, 1963, pp. 497- 509; G. MASCH, «Der Renvoi. Plädoyer für die Begrenzung einer überflüssigen Rechtfigur», RabelsZ, 1997, pp. 285-312; L. MigLIORINO, «La questione del rinvio e le soluzioni accolte nelle convenzioni internazionali», RDIPP, 1996, pp. 499-512; J. MAURY Y J. DÉRRUPÉ, «Le renvoi», Juris Classeur droit international, fascículos 532A, 1962, 532 B (1962) y 532 C (1965); A. T. von Mehren, «The Renvoi and its Relation to Various Approachs to the Conflict-of-Law Problem», XX Century Compara- 
nacional del causante. El reenvío puede, así, «dinamitar» todas las normas de conflicto del país cuyas autoridades conocen del asunto. Por ello, por el hecho de que el reenvío puede «desactivar» las normas de conflicto como un auténtico deus ex machina, el reenvío es polémico. El reenvío se ha convertido en un campo de batalla de espectaculares enfrentamientos entre los expertos en DIPr., y también entre diferentes corrientes jurisprudenciales.

tive and Conflicts Law. Legal Essays in Honour of H.E.Yntema, Leyden, Sijthoff, 1961, pp. 380-394; L. MigLioRiNO, «La questione del rinvio e le soluzioni accolte nelle convenzioni internazionali», RDIPP, 1996, pp. 499-512; KL. MÜLLER, «Zum Problem der Gesamtverweisung», en Rechtsvergleichung und Rechtsvereinheitlichung. Festschrift Institut für ausländisches und internationales Privat- und Wirtschaftsrecht der Universität Heidelberg, Heidelberg, 1967, pp. 191-212; F. NAVARRETE, El reenvío en el Derecho internacional privado, Santiago, Editora Jurídica de Chile, 1969; R. DE NovA, «Considerazioni sul rinvio in diritto inglese», RDI, 1938, pp. 388-426; ID., «Il rinvio in Froland e Boullenois», DI, 1966, pp. 361-368; A. E. VON OVERBECK, «Renvoi in the Institute of International Law», AJCL, 1963, pp. 544-548; ID., «Les questions générales du droit international privé à la lumière des codifications et projets récents», RCADI, 1982-III, t.176, pp. 127-167; M. PAGENSTECHER, Der Grundsatz des Entscheidungseinklangs im internationalen Privatrecht. Ein Beitrag zur Lehre des Renvoi, Wiesbaden, 1951 (también en Akadamie der Wissenschaft und Literatur in Mainz, Abhandlungen der geistes- und sozialwissenschaftlichen Klasse, 1951, pp. 353420); ID., «En quel cas le juge allemand est-il obligé de respecter le renvoi au premier degré? Remarques critiques sur le problème du renvoi», RHDI, 1953, pp. 207-230; J. PERROUD, «Encore la question du renvoi», RCDIP, 1937, pp. 492-506; M. PHILONENKo, «L'affaire Forgo (1874-1882). Contribution a l'étude des sources du droit international privé français», JDI Clunet, 1932, pp. 281-322; ID., La théorie du renvoi en droit comparé, París, Librairie du droit, 1935; P. PICONE, «Il rinvio nel diritto internazionlae privato italiano», Estudos em homenagem à Professora Doutora Isabel de Magalhães Collaço, vol. I, Almedina, Portugal, 2002, pp. 585-603; A. PiLLET, «Contre la théorie du renvoi», RCDIP, 1913, pp. 1-14; W. RAEBURN, «The 'Open Offer' Formula and the Renvoi in Private International Law», BYBIL, 25, 1948, pp. 211-230; P. A. REICHART, Der Renvoi im schweizerischen IPR: Funktion und Bedeutung, Zürich, 1996; J. G. SAuvEPLANNE, «Renvoi», IECL, vol. III, chapter 6, 1990 (37); A. F. SCHNITZER, «Der Renvoi.Rück- und Weiterverweisung im Internationalen Privatrecht», Schweizerische Juristen-Zeitung, 1973, pp. 213-219; E. O. SCHREIBER, «The Doctrine of Renvoi in Anglo-american Law», Harvard Law Review, 1917-1918, pp. 523-571; C. SCHRODER, «Vom Sinn der Verweisung im Internationalen Schuldvertragsrecht», IPrax, 1987, pp. 90-92; I. SCHWANDER, «Einige Gedanken zum Renvoi», en Liber amicorum Adolf F.Schnitzer, Genève, 1979, pp. 411-424; M. Schwimann, «Angloamerikanische lex-foriRegel als 'versteckte Rückverweisung'?», en Festschrift Friedrich Wilhelm Bosch, Bielefeld, 1976, pp. 909-917; M. SonNENTAG, Der Renvoi im Internationalen Privatrecht, Tübingen, Mohr Siebeck, 2001; G. SPERDUTI, «A proposito di una recente concezione semplificata del rinvio», Comunicazione e Studi, XII, 1966, pp. 677-687; H. ValladaO, «Conflitos no espaço das normas di direito internacional privado. Renuncia e devoluçao», Revista dos Tribunais, Sao Paulo, 1965, pp. 7-21; P. VENTURI, «Sul c.d. rinvio 'in favorem' nel sistema italiano di di diritto internazionale privato», RDIPP, 1999, pp. 525-556; M. VIRGÓs SoRIANO, «Derecho de sucesiones y reenvío: la respuesta del sistema español», Anales de las Academia Matritense del Notariado, n. 42, 2004, pp. 181-210; W. WENGLER, «Die Beachtlichkeit des fremdem Kollisionsrecht. Eine Bestandsaufnahme und Besinnung zum Renvoi Probleme», Internationales Recht und Diplomatie, 1956, pp. 56-80. 
Además, no hay especialista en Derecho internacional privado que se precio de ello que no tenga su propia opinión sobre el reenvío. Ya a principios del siglo XX ello era perceptible gracias a la exhaustiva obra E. POTU, que pasó revista a la opinión de cerca de doscientos autores y tuvo presentes unos trescientos cincuenta estudios jurídicos de todo tipo sobre el reenvío ${ }^{8}$. Y eso fue en 1913. Ahora, casi cien años después de la obra de E. PoTU, el número de estudios sobre el reenvío y la sutileza de los argumentos empleados sobre el controvertido instituto se han multiplicado de modo exponencial. Algunos ejemplos de la polémica emotiva sobre el reenvío pueden extraerse de la intensidad con la que algunos autores se refieren al reenvío. J. G. VERPLAETSE recordaba a «Hans Lewald, que sólo una vez provocó el 'aplauso de pies', tan característico de las universidades alemanas, siendo ésta cuando habló de los herederos bávaros bajando de sus montes para reivindicar contra el Estado francés la herencia de Forgo» ${ }^{9}$. El gran tratadista G. C. CHESIRE escribía con flema británica que «ojalá Forgo nunca hubiera nacido, o en caso contrario, quedase enterrado para siempre» ${ }^{10}$. Y los australianos DAVIES, RICKETSON y LINDELL han escrito que «el reenvio es una materia amada por los profesores, odiada por los alumnos, e ignorada-cuando la perciben-, por los abogados y los jueces» ${ }^{11}$. Y tienen una gran parte de razón. De todos modos, en la pasión que envuelve el debate sobre el reenvío suele olvidarse que discutir no es dialogar. En la discusión los contendientes tratan de vencer y no de convencer. De la discusión se extrae un nulo aprovechamiento científico. Por ello, como ya escribían los clásicos, debe recordarse que las disputas excesivas hacen desaparecer la verdad (nimium altercando veritas amittitur) y que es mejor dialogar que discutir.

\section{Ley aplicable a la sucesión en Derecho Internacional Privado español}

6. La Ley aplicable a las sucesiones en DIPr. español se determina con arreglo al art. 9.8 Cc. El precepto contiene tres soluciones diferentes.

a) Regla general: «La sucesión por causa de muerte se regirá por la ley nacional del causante en el momento de su fallecimiento cualesquiera que sean la naturaleza de los bienes y el país donde se encuentren».

b) Regla específica 1: "Sin embargo, las disposiciones hechas en testamento y los pactos sucesorios ordenados conforme a la ley nacional del tes-

\footnotetext{
${ }^{8}$ E. Potu, La question du renvoi en droit international privé, Dijon, Jouve, 1913.

${ }^{9}$ J. G. VerplaETSE, Derecho Internacional Privado, Madrid, 1954, p. 88.

${ }^{10}$ CheSIRE AND North, Private International law, Butterworths, London-Dublin, Edinburgh, 12.. ed., 1992, pp. 58-73.

${ }^{11}$ DAVIES / Ricketson / Lindell, Conflict of Laws: Commentary and Materials, 1997, parágrafo 7.3.1, citado por A. BRIGGS, «ln Praise and Defence of renvoi», ICLQ, 1998, pp. 877-884, esp. p. 878.
} 
tador o del disponente en el momento de su otorgamiento conservarán su validez, aunque sea otra la ley que rija la sucesión, si bien las legítimas se ajustarán, en su caso, a esta última».

c) Regla específica 2: «Los derechos que por ministerio de la ley se atribuyan al cónyuge supérstite se regirán por la misma ley que regule los efectos del matrimonio, a salvo siempre las legítimas de los descendientes». Esta regla segunda específica se añadió al art. 9.8 Cc. por la Ley 11/1990 de 15 de octubre.

7. Los rasgos fundamentales del art. $9.8 \mathrm{Cc}$. son los siguientes ${ }^{12}$ : a) concepción personalista de la sucesión; b) concepción unitaria de la sucesión; c) regulación del fondo de la sucesión; d) Lucha contra el conflicto móvil; e) necesidad de precisar la nacionalidad del causante; f) solución general y soluciones específicas; g) ámbito material amplio del art. $9.8 \mathrm{Cc}$.

${ }^{12}$ En torno a las sucesiones en DIPr. español, vid. A.-L. CALvo CARAVACA, «Art. 9.8 Cc.», Com.Cc. y Comp.For., 2. ${ }^{a}$ ed., 1995, pp. 350-391; ID., «La sucesión hereditaria en el Derecho internacional privado español», RGD, 1986, pp. 3103-3138; E. CASTELlanos RuIZ, Unidad vs. pluralidad legal de la sucesión internacional, Granada, Comares, 2001; ID., «Art. 9.8 Cc.», Legislación de Derecho internacional privado, comentada y con jurisprudencia, Madrid, Colex, 2002, pp. 57-69; ID., «Reenvío, unidad de la sucesión y armonía internacional de soluciones en el Derecho sucesorio», Internacional Law. Revista Colombiana de Derecho Internacional, diciembre-2003, pp. 211-259; ID., «Reenvío, unidad de la sucesión y armonía internacional de soluciones en el Derecho sucesorio: antes y después de la STS de 23 septiembre 2002», en A.-L. Calvo Caravaca/ E. Castellanos Ruiz (dirs.), El Derecho de familia ante el siglo XXI: aspectos internacionales, Madrid, Colex, 2004, pp. 239-269; Id., «Sucesión hereditaria» en A.-L. Calvo CaravaCa / J. CARrascosa GonZÁlez (Directores), Derecho internacional privado, vol. II, Granada, Comares, 8. ${ }^{a}$ ed., 2007, pp. 250-299; M. Aguilar Benítez De Lugo, «Art. 9.8. ${ }^{\circ}$ Cc.», Com.Cc. y Comp.For., 1978, pp. 189-194; M. DE ANGulo RodrígueZ, «Art. 9.8 Cc.», CRef.Cc., 1977, pp. 481-489; L. AreCHEdERra ARANZADI, «Art. 9.8 Cc.», AA.VV. (Coordinador, R. BERCOVITZ RodRíGUEZ-CANO), Comentarios a las reformas del Código civil (Desde la ley 21/1987 de 11 de noviembre a la ley 30/1991, de 20 de diciembre), Tecnos, Madrid, 1993, pp. 470-504; A. BORRÁs RodríGUEZ, «Art. 9.8 Cc.», Com.Cc. Min.Justicia, 1991, pp. 95-98; A. BorRÁs RodríGueZ / J. GonZÁlez CAMpos, «Sucesión hereditaria (DIPrivado)», EJB, IV, 1995, pp. 6405-6409; P. Diago Diago, «La sucesión y el fenómeno migratorio desde la perspectiva del Derecho internacional privado español», en J. L. Collantes GonZÁlez / F. SERRANo Migallón, El Derecho español y europeo, Derecho civil a 200 años del Código de Napoleón, Ed. Porrúa - UNAM, México, 2005, pp. 671-692; A. LAMARCA I MARQUÈS, «Veïnatge civil, determinació del règim econòmic matrimonial i llei aplicable a la successió. Check-list i criteris d'actuació professional», Revista jurídica de Catalunya, 2007, núm. 1, pp. 1-74; A. MARÍn LÓPEZ, Las sucesiones en Derecho internacional privado, con especial referencia al Derecho español, Granada. 1957; V. L. Simó SANTONJa, Derecho sucesorio comparado. Conflicto de leyes en materia de sucesiones, Madrid, 1968; ID., «Normas de Derecho civil internacional sobre donaciones y sucesiones», Academia matritense del Notariado. Estudios, tomo I, vol. II, Madrid, 1977, pp. 41-82. A. RODRÍGUEZ BENOT, «Sucesión mortis causa y modelos de familia en el tráfico jurídico externo», en A.-L. Calvo Caravaca / E. Castellanos Ruiz (Dir.), El Derecho de Familia ante el siglo XXI: aspectos internacionales, Colex, Madrid, 2004, pp. 675-704. 
8. a) Concepción personalista de la sucesión. La sucesión por causa de muerte se rige por la Ley personal del causante. En DIPr. español, como es notorio, la Ley «personal» es la Ley «nacional». Lo dice de modo clarísimo el art. 9.1 Cc. En cualquier caso, el art. 9.8 Cc. se refiere, directamente, a la Ley «nacional»y no a la Ley «personal» del causante. En los supuestos de Derecho interregional, cubiertos también por el art. $9.8 \mathrm{Cc}$. (= porque así lo indica el art. $16 \mathrm{Cc}$.), la nacionalidad del causante viene reemplazada por la «vecindad civil» del causante (SAP Zaragoza 10 noviembre 2004 [causante aragonés y consorcio], STS 29 marzo 1892, STS 5 julio 1893, STS 7 febrero 1899, STS 14 diciembre 1901, STS 16 diciembre 1904). Esta opción en favor de la «Ley nacional del causante» se explica por varias razones.

Primera. España ha sido, tradicionalmente, un país de emigración. Pues bien, con el art. $9.8 \mathrm{Cc}$., los herederos de los emigrantes españoles que partían a América y otros países, quedaban protegidos con arreglo al rígido sistema de legítimas del Derecho español (P. DiAGo DiAGO ${ }^{13}$ ). Ello presentaba, además, cierta lógica en los casos en los que el emigrante español dejaba no sólo a sus familiares en España, sino que dejaba también una parte relevante de su patrimonio en España (STS 30 enero 1960 [sucesión de ciudadano español cuyo patrimonio principal radicaba en Méjico]). Sin embargo, varias observaciones son precisas: (a) Cuando el litigio sucesorio o la sucesión misma se abre en país extranjero, los tribunales y autoridades de dichos países aplican sus propias normas de conflicto. Tales normas de conflicto no tienen por qué coincidir con lo que expresa el art. $9.8 \mathrm{Cc}$. Y por tanto, la Ley aplicable a la sucesión puede ser una Ley estatal o varias y diferentes Leyes, que bien pueden no ser la Ley nacional del causante. Por tanto, en dichos casos, la protección de los descendientes de los causantes españoles no está, en absoluto, garantizada (G. BALLADORE PALLIERI ${ }^{14}$ ); (b) En la actualidad, la justificación de la «protección de los herederos de los emigrantes españoles» ha perdido peso específico. España es ahora un país de inmigrantes cuyas autoridades y tribunales se ven obligados a aplicar las Leyes extranjeras de causantes extranjeros que residen y poseen bienes en España. Ello carece de sentido, sobre todo cuando la sucesión comprende bienes inmuebles sitos en España y, por tanto, las resoluciones españolas en materia sucesoria están llamadas a producir efectos exclusivamente en España y no en el Estado del que es nacional el causante (I. A. CALVO VIDAL ${ }^{15}$ ). En suma: la aplicación de

${ }^{13}$ P. Diago Diago, «La sucesión y el fenómeno migratorio desde la perspectiva del Derecho internacional privado español», en J. L. Collantes GonZÁLEZ / F. SERRANO MigalLón, El Derecho español y europeo, Derecho civil a 200 años del Código de Napoleón, Ed. Porrúa - UNAM, México, 2005, pp. 671-692.

${ }^{14}$ G. Balladore Pallieri, Diritto internazionale privato, en «Trattato di diritto civile e commerciale», Ed.Giuffré, 1974, pp. 199-209.

${ }^{15}$ I. A. CALVo VIDAL, «Nota a RDGRN de 18 enero 2005 (sucesiones)», REDI, 2005, pp. 1028-1033. 
la Ley nacional del causante produce, hoy día, con extrema frecuencia, el «vértigo de la Ley nacional» del que expresivamente habló con pasión J. P. NiBOYET: una desmesurada e injustificada extensión de las cuestiones regidas por la Ley nacional de la persona que alcanza, también, a las cuestiones sucesorias $^{16}$. Y además, se verifica la «paradoja de la nacionalidad» (A. FLESSNER $)^{17}$ : cuanto más integrado en España está el sujeto, más frecuentemente debe aplicarse su Ley nacional. Lo que revela que, con extrema frecuencia, la Ley nacional del causante no es la Ley del país más estrechamente vinculado con el supuesto sucesorio.

Segunda. En Derecho español se sigue un sistema de sucesión romana. Lo relevante es, en dicho sistema, la «persona del causante», que debe ser «reemplazada» por otra persona (= el heredero) en sus derechos y obligaciones (= el heredero «recoge» $\mathrm{y}$ «asume» todas las relaciones y/o posiciones jurídicas [universitas juris] de las que el causante era titular y que son transmisibles [hereditas sustinet personam defuncti]). Por ello se establece que la Ley que rige la sucesión es la Ley nacional del causante.

9. b) Concepción unitaria de la sucesión. La sucesión se regula siempre por una sola Ley estatal. Por ello, como dice expresamente el art. $9.8 \mathrm{Cc}$., no es relevante que la sucesión afecte a bienes muebles o inmuebles y tampoco es relevante el lugar de situación de los bienes que cubre la sucesión. El TS ha subrayado de forma terminante que el art. 9.8 Cc. exige que la sucesión debe quedar siempre sujeta a una sola y única Ley (STS 14 diciembre 1901, STS 11 diciembre 1892, STS 11 diciembre 1893, STS 5 julio 1893, STS 27 octubre 1900, STS 7 febrero 1899, STS 16 diciembre 1904, STS 23 octubre 1915, STS 15 noviembre 1996, STS 21 mayo 1999, STS 22 septiembre 2003, RDGRN 18 junio 2003, RDGRN 11 marzo 2003). Ahora bien, algunas observaciones son necesarias.

1. $\left.{ }^{\circ}\right)$ La «ilusión óptica» de la unidad de la sucesión. Si la sucesión se resuelve ante autoridades extranjeras, éstas aplicarán sus propias normas de conflicto, que pueden diferir del art. $9.8 \mathrm{Cc}$. y pueden seguir, incluso, un sistema de fraccionamiento legal de la sucesión. En tal caso, el hecho de que

${ }^{16}$ J. P. NiboYet, Principios de Derecho internacional privado, Madrid, Ed. Reus, 1930, pp. 550-557. También J. D. GonZÁLEZ CAMPOS, «Les liens entre la compétence judiciaire et la compétence legislative en droit international privé», RCADI, vol. 156, 1977, pp. 233-376, esp. pp. 284-290, así como M. A. Amores Conradí en J. D. González Campos y otros, Derecho internacional privado, parte especial, Eurolex, 1995, 6. ${ }^{a}$ ed., p. 349.

${ }^{17} \mathrm{La}$ «paradoja de la nacionalidad» viene explicada por A. FLESSNER, «Fakultatives Kollisionsrecht», RabelsZ., 1970, vol. 34, pp. 547-584; ID., Interessenjurisprudenz im internationalen Privatrecht, Tübingen, 1990, p. 147. Se trata de un fenómeno ya avanzado años antes por la doctrina que había puesto de relieve la pérdida de valor de la nacionalidad como vínculo que demuestra dependencia de las personas respecto a un Estado. Así, J. F. REZEK, «Le droit international de la nationalité», RCADI, 1986, vol. 198, pp. 333-400. 
los tribunales españoles apliquen el art. 9.8 Cc. no garantiza, en absoluto, la aplicación de la misma Ley a toda la sucesión (E. VITTA, R. MonACO, E. BET$\left.\mathrm{TI}^{18}\right)$. En numerosos supuestos, y diga lo que diga el art. $9.8 \mathrm{Cc}$., la sucesión de los bienes inmuebles sitos en el extranjero se regirá por la Ley de ese Estado si tal país sigue un sistema territorial y si el problema sucesorio se resuelve ante los tribunales o autoridades de dicho país (M. DE LASALA LLANAS, M. MOYA EsCUDERO $\left.{ }^{19}\right)$. Y el objetivo de la «unidad legal de la sucesión», perseguido por el art. 9.8 Cc., será, en tal caso, sólo una «ilusión óptica» (P. MAYER / V. HEUZÉ ${ }^{20}$ ). Para evitar dicha espejismo legal, ciertos sistemas extranjeros de DIPr. siguen un criterio más práctico. Emplean una regla de «conflicto de sistemas» (T. BALLARINO / A. BONOMI ${ }^{21}$ ): la Ley aplicable a la sucesión será la determinada por las normas de conflicto del país donde los bienes se hallaren o por las normas de conflicto del país donde el causante tenía su último domicilio (art. 91.1 LDIPr. Suiza, art. 3.3 EGBGB Alemania).

2. $\left.{ }^{\circ}\right)$ Eliminación de problemas calificatorios. La «unidad legal de la sucesión», sin distinción entre sucesión respecto de bienes «muebles»e «inmuebles», evita gravísimos problemas de calificación de los bienes hereditarios.

Estos problemas son muy frecuentes en los países que siguen el modelo escisionista, como Francia (M. REVILLARD, F. MÉLIN ${ }^{22}$ ). En efecto, existen activos sucesorios, como los créditos, las rentas, los derechos de propiedad a tiempo parcial, e incluso las colmenas de miel, que son considerados «muebles» en unos países e «inmuebles» en otros países. En efecto, las colmenas de miel son consideradas «bienes inmuebles» por destino en Derecho francés, pero «muebles» en Derecho holandés (P. LAGARDE ${ }^{23}$ ). Además, en los países que emplean una norma de conflicto para determinar la Ley aplicable a la sucesión de los bienes inmuebles, y otra norma de conflicto para determinar la Ley aplicable a la sucesión de los muebles, la doctrina está

${ }^{18}$ E. VITTA, Corso di Diritto internazionale privato e processuale, Torino, UTET, 3. a ed., 1989, pp. 291-307, esp. p. 292, con cita de las opiniones de E. BETTI y R. MonACO.

${ }^{19}$ M. DE LASAla Llanas, Sistema español de Derecho civil internacional e interregional, Ed. Rev. Derecho privado, Madrid, 1933, pp. 5-56; M. MoYA EscudERo, «Nota a la SAT Granada 22 diciembre 1988», REDI, 1990, vol. XLII, pp. 635-637.

${ }^{20}$ P. MAYer / V. HeuZÉ, Droit international privé, París, Montchrestien, 8. a ed., 2004, pp. 583-604, esp. p. 586.

${ }^{21}$ T. Ballarino / A. Bonomi, Diritto internazionale privato, 3. a ed., Cedam, 1999, pp. 501-540, esp. pp. 504-506.

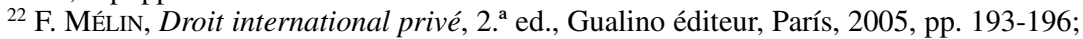
M. REVILlaRD, Droit international privé et communautaire: pratique notariale, Defrénois,

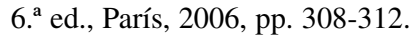

23 P. Lagarde, «Successions», E.Dalloz DI, vol. II, 1969, pp. 876-895; ID., «Partage», E.Dalloz DI, vol. II, 1969, pp. 560-568; P. LAGARDE, «La nouvelle convention de La Haye sur la loi applicable aux successions», RCDIP, 1989, vol. 78, pp. 249-275. 
dividida. Algunos autores opinan que la calificación de tales bienes se debe realizar con arreglo a la Ley del país de su situación física (P. LEREBOURSPigGeOnNIÈRE, J. HÉRON ${ }^{24}$ ), posición seguida por algunos legisladores extranjeros (art. 3 LDIPr. Rumanía 1992, art. 3078 Código civil Québeq, art. 3525 Código civil Louisiana, y jurisprudencia en Alemania e Inglaterra), por respeto a la «Soberanía territorial extranjera». Pero otros autores defienden que la calificación de los bienes como «muebles» $\mathrm{O}$ «inmuebles» debe realizarse con arreglo a la Lex Fori (TGI Seine 12 enero 1966, J. P. NiBoyet, H. BatifFol / P. Lagarde, M. ReVILlard ${ }^{25}$ ).

10. c) Regulación del fondo de la sucesión. El art. 9.8 Cc. establece la Ley aplicable, exclusivamente, al «fondo» o «sustancia» de la sucesión. Ello obliga a distinguir entre «cuestiones sucesorias de fondo» (= sujetas al art. $9.8 \mathrm{Cc}$.), y «cuestiones sucesorias de forma» y de «capacidad», excluidas del art. 9.8 Cc. Para practicar tal distinción, es necesario llevar a cabo una «calificación» de la cuestión debatida. La calificación para decidir la norma de conflicto aplicable debe realizarse siempre con arreglo al Derecho material español (art. 12.1 Cc.). Con arreglo a dicho criterio de calificación lege fori, puede afirmarse lo siguiente (E. VITTA $\left.{ }^{26}\right)$.

$\left.1 .^{\circ}\right)$ Son cuestiones sucesorias de «forma» no reguladas por el art. 9.8 Cc. todas aquellas cuestiones que se refieren al modo de exteriorizar o manifestar la voluntad de los sujetos que intervienen en una sucesión (B. BAREL / ST. ARMELLINI ${ }^{27}$ ): testamento ológrafo, cerrado, abierto, mancomunado, oral, sacramental, testamento contractual, forma de la partición hereditaria, de la aceptación, etc. (RDGRN 6 marzo 1997).

2. $\left.{ }^{\circ}\right)$ Son cuestiones sucesorias de «capacidad» no regidas por el art. 9.8 Cc. las que se refieren a la capacidad jurídica (Rechtsfähigkeit) o aptitud para ser sujeto de derechos y obligaciones y también las que se refieren a la capacidad de obrar «general» (Handlungsfähigkeit), es decir, las relativas a la idoneidad para realizar eficazmente actos jurídicos. Debe subrayarse que el

${ }^{24}$ P. Lerebours-Piggeonnière, «Observations sur la question du renvoi», JDI Clunet, 1924, pp. 877-903; J. HéRON, Le morcellement des successions internationales, París, 1986, pp. 23-24.

${ }^{25}$ H. Batiffol / P. Lagarde, Droit international privé, t. I, 8. a ed., LGDJ, París, 1993, pp. 480-486; M. REVILLARD, Droit international privé et communautaire: pratique notariale, Defrénois, 6. ${ }^{a}$ ed., París, 2006, pp. 308-312; J. P. NiBoyet, Traité de droit international privé français, París, Sirey, 1944; J. P. NiBOYET, Principios de Derecho internacional privado (traducción española por A. Rodríguez Ramón), 1. a ed., Madrid, Ed. Reus, 1930, pp. 719720 y $356-360$.

${ }^{26}$ E. VITTA, Corso di Diritto internazionale privato e processuale, Torino, UTET, 3. a ed., 1989, pp. 291-307, esp. p. 292; ID., Diritto internazionale privato (vol. II), 1979, pp. 101203.

${ }^{27}$ B. Barel / St. Armellini, Diritto internazionale privato, 2006, pp. 173-182. 
Derecho sucesorio está plagado de circunstancias como las incapacidades relativas o prohibiciones de suceder, incapacidades absolutas y causas de desheredación y de indignidad. Todas estas cuestiones son limitaciones o prohibiciones legales para suceder. No afectan a la «capacidad» y sí al régimen de la sucesión, razón por la que deben estar sujetas al art. 9.8 Cc. y a la Lex Successionis (A.-L. CALVO CARAVACA ${ }^{28}$ ). El art. 9.1 Cc. es inaplicable a estas cuestiones.

11. d) Lucha contra el conflicto móvil. El art. $9.8 \mathrm{Cc}$. emplea la conexión «nacionalidad del causante». Pero «congela» dicha circunstancia en el tiempo. En efecto: la nacionalidad relevante es la nacionalidad del causante «en el momento de su fallecimiento». Con ello se logra un claro objetivo: evitar problemas de «conflicto móvil». En efecto, aunque el causante haya ostentado diferentes nacionalidades durante su vida, sólo una es relevante a efectos de determinar la Ley que rige su sucesión: la nacionalidad que ostenta al momento de su fallecimiento (nacionalidad tempore mortis). Esta «congelación en el tiempo» de la nacionalidad del causante solventa los problemas de conflicto móvil que generaba el antiguo art. 10.2 Cc. (versión de 1889), precepto que no concretaba el momento temporal en el que había que considerar la nacionalidad del causante.

12. e) Necesidad de precisar la nacionalidad del causante. Es muy frecuente que los tribunales españoles deban concretar la nacionalidad del causante en supuestos extremadamente complejos (SJPI Calatayud 23 diciembre 1985, SAT Zaragoza 10 abril 1987, SJPI núm. 1 Pamplona 16 julio 1986, STS 19 julio 1989). Al respecto cabe afirmar lo que sigue: 1. ${ }^{\circ}$ ) La precisión de la nacionalidad «española» del causante se debe llevar a cabo, exclusivamente y siempre, con arreglo al Derecho «español» de la nacionalidad. $2 .^{\circ}$ ) La precisión de la nacionalidad «extranjera» del causante debe realizarse siempre y exclusivamente con arreglo al Derecho «extranjero» del país cuya nacionalidad se discute si ostentaba o no dicho causante en el momento de su fallecimiento. $3^{\circ}$ ) El art. $9.8 \mathrm{Cc}$. se refiere a la Ley «nacional» del causante, no a su Ley «personal». En primer término, esta distinción no parece relevante en DIPr. español, porque Ley «personal» equivale a Ley «nacional» (art. 9.1 Cc.). Pero en segundo término sí que lo es, porque toda persona tiene una Ley «personal» aunque carezca de nacionalidad. Es por ello por lo que, en el caso de causante apátrida, debe detectarse cuál es la Ley «personal» del causante sin nacionalidad. A tal efecto debe estarse al art. $12.1 \mathrm{de}$

${ }^{28}$ A.-L. Calvo Caravaca, «Art. 9.8 Cc.», Com.Cc. y Comp.For., 2. ${ }^{\text {a }}$ ed., 1995, pp. 350391; ID., «Sucesión hereditaria», en J. D. GONZÁlez CAMPOS Y OTROS, DIPr. parte especial, 1995, pp. 393-422; ID., «La sucesión hereditaria en el Derecho internacional privado español», $R G D, 1986$, pp. 3103-3138. 
la Convención de Nueva York, de 28 septiembre 1954 sobre estatuto de los apátridas, que indicará cuál es la Ley personal del causante, que conduce a hacer aplicable la Ley del país de su domicilio, y en defecto de éste, la Ley del de su mera residencia de facto incluso aunque sea una residencia «no habitual». $4^{\circ}$ ) En el caso de causante no apátrida pero con nacionalidad indeterminada, se aplica el art. $9.10 \mathrm{Cc}$., que conduce a hacer aplicable la Ley del país de residencia habitual del causante. 5. $^{\circ}$ ) En el caso de causante con múltiple nacionalidad, se estará a los Convenios internacionales aplicables y en su defecto, al art. $9.9 \mathrm{Cc}$., para precisar la «nacionalidad prevalente» del causante (STS 27 mayo 1968, Bosch vs. Campomar, si bien anterior al actual art. $9.9 \mathrm{Cc}$.).

13. f) Solución general y soluciones específicas. El art. $9.8 \mathrm{Cc}$. contiene una «solución general» que consiste en la aplicación, a la sucesión mortis causa, de la Ley nacional del causante en el momento de su fallecimiento. Pero junto a esta solución general, el precepto recoge otras «soluciones específicas»: (a) solución para los casos de sucesión testada y contractual en los que el testador ostentaba una nacionalidad en el momento de otorgamiento del testamento, pero ostentaba otra nacionalidad diferente en el momento de su fallecimiento; (b) solución para determinar la Ley aplicable a los derechos sucesorios del cónyuge viudo.

14. g) Ámbito material amplio del art. 9.8 Cc. El art. 9.8 Cc. utiliza como supuesto de hecho un «concepto amplio de DIPr.»: la «sucesión por causa de muerte». Ello permite incluir en el precepto toda cuestión sucesoria de fondo, con independencia del tipo de sucesión de que se trate e incluso en el caso de un tipo de sucesión desconocida en Derecho español. Así, el «supuesto de hecho» del art. $9.8 \mathrm{Cc}$. cubre las donaciones mortis causa (STS 4 octubre 1982, RDGRN 6 marzo 1997) (E. VITTA, M. REVILLARD ${ }^{29}$ ), el trust sucesorio en sus diferentes e imaginativas variedades, la sucesión contractual, testamentaria, intestada, etc. Todos estos supuestos afectan al fondo de la sucesión, por lo que se encuentran cubiertos por la expresión «sucesión por causa de muerte» y por el art. $9.8 \mathrm{Cc}$.

${ }^{29}$ M. REvillard, Droit international privé et communautaire: pratique notariale, Defrénois, 6. ${ }^{\text {a }}$ ed., París, 2006, p. 328; E. VITTA, Corso di Diritto internazionale privato e processuale, Torino, UTET, 3. ${ }^{\text {a }}$ ed., 1989, p. 309; ID., Diritto internazionale privato, (III vols.), UTET, 1979 pp. 101-203. 


\section{Sucesión internacional y reenvío en Derecho Internacional Privado español: antecedentes históricos}

\section{El caso Forgo y el debate doctrinal sobre el reenvío}

15. En DIPr. español, sólo el reenvío de primer grado es posible (art. 12.2 Cc.). Son excepciones los arts. 98 y 162 de la Ley cambiaria y del cheque, sin incidencia alguna en los casos sucesorios, que admiten el reenvío «de segundo grado» ${ }^{30}$. Pues bien: se trata ahora de concretar si, en materia sucesoria, procede aceptar el reenvío de primer grado que las normas de conflicto extranjeras hacen en favor de las normas materiales españolas. Las normas de conflicto de los distintos países del mundo utilizan puntos de conexión muy diferentes en materia de sucesiones mortis causa ${ }^{31}$. Ello explica que el «reenvío» sea muy frecuente en esta materia.

${ }^{30}$ La explicación de la existencia de estas normas específicas que admiten el reenvío de segundo grado es sencilla. Se trata de normas directamente copiadas del Derecho cambiario ginebrino (art. 2.I in fine del Convenio destinado a reglamentar ciertos conflictos de leyes en materia de letras de cambio y de pagarés a la orden hecho en Ginebra el 7 junio 1930 y del Convenio de Ginebra de 19 marzo 1931 destinado a reglamentar ciertos conflictos de leyes en materia de cheques, Convenios nunca ratificados por España). Estos preceptos fueron, efectivamente, copiados por el legislador de 1985 en la LCCh. sin que los parlamentarios españoles advirtieran su falta de sintonía con el art. 12.2 Cc. Por otro lado, la lógica de un reenvío de segundo grado en el contexto de un Convenio internacional es clara, pues se alcanza una armonía internacional de soluciones conflictuales. Así es, porque todo tribunal de los Estados parte que conozca del caso aplicará la misma Ley. Sin embargo, fuera de tal contexto convencional (= como ocurre en los preceptos citados de la Ley cambiaria y del cheque), el reenvío de segundo grado carece de sentido y supone una desviación de la regla general (art.12.2 Cc.), difícilmente justificable, como explican A. BORRÁs RODRíGUEZ, «Art. 12.2 Cc...», 1991, p. 141, J. D. GONZÁLEZ CAMPOS, «Las normas sobre conflictos de leyes en materia de letra de cambio, pagaré y cheque: presupuestos, soluciones y problemas», Estudios sobre la ley cambiaria y del cheque [dir. A. MenÉndez MENÉndez], Madrid, 1991, pp. 965-968; N. BouzA VIDAL, «Art. 12.2 Cc.», Com.Cc. y Comp.For., 2. ${ }^{\text {a ed., }}$ 1995, pp. 880-894, esp. p. 884.

${ }^{31}$ Los distintos sistemas de DIPr. de los diferentes Estados siguen uno de estos tres modelos conflictuales: a) Sistema de la sucesión germánica. La sucesión se concibe como una cuestión cuyo centro son los bienes dejados por el causante y no la persona del causante. Los bienes inmuebles se localizan en el territorio donde se hallan sitos (inmobilia regentur lege loci), y los bienes muebles, difíciles de localizar físicamente, se consideran situados, normalmente, en el territorio del Estado donde el causante tuvo su último domicilio (mobilia sequuntur personam). La sucesión se rige por la Ley del país en el que se encuentran los bienes. En realidad, hay tantas sucesiones como países de situación de los bienes (quot territoria tot hereditates - tot hereditates quot patrimonia, diversis territoriis obnoxia). b) Sistema de la sucesión romana. La sucesión se concibe como un sistema legal de sustitución de la persona del causante por otra persona o personas. Estas personas «recogen» $\mathrm{y}$ «asumen» todas las relaciones y/o posiciones jurídicas (universitas juris) de las que el causante era titular y que son transmisibles (hereditas sustinet personam defuncti). Lo importante, para este sistema sucesorio, es el reemplazo de una persona por otra persona (sucessio 
16. Es cierto que existían algunos precedentes sobre el problema del reenvío antes de 1878 en la jurisprudencia extranjera ${ }^{32}$. Pero eran precedentes inconexos que nunca atrajeron la atención de doctrina y jurisprudencia de un modo relevante. Por ello hay que admitir, sin duda razonable alguna, que el reenvío nació, como problema propio y como objeto de estudio, precisamente, en torno a un caso de sucesión internacional de un bávaro en Francia en el siglo XIX: el famosísimo, celebérrimo y comentado hasta el infinito caso Forgo (Sent. Cour de Cassation francesa de 24 junio 1878, Forgo). El supuesto fue el siguiente: J. Forgo, súbdito de nacionalidad bávara, falleció sin testamento en Francia, país donde había vivido casi toda su vida. Al no dejar herederos, la Administración francesa sostuvo que le correspondía el caudal hereditario, fundándose en el art. 768 del Código civil francés, precepto que afirma que, a falta de descendientes o cónyuge supérstite, la sucesión de los hijos ilegítimos corresponde al Estado. Forgo era hijo ilegítimo. Frente a esta postura, unos parientes bávaros de J. Forgo (los Ditchl) sostenían la aplicación de una norma de conflicto francesa a cuyo tenor la sucesión mobiliaria queda sujeta a la ley del domicilio legal del causante, que J. Forgo había siempre mantenido en Baviera hasta su muerte. El Tribunal de Pau desestimó la pretensión de los parientes bávaros, y éstos apelaron al Tribunal de Burdeos, y obtuvieron sentencia favorable. La Administración francesa recurrió en casación, y la Cour de Cassation afirmó que la remisión hecha por la norma de conflicto francesa debía entenderse efectuada en favor de la norma de conflicto bávara en materia de sucesiones, que a la sazón,

in jus defuncti). En consecuencia, la sucesión se rige por una sola Ley, que se determina con arreglo a «puntos de conexión personales» (= el último domicilio del causante, la nacionalidad del causante al tiempo de su fallecimiento, etc.). c) Sistema de la Professio Juris. Para este sistema lo relevante es que la sucesión es un acto de disposición del causante de carácter fundamentalmente patrimonial. En los casos internacionales, el causante ordena su sucesión con arreglo a la Ley que prefiera de entre las Leyes de los países conectados con el supuesto sucesorio. El causante elige la Ley aplicable mediante una declaración al efecto o Professio Juris. Ejemplos: art. 25.2 EGBGB, art. 46.2 Ley Italia DIPr. 1995, art. 3098.2 Código Civil Quebeq 1991, art. 90.2 Ley DIPr. Suiza 1987, art. 79 Código Belga DIPr. 2004, y Convenio de La Haya de 1 agosto 1989 [Ley aplicable a las sucesiones por causa de muerte].

${ }^{32}$ Así lo detallan A. MARín LóPEZ, Derecho internacional privado I (parte general), 1994, pp. 251-252; A. Miaja de la Muela, Derecho internacional privado I, 1985, p. 319; M. Aguilar Navarro, Derecho internacional privado, vol. I, tomo II, parte 2. a , 1975, pp.160-162; J. A. TOMÁs ORTIZ DE LA TORRE, Derecho internacional privado II, 1990, pp. 101-105; J. P. NiBOYET, «Froland, les questions de qualifications et la question du renvoi», RCDIP, 1926, pp. 1-25; R. DE NovA, «Il rinvio in Froland e Boullenois», DI, 1966, pp. 361368; M. Philonenko, La théorie du renvoi en droit comparé, París, Librairie du droit, 1935 , pp. 177-178. La mejor exposición de los perfiles históricos de la polémica doctrinal relativa al reenvío puede seguirse, sin duda, en PH. FRANCESCAKIS, La theorie du renvoi et les conflits de systèmes en droit international privé, París, Sirey, 1958 (con referencias doctrinales muy abundantes), esp. en pp. 97 y 261. 
declaraba aplicable la ley del Estado correspondiente al domicilio de hecho del causante, que estaba en Francia, por lo que aplicó el Derecho material francés y los bienes fueron definitivamente adjudicados al Estado francés. La solución dada al asunto se basó en un reenvío en favor del Derecho francés, -reenvío de primer grado, esto es, en favor de la Ley del foro-. Es curioso constatar que Forgo prestó -por un error administrativo-, el servicio militar en Francia -lo que explicaría que se le denegase el permiso de residencia, que era para los extranjeros-. Y también sorprenden ciertas circunstancias de Derecho en el caso Forgo, como el que los tribunales franceses aplicasen de oficio el Derecho extranjero, en una época en que el Derecho extranjero era tratado procesalmente, de manera unánime, como un hecho, o que se supiese que dos normas de conflicto -la francesa y la bávara-, literalmente muy semejantes, se referían, sin embargo, al domicilio de derecho o de hecho respectivamente. Probablemente, como explica M. PHILONEnKo, haya que atribuir ambas cuestiones a la presencia en el transcurso del litigio del prof. AUBRY, consejero de los tribunales, profesor de la Universidad de Estrasburgo y excelente conocedor del Derecho alemán ${ }^{33}$.

17. Tras el caso Forgo, las opiniones sobre el reenvío fueron de lo más dispar. Partidarios y adversarios del reenvío se enzarzaron en una inmisericorde contienda doctrinal que todavía persiste. Varias etapas pueden distinguirse.

18. a) Primera época: reacción contra el reenvío. En un primer momento, el reenvío suscitó las críticas y el rechazo de la inmensa mayoría de la doctrina. La mayor parte de los autores se apresuró a expedir una lettre de cachet para condenar sin juicio previo al reenvío. Así, el gran internacionalista A. PILlet escribió «yo me cuento entre los espíritus atrasados que no aciertan a percibir la belleza de esta doctrina del reenvío inventada por la Administración para asegurar al fisco una herencia disputada» ${ }^{34}$. Y el no menos sagaz E. BARTIN afirmaba que el reenvío «es la bestia imaginaria de los copleros del medioevo, la bestia que se come las patas» ${ }^{35}$. El IDI, en dos

${ }^{33}$ M. Philonenko, «L'affaire Forgo (1874-1882). Contribution a l'étude des sources du droit international privé français», JDI Clunet, 1932, pp. 281-322. La solución dada al asunto Forgo por la Cour de Cassation gala se basó, como es fácil apreciar, en un reenvío en favor del Derecho francés -reenvío de primer grado, esto es, en favor de la ley del foro-. Los casos más antiguos de reenvío operaron en un contexto publicista del DIPr:: se estimaba que un país hacía una «concesión» a otro país cuando declaraba la aplicación de la Ley de ese otro país, por lo que resultaba lógico que si la Ley dicho país no aceptaba su propia aplicación y remitía a su vez a la Ley del primer país, se proclamase la aplicación del Derecho del Foro.

${ }^{34}$ A. Pillet, «Contre la doctrine du renvoi», Revue de droit international privé et de droit penal international, 1913, pp. 1 y ss., también reproducido en Mélanges Pillet, II, París, 1924, pp. 129 y ss.

${ }^{35}$ E. BARTIN, «Encore le renvoi», JDI Clunet, 1931, p. 1260. 
resoluciones de 1898 y de 1900, condenó el reenvío. En general, el reenvío fue atacado por varios motivos: (a) el reenvío provocaba inseguridad jurídica (= la Ley aplicable a un caso internacional ya no es la señalada por la norma de conflicto de la Lex Fori, sino otra Ley, la que señalen las normas de conflicto de la Lex Causae, lo que oscurece la precisión de cuál será, realmente, la Ley reguladora de la sucesión mortis causa); b) era un artificio para evitar la aplicación de la Ley designada por la norma de conflicto (= lo que destruía la «Justicia conflictual» inscrita en el punto de conexión de la norma de conflicto de la Lex Fori); (c) no reportaba ninguna ventaja material (= el reenvío era un «mecanismo ciego» que no atendía para nada ni al contenido de la Ley finalmente aplicable al caso, ni a la finalidad de las Leyes en conflicto, ni al resultado concreto derivado de la aplicación de una u otra Ley al supuesto concreto); (d) conducía a una «cadena de remisiones» que se interrumpía arbitrariamente (= pues nada autoriza a «detener» el reenvío en algún momento y aplicar un concreto Derecho material); (e) Suponía una renuncia a la Soberanía del Estado cuyos tribunales conocían del asunto, ya que implicaba no aplicar su norma de conflicto, sino aplicar una norma de conflicto extranjera (= lo que se entiende en un contexto en el que los conflictos de Leyes reciben la lectura de un «conflicto entre Estados» para dilucidar la Ley aplicable a una situación privada internacional).

19. b) Segunda época: reacción en favor del reenvío. Ya en el siglo XIX y primeros años del siglo Xx, el reenvío contraataca y atrae a numerosos partidarios. Además, la jurisprudencia, por razones muy diversas, lo admitió en muchos países (= generalmente porque, de ese modo, se evitaba aplicar normas de conflicto de escasa calidad y/o porque se potenciaba la aplicación de la Lex Materialis Fori). El mismo IDI aceptó con ciertas limitaciones el reenvío en relación con la capacidad de la persona (Oslo 1932). En su defensa se utilizaron, fundamentalmente, estos argumentos: $1 .^{\circ}$ ) El reenvío como remedio a los conflictos de Soberanía. Se estimaba que si un país hacía una «concesión» a otro país cuando declaraba la aplicación de la Ley de ese otro país, era lógico que si la Ley de dicho país no aceptaba su propia aplicación y remitía a su vez a la Ley del país cuyos tribunales conocían del asunto, se proclamase la aplicación del Derecho de este último país (J. WeSTLAKE ${ }^{36}$ ). Un Derecho estatal no debe ser aplicado contra la voluntad del legislador que lo ha promulgado, pues ello sería un atentado contra la Soberanía del Estado extranjero (J. P. NiBOYET ${ }^{37}$ ). No obstante, este argumento basado en la

${ }^{36}$ J. Westlake, A treatise On Private International Law, with Principal Reference to Its Practical Application in England, 1880, 2. ${ }^{\text {a }}$ ed., 1880, p. 237, en relación con la doctrina de la «Proper Law».

${ }^{37}$ J. P. NiboYet, «Froland, les questions de qualifications et la question du renvoi», $R C D I P, 1926$, pp. 1-25. 
Soberanía extranjera hoy resulta totalmente obsoleto, pues se ha abandonado la idea de que el DIPr. resuelve «conflictos legislativos entre Estados» (J. G. SAUVEPLANNE ${ }^{38}$ ). 2. $^{\circ}$ ) El reenvío-coordinación. El reenvío puede conducir a una «armonía internacional de soluciones»(H. BATIFFOL $\left.{ }^{39}\right)$ : si se admite el reenvío, el juez español que conoce del asunto resuelve la cuestión de igual modo a como lo haría el juez extranjero, pues aplica la norma de conflicto extranjera. La «relatividad del DIPr.» desaparece y se facilita la eficacia de la sentencia en el país extranjero al que remite la norma de conflicto del país cuyos tribunales conocen del asunto. $3 .^{\circ}$ ) El reenvío como remedio contra el Bad Forum Shopping. Gracias al reenvío, los litigantes no podrán eludir la aplicación de la Ley que hubiera aplicado el tribunal del país más vinculado con el caso (A. BRIGGS ${ }^{40}$ ).

20. c) Tercera época: el «reenvío funcional»o «reenvío-expediente». En la segunda mitad del siglo Xx comienza a imponerse otra óptica en relación con el reenvío. Las nuevas Leyes de DIPr. de los diferentes países, la jurisprudencia más cuidada y la doctrina más moderna estiman que el reenvío no debe operar como una regla «automática» ni como una regla «general» ${ }^{41}$. Y ello por distintas razones.

1..$^{\circ}$ El reenvío no garantiza, en todos los casos, una «armonía internacional de soluciones» de DIPr. En efecto, la admisión del reenvío supondría, teóricamente, que la solución dada a la situación sería igual tanto si conociese del mismo caso un tribunal español como si conociese del mismo caso el tribunal extranjero correspondiente al Derecho al que remite la norma de conflicto española (P. LEREBOURS-PIGGEONNIÈRE ${ }^{42}$ ). Así, el tribunal español aplicaría, gracias al reenvío, la norma de conflicto extranjera, que es la misma que aplicaría el tribunal extranjero. Ello garantiza que el Derecho aplicable a la situación privada internacional sea el mismo, sin que dependa de cuál sea el tribunal competente.

Pero mucho cuidado: para que se produzca una «armonía internacional de soluciones de DIPr., es preciso que el Derecho extranjero no admita el reenvío, ya que, en tal supuesto, la solución que darían al caso los tribunales extranjeros sería contraria, nuevamente, a la suministrada por los tribunales

\footnotetext{
${ }^{38}$ J. G. SAuVEPLANNE, «Renvoi», IECL, vol. III, chapter 6, 1990, p. 3.

${ }^{39}$ H. BATIFFOL, «Réflexions sur la coordination de systèmes nationaux», RCADI, 1967, vol. 120, pp. 165-188.

${ }^{40}$ A. BRIGGS, «ln Praise and Defence of renvoi», ICLQ, 1998, pp. 877-884.

${ }^{41}$ B. AudiT, «Le caractère fonctionnel...», 1984, pp. 327-333; PH. FranCESCAKIS, La theorie du renvoi..., 1958, pp. 261-262; A.E.VON OvERBECK, «Les questions générales...», 1982, p. 167; H. BATIFFOL / P. LAGARDE, Droit international privé I, 1993, pp. 506-509.

42 P. LeREbours-PIgGEONNIÈRE, «Observations sur la question du renvoi», JDI Clunet, 1924, pp. 877-903.
} 
españoles (E. VitTa, H. LeWALd, J. Derruppé, P. Courbé ${ }^{43}$ ). Sólo el reenvío de segundo grado sirve, en ciertas condiciones, para alcanzar esta armonía internacional de soluciones (L. RAAPE, J. DERRUPÉ, E. CASTELlANOS RUIZ ${ }^{44}$ ).

$\left.2 .^{\circ}\right)$ El reenvío comporta una ignorancia del mandato material de la norma de conflicto. Ejemplo: la norma de conflicto española (art. $9.8 \mathrm{Cc}$.) indica que la Ley nacional del causante debe regir la sucesión. Pues bien: admitir el reenvío supone que la sucesión ya no será regulada por la Ley nacional del causante, sino por «otra Ley estatal», la Ley designada por las normas de conflicto del Derecho del país de la nacionalidad del causante. Por tanto, el reenvío «destruye» la solución que el legislador ha considerado «justa» a la hora de indicar la Ley aplicable a una situación privada internacional (E. Bartin, A. Pillet, A. Borrás Rodríguez, M. DE Lasala Llanas ${ }^{45}$ ), como indica la SAP Alicante 7 junio 2001.

$3^{\circ}$ ) El reenvío provoca inseguridad jurídica. La admisión del reenvío hace «imprevisible» la Ley aplicable al supuesto. La precisión de la Ley aplicable a la situación privada internacional resulta difícil y compleja, pues debe conocerse y aplicarse la norma de conflicto del país cuyos tribunales conocen del asunto y las normas de conflicto del Derecho extranjero al que el DIPr. español remite $\left(\mathrm{H}\right.$. LEWALD $\left.{ }^{46}\right)$. El reenvío lleva a las normas de con-

${ }^{43}$ H. LEWALD, «La théorie du renvoi», RCADI, 1929-IV, vol. 29, pp. 519-616; J. DERRUPPÉ, «Plaidoyer pour le renvoi», TCFDIP, 1964-1966, pp. 181-107; E. VITTA, Corso di Diritto internazionale privato e processuale, Torino, UTET, 3. ${ }^{a}$ ed., 1989, p. 166; P. COURBE, Droit international privé, Colin-Dalloz, París, 2000, p. 85.

${ }^{44}$ J. DERRUPPÉ, «Plaidoyer pour le renvoi», TCFDIP, 1964-1966, pp. 181-107; L. RAA$\mathrm{PE}$, «Les rapports juridiques entre parents et enfants comme point de départ d'une explication pratique d'anciens et de nouveaux problemes du droit international privé», RCADI, 1934, vol. 50, pp. 405-544, concr. p. 413, donde expone su famosa tesis de la roca de bron$c e$, roca contra la que se estrellarían, según su defensor, y con fatal resultado, los adversarios del reenvío; E. CASTELlanos RuIZ, Unidad vs. pluralidad legal de la sucesión internacional, Granada, Comares, 2001, pp. 40-41; ID., «Art. 9.8 Cc.», Legislación de Derecho internacional privado, comentada y con jurisprudencia, Madrid, Colex, 2002, pp. 57-69; ID., «Reenvío, unidad de la sucesión y armonía internacional de soluciones en el Derecho sucesorio», Internacional Law. Revista Colombiana de Derecho Internacional, diciembre2003, pp. 211-259; ID., «Reenvío, unidad de la sucesión y armonía internacional de soluciones en el Derecho sucesorio: antes y después de la STS de 23 septiembre 2002», en A.-L. Calvo Caravaca/ E. Castellanos Ruiz (dirs.), El Derecho de familia ante el siglo Xxi: aspectos internacionales, Madrid, Colex, 2004, pp. 239-269.

${ }^{45}$ E. BARTIN, «Les conflits entre dispositions législatives de droit international privé. Théorie du renvoi», RDILC, 1898, pp. 129-159; E. BARTIN, Principes de droit international privé selon la loi et la jurisprudencie françaises, vol. I, París, 1930, pp. 1-69; A. PILleT, «Contre la théorie du renvoi», RCDIP, 1913, pp. 1-14; A. BorRás RodríGuEZ, «Art. 12.2 Cc...», 1991, p. 140; M. DE LaSAla Llanas, Sistema español de Derecho civil internacional e interregional, Madrid, 1933, pp. 247-248, en relación, específicamente, con la sucesión.

${ }^{46}$ H. LEWALD, «La théorie...», 1929, pp. 565 y 615. 
flicto a una situación límite próxima a la «teoría del caos»: para conocer el Derecho aplicable a una sucesión, el tribunal español debería tener presentes las normas de conflicto de los sistemas extranjeros a los que pudiera remitir la norma de conflicto española, y quizás ulteriores remisiones. Además, considerar en su conjunto el Derecho extranjero al que remite la norma de conflicto española lleva a una cadena de reenvíos sin final, a una «sala de los espejos» (F. $\mathrm{KAHN}^{47}$ ), a un «ping-pong internacional» $\left(\mathrm{C}\right.$. BUZZATI $\left.{ }^{48}\right)$, a un tiovivo o Merry-go Round internacional (J. G. SAUVEPLANNE ${ }^{49}$ ), o a concebir un fiero animal que se muerde su propia cola (E. BARTIN $\left.{ }^{50}\right)$.

Resultado: los sistemas de DIPr. más modernos y la doctrina actual entienden que el reenvío no debe operar como «regla general». En efecto, posturas muy radicales en favor incondicionado del reenvío, como las que sostuvieron algunos de los primeros autores que reflexionaron sobre el asunto, tales como J. Westlake y J. P. NiBOYET, y posturas radicalmente contrarias al reenvío en todo caso, como las que sostienen algunos autores contemporáneos $^{51}$, ignoran que en el arte del Derecho, el justo término (ne quid nimis, est modus in rebus) suele ser la regla más razonable y útil. Ello permite recoger los beneficios del reenvío pero, al mismo tiempo, permite eliminar sus consecuenciads indeseables. Actualmente, doctrina, legislación y jurisprudencia conciben el reenvío como un mero instrumento que sólo debe operar para conseguir un resultado más justo en el caso concreto. Es el «reenvío funcional» o «reenvío-expediente», ya anunciado por la doctrina durante el siglo Xx (H. Lewald, PH. Francescakis, P. Courbé ${ }^{52}$ ).

${ }^{47}$ F. KAHN, «Der Grundsatz der Rückverweisung im deutschen bürgerlichen Gesetzbuch und auf dem Haager Kongress für internationales Privatrecht», Jherings Jahrbücher, 1896, pp. 366-392.

${ }^{48}$ C. BuZZATI, Il rinvio nel diritto internazionale privato, Milano, 1959, p. 77.

${ }^{49}$ J. G. SauvePLAnNe, «Renvoi», IECL, vol. III, chapter 6, 1990, (37 pp.), esp., pp. 2-4.

${ }^{50}$ E. BARTIN, Principes de droit international privé selon la loi et la jurisprudence françaises, vol. I, París, 1930, p. 211.

${ }^{51}$ Ad ex. S. SÁNCHEZ LORENZO, «Ámbito del reenvío en la determinación de la Ley aplicable a la sucesión hereditaria», Anuario Español de Derecho internacional privado, 2004, pp. 1144-1146.

${ }^{52}$ H. LEWALD, «La théorie du renvoi», RCADI, 1929-IV, vol. 29, pp. 519-616; ID., «Renvoi Revisited?», en Fragen des Verfahrens- und Kollisionsrechtes, Festschrift Hans Fritzsche, Zürich, 1952, pp. 165-180; J. F.AubERT, «Renvoi in Swiss Law», AJCL, 1956, pp.478486; Id., «Une révision du droit international privé: la 'Théorie du renvoi' de M.Francescakis», Schweizerisches Jahrbuch für internationales Recht, 15, 1958, pp.187-214; P. FRANCESCAKIS, La théorie du renvoi et les conflits de systèmes en droit international privé, París, Sirey, 1958, pp. 55-56; ID., «Renvoi», E.Dalloz DI, vol. II, 1969, pp. 751-759; B. AUDIT, «Le flux et reflux de la crise des conflits de lois», TCFDIP, 1988, pp. 59-7, esp. p. 70. En el mismo sentido se orienta la Resolución del IDI sobre la aplicación del DIPr. extranjero de 23 agosto 1999 (RCDIP, 2000 p. 135).

P. Courbé, Droit international privé, Colin-Dalloz, París, 2000, pp. 87-88. 


\section{El reenvío en Derecho internacional privado español antes de 1974}

21. Aunque la cuestión del reenvío era conocida por la doctrina española en 1889, lo cierto es que la redacción originaria del Código Civil de dicho año guardó un total silencio sobre el reenvío. En general, las normas de DIPr. contenidas en la redacción originaria del Código Civil eran muy parcas, insuficientes y poco brillantes. Por ello, no debe extrañar que el reenvío fuera ignorado de modo lapidario por el legislador. Esta situación condujo a la presencia de enormes dudas sobre la admisión del reenvío en la práctica de los tribunales españoles ${ }^{53} \mathrm{y}$ en la doctrina ${ }^{54}$. En efecto, hasta nada menos que 1996, el TS nunca se manifestó, en ningún caso, de forma clara sobre la cuestión del reenvío. En general, el TS ignoraba con total tranquilidad los problemas de reenvío (STS 10 febrero 1926, STS 21 febrero 1935, STS 27 mayo 1968, STS 6 junio 1969, STS 5 noviembre 1971). Por otro lado, el llamado Proyecto Yanguas de 25 enero 1944 para la reforma del Código Civil negaba el reenvío por influjo del entonces reciente art. 30 del Código civil italiano de 1942, al que el profesor YANGUAS profesaba una indisimulada devoción. Pero el texto se quedó en un mero Proyecto. El posterior Proyecto Trías de 14 noviembre 1962 admitía el reenvío de retorno a través de una fórmula idéntica a la finalmente consagrada en el hoy vigente art. 12.2 Cc. El ponente de dicho Proyecto, el Prof. J. M. TRíAS DE BES, acogió las tesis del Profesor J. D. TRíAs GIRÓ, padre del primero, que había emitido una opinión ${ }^{55}$ que fue decisiva para aceptar el reenvío en el muy célebre y pionero caso del Auto del Juzgado de distrito del Hospital de Barcelona de 3 agosto 1900 [reenvío de la Ley escocesa a la españo-

\footnotetext{
${ }^{53} \mathrm{Al}$ respecto, vid. J. CARRASCOSA GONZÁLEZ, «Comentario al art. 9.8 Cc.», en Jurisprudencia civil comentada. Código Civil (Dir. M. Pasquau Liaño), Ed. Comares, Granada, 2000, pp. 190-201; J. CARRASCOSA GONZÁLEZ, «Comentario al art. 12.2. Cc.», en Jurisprudencia civil comentada. Código Civil (Dir. M. Pasquau Liaño), Ed. Comares, Granada, 2000, pp. 345-352.

${ }^{54}$ L. Gestoso Tudela, «La teoría de la referencia en Derecho internacional privado», Anales de la Universidad de Murcia, Curso 1946/1947, pp. 193-203; A. MARín LóPEZ, Derecho internacional privado I, 1994, pp. 268-269; M. AgUILAR NAVARro, Derecho internacional privado, vol. I, t. II, parte 2. ${ }^{a}$, 1975, pp. 179-182; M. DE LASALA LlanAS, Sistema español de Derecho civil internacional e interregional, Ed. Rev. Derecho privado, Madrid, 1933, pp. 5-56 y pp. 247-248.

55 J. D. TRÍAS GIRó, «De la théorie du renvoi devant les tribunaux espagnols», JDI Clunet, 1901, pp. 905-921; ID., «La solución de retorno (Renvoi) ante los Tribunales de España», RJC, 1901, pp. 173-189; J. M. TRIAS DE BES, Derecho internacional privado, Madrid, Ed. Reus, 1934, Barcelona, pp. 32-34: «El caso resuelto por dicha sentencia era el siguiente: don T. A. escocés, súbdito británico, otorgó testamento, en 23 junio de 1898, ante notario de esta ciudad [Barcelona], donde tenía establecida su industria y en donde había adquirido inmuebles de importancia, Falleció en 1899, conservando su nacionalidad británica, pero habiendo residido cincuenta años en Barcelona, lugar de su última residencia».
} 
la $]^{56}$. Fue precisamente este caso, el primer caso sobre reenvío en España, el que marcó la pauta. El juzgador se pronunció a favor del reenvío y, a falta de norma positiva expresa que autorizara dicho reenvío y a falta de toda jurisprudencia, se apoyó en la costumbre y en los principios generales del Derecho. Ello fue decisivo, pues visto que bis dat cui cito dat, quedó diseñada una clara línea muy proclive al reenvío en el proceder de los tribunales españoles.

\section{El reenvío en Derecho internacional privado español desde 1974 a 1996}

22. En 1974, el legislador español se ocupa, por fin, del reenvío en DIPr. español. El nuevo art. 12.2 Cc. es el precepto clave. En efecto, dicha norma fue introducida por el Decreto 1836/1974, de 31 de mayo, por el que se sanciona con fuerza de ley el texto articulado del Título Preliminar del Código civil (BOE núm. 163, de 9 de julio de 1974), que siguió las líneas marcadas por la Ley 3/1973, de 17 de marzo, de bases para la modificación del Título Preliminar del Código civil (BOE núm. 69, de 21 marzo de 1973).

23. El texto del art. 12.2 Cc., que como se ha recordado, data de 1974, afirma lo siguiente: «La remisión al Derecho extranjero se entenderá hecha a su ley material, sin tener en cuenta el reenvío que sus normas de conflicto puedan hacer a otra ley que no sea la española». Pero hay que afirmar desde ya que el art. 12.2 Cc. (= que teóricamente venía a arrojar luz sobre el tema del reenvío), sembró más dudas que otra cosa. Una brevísima exégesis del precepto muestra este balance.

1. ${ }^{\circ}$ ) El precepto presenta una caótica redacción: a) Una afirmación contradictoria: si la remisión al Derecho extranjero, se dice, lo es en favor de su Ley material, ¿cómo se afirma, acto seguido, que se pueden «tener en cuenta» las normas de conflicto extranjeras si remiten al Derecho español? Resulta entonces que la «declaración de principios» del art. 12.2 Cc. (= remisión a la Ley material extranjera), es, simplemente, falsa o como mal menor, es sólo una afirmación de principios pero con un alcance muy relativo ${ }^{57}$; b) Una

\footnotetext{
${ }^{56}$ Auto del Juzgado de distrito del Hospital de Barcelona de 3 agosto 1900: «la ley escocesa (...) no acepta la competencia que le atribuye la ley española (...) y se remite a su vez. a ésta, fundada en que habiendo dejado el difunto sus bienes muebles y raíces en Barcelona, a la ley de este territorio es la que debe regular la sucesión de aquél (...) considerando que, no habiendo en España ley que resuelva tal conflicto, debe acudirse a la costumbre o a los principios generales del Derecho, según el art. $6^{\circ}{ }^{\circ}$ del expresado Código civil, y en este caso, vista la opinión de varios tratadistas y el dictamen del catedrático de Derecho internacional de esta Universidad, don Juan de Dios Trías, que obra en este expediente, no queda duda alguna de que la sucesión de don Tomás A. debe regularse por la ley de Cataluña por radicar en Barcelona los bienes dejados por aquél». Vid. J. M. TRIAS DE BES, Derecho internacional privado, Madrid, Ed. Reus, 1934, Barcelona, pp. 32-34.

57 J. PÉrez Montero, «Art. 12.2 Cc.», CRef.Cc., 1977, pp. 592-638.
} 
«doble negación»: no se tendrán en cuenta las normas de conflicto extranjeras que no remitan al Derecho español. Peor redactado, imposible.

$\left.2^{\circ}{ }^{\circ}\right)$ El objetivo del art. 12.2 Cc. es aceptar, exclusivamente, el «reenvío de retorno» o «reenvío de primer grado». Cuando la norma de conflicto española remite a una Ley extranjera, se puede aceptar la remisión hecha por las normas de conflicto extranjeras en favor de la Ley sustantiva española (erróneamente: SAP Alicante 7 junio 2001). Y nunca se aceptará la remisión que las normas de conflicto de la Lex Causae puedan realizar en favor del Derecho de un Estado que no sea España.

3. $\left.{ }^{\circ}\right) \mathrm{El}$ art. 12.2 Cc. admite el reenvío de primer grado, dentro de ciertos límites, en relación, teóricamente, con cualquier norma de conflicto y en cualquier materia: contratos, sucesiones, régimen económico del matrimonio, etc. El precepto, realmente, no contiene ningún límite al respecto.

4. $\left.{ }^{\circ}\right)$ El precepto no es claro en torno a la espinosa cuestión del carácter facultativo o imperativo del reenvío. Hasta 1996 las dudas eran muy profundas en los tribunales españoles: si la norma de conflicto extranjera reenvía al Derecho español, ¿debe aceptarse obligatoriamente dicho reenvío? ¿O puede el tribunal tomar en consideración ciertos datos para decidir si procede o no aceptar el reenvío en favor de la Ley española en relación con el caso concreto?

24. Sin embargo, la jurisprudencia española, fiel a sí misma, no varió un ápice su postura sobre el reenvío tras el nuevo art. 12.2 Cc. de 1974. Los pronunciamientos de los tribunales inferiores eran poco concluyentes y más bien oscuros. Y lo más importante: el TS, tras 1974, siguió en silencio en torno al asunto del reenvío hasta la STS 15 noviembre 1996. En definitiva, antes de la entrada en escena del TS en la citada STS 15 noviembre 1996, la jurisprudencia española sobre el reenvío de primer grado en materia sucesoria era oscilante, imprecisa y sospechosa.

$\left.1 .^{\circ}\right)$ La mayor parte de los pronunciamientos jurisprudenciales eran favorables al reenvío (Auto Juzgado de distrito del Hospital de Barcelona de 3 de agosto de 1900 [reenvío de la Ley escocesa a la española], RDGRN 30 junio 1956 [reenvío de la Ley argentina a la española] ${ }^{58}$, SJPI núm.10 Madrid 18 febrero 1974, SAT Granada 22 diciembre 1988 [reenvío de la Ley de Maryland a la Ley española, en perjuicio de la unidad y universalidad de la sucesión], SAP Málaga 18 diciembre 1996 [reenvío de la Ley inglesa a la española que afectaba exclusivamente a inmuebles sitos en España], SAP Alicante 19 noviembre 1991 [reenvío de la Ley escocesa en favor de la Ley española, pues los bienes inmuebles se hallaban en España, aunque ello com-

${ }^{58}$ RDGRN 30 junio 1956 (AnDGRN, pp. 40-48): «dado que (...) el art. 7 del Código civil argentino otorga la preferencia a la Ley del domicilio, que la causante tenía establecido en territorio español, procede aplicar la ley española...». 
portaba el fraccionamiento legal de la sucesión, sentencia confirmada, sin consideraciones expresas sobre el reenvío, por la STS 23 octubre 1992]).

$\left.2^{\circ}{ }^{\circ}\right)$ Ciertas resoluciones, en posición muy minoritaria, rechazaron el reenvío en materia sucesoria (SAT Palma de Mallorca 17 febrero 1965 [aplicación de la Ley sustantiva argentina], o se mostraron muy reacias a ello, aunque realmente, no se pronunciaran sobre la cuestión (SAP Badajoz 11 julio 1995 [sucesión de causante inglés con domicilio en España y bienes inmuebles en España $\left.{ }^{59}\right]$ ).

$\left.3^{\circ}{ }^{\circ}\right)$ Otras sentencias pudieron emplear el reenvío de retorno en materia sucesoria, pero no tomaron posición sobre el particular (STS 11 mayo 1989 [sucesión testada de causante venezolano relativa a inmuebles sitos en España], STS 27 abril 1978 [sucesión de causante mejicano con inmuebles en España], STS 17 diciembre 1991 [sucesión regida por el Derecho marroquí, que hubiera provocado un reenvío en favor del Derecho español, lo que al fínal no ocurrió porque el TS estimó que el DIPr. marroquí no se había probado], STS 23 octubre 1992 [el TS bendice el criterio adoptado por la SAP Alicante 19 noviembre 1991, que había aceptado el reenvío en favor de la Ley española aunque dicho reenvío provocó un fraccionamiento legal de la sucesión]).

$\left.4^{\circ}{ }^{\circ}\right)$ Pero hasta 1996, la jurisprudencia española sobre el reenvío era también sospechosa. En efecto, se podía apreciar que, antes de la STS 15 noviembre 1996, la jurisprudencia precedente de los tribunales inferiores había seguido, como denunciaba la doctrina, una solución nacionalista y legeforista. El reenvío se aceptaba con el solo propósito de hacer aplicable la Ley española, sin más consideraciones ${ }^{60}$. Las palabras de J. DE YANGUAS MESSÍA eran certeras: «la única, inconfesable razón creadora del reenvío, fue la disimulada atracción de todos los casos de Derecho internacional privado a la ley del juez, bajo la apariencia de una correcta aplicación de la ley extranjera declarada competente, para regirlos, por la propia Lex Fori» ${ }^{61}$.

25. Otro factor de complicación se añadió durante los años ochenta del pasado siglo al ya de por sí confuso asunto del reenvío: la incidencia de los Convenios internacionales que contienen normas de conflicto y que fueron ratificados por España a partir de la década de los años ochenta. Estos Con-

${ }^{59}$ SAP Badajoz 11 junio 1995: «El causante no quería dejar nada a sus hijos, con arreglo a la Ley inglesa podía hacerlo, no cabe pues nada más que formalmente en pensar en problemas de desheredación o de preterición y de aquí surge la conclusión de que no siempre el reenvío es aconsejable y de que este supuesto es uno de los que exigirían mayor meditación».

${ }^{60}$ A. Borrás Rodríguez, «Art.12.2 Cc...», 1991, p. 141; A.-L. Calvo Caravaca en UNED, Derecho internacional privado I, 1993, pp. 146-148.

${ }^{61}$ J. DE YANGuAs Messía, Derecho internacional privado, 1970, Reus, Madrid, pp. 288289. 
venios internacionales hacen inaplicable el art. $12.2 \mathrm{Cc}$. en las materias que regulan. En este sentido, existen tres grupos de Convenios internacionales desde la perspectiva del reenvío (L. MigLIORINO ${ }^{62}$ ).

a) Convenios internacionales que rechazan el reenvío. La mayor parte de los Convenios internacionales de DIPr. rechazan el reenvío. Explicación: no todos los Estados partes lo admiten en sus sistemas de DIPr. de producción interna. Estos Convenios niegan el reenvío a través de diferentes bases jurídicas. Primero: algunos Convenios indican que la Ley aplicable es la «Ley interna» de un Estado. Con ello se excluye la consulta de las normas de conflicto extranjeras y se evita todo reenvío. Ejemplo 1: el art. 4 Convenio de La Haya de 2 octubre 1973 (Ley aplicable a las obligaciones alimenticias) indica que «la ley interna de la residencia del acreedor de alimentos regirá las obligaciones alimenticias a que se refiere el art. $1 »$. El precepto evita todo reenvío, porque está prohibido consultar las normas de conflicto del país de residencia del acreedor de alimentos. Ejemplo 2: el reenvío es también imposible, por la misma razón, en el Convenio de La Haya de 4 mayo 1971 (accidentes de circulación por carretera), cuyo art. 3 dispone que «la Ley aplicable será la ley interna del Estado en cuyo territorio haya ocurrido el accidente». Segundo: otros Convenios prohíben de modo expreso el reenvío. Ejemplo: el art. 15 Convenio de Roma 19 junio 1980 (Ley aplicable a las obligaciones contractuales) indica que «cuando el presente Convenio prescriba la aplicación de la Ley de un país, se entenderá por tal las normas jurídicas en vigor en ese país, con exclusión de las normas de Derecho internacional privado». El precepto prohíbe expresamente todo reenvío. Tercero: otros Convenios prohíben el reenvío de modo implícito. Tales Convenios sólo contienen una «causa tasada» de inaplicación de la Ley designada por la norma de conflicto convencional, la contrariedad de la Ley designada con el orden público internacional del Estado de que se trate. La Ley extranjera no puede dejar de aplicarse en virtud de un reenvío. Ejemplo: el Convenio de Munich de 5 septiembre 1980 (ley aplicable a los nombres y apellidos) nada dispone sobre el reenvío. Pero la única causa que el convenio admite para no aplicar el Derecho extranjero designado por la norma de conflicto es su contrariedad con el orden público internacional. A sensu contrario, un posible reenvío no puede ser causa de inaplicación de la Ley designada por la norma de conflicto recogida en el Convenio.

b) Convenios internacionales que parecen aceptar el reenvío. Dos Convenios internacionales -de los vigentes para España- parecen admitir el reenvío. Pero es una impresión engañosa. En el fondo, no admiten ningún

${ }^{62}$ L. MiglioRino, «La questione del rinvio e le soluzioni accolte nelle convenzioni internazionali», RDIPP, 1996, pp. 499-512. 
tipo de reenvío (E. D. GRAUE ${ }^{63}$ ): (a) El art. 42 Convenio de Washington de 18 marzo 1965 (arreglo de diferencias relativas a inversiones entre Estados y nacionales de otros Estados) parece admitir el reenvío. Pero esta impresión, como se ha dicho, es un espejismo (A. GIARDINA ${ }^{64}$ ). Dicha norma indica el «sistema de DIPr.» aplicable y no el «Derecho estatal» aplicable, por lo que resuelve un «conflicto de sistemas», no un «conflicto de Leyes». (b) El art. 3 Convenio de La Haya de 25 octubre 1980 (secuestro internacional de menores) parece admitir el reenvío. Pero tampoco es verdad (A. E. ANTON, G. CARELLA ${ }^{65}$ ). La norma indica el «DIPr. aplicable», por lo que resuelve un «conflicto de sistemas» y no un «conflicto de Leyes».

c) Convenios internacionales que admiten el reenvío. Algunos Convenios internacionales, escasos, admiten el reenvío. Incluso el reenvío de segundo grado. Ejemplos: art. 5 Convenio de La Haya 14 marzo 1978 (Ley aplicable a los regímenes matrimoniales) y art. 4 Convenio de La Haya de 1 agosto 1989 (Ley aplicable a las sucesiones por causa de muerte). Ello se debe a la mediocridad de los redactores de ambos Convenios, que no tuvieron presentes los inconvenientes de esta solución (Y. LEQUETTE ${ }^{66}$ ). Pero debe subrayarse de modo terminante que, por fortuna, ninguno de estos Convenios internacionales está en vigor para España. Así que menos problemas.

\section{El reenvío de primer grado en materia sucesoria: los arts. 9.8 y 12.2 del Código Civil}

\section{El reenvío como herramienta al servicio del art. 9.8 del Código Civil}

26. El reenvío de primer grado en favor de la Ley sustantiva española (art. $12.2 \mathrm{Cc}$.) es un «instrumento accesorio» de la norma que determina la Ley reguladora de la sucesión, que es el art. $9.8 \mathrm{Cc}$. El art. $12.2 \mathrm{Cc}$. es una «norma de aplicación» que está «al servicio» del art. 9.8 Cc., que es una

63 E. D. GRAUE, Internationales Privatrecht Rück- und Weiterverweisung, Berlín, Schweitzer, 1981, pp. 55-56; ID., «Rück- und Weiterverweisung (renvoi) in den Haager Abkommen, Grandeur et déclin du renvoi dans les Conventions de Haye», RabelsZ., 1993, pp. 26-62.

${ }^{64}$ A. GiardinA, «L'exécution des sentences du Centre international pour le réglement des différends relatifs aux investissements», RCDIP, 1982, pp. 273-293.

65 A. E. AnTON, «The Hague convention of international child abduction», ICLQ, 1981, vol. 30, pp. 537-567; G. CARELLA, «La convenzione dell'Aja del 1980 sugli aspetti civili della sottrazione internazionale di minori», RDIPP, 1994, pp. 777-794.

66 Y. LeQueTte, «Le renvoi de qualifications», Mélanges dédiées a Dominique Holleaux, París, Litec, 1990, pp. 249-262 ; Id., «Le Droit international privé de la famille à l'épreuve des Conventions internationales», RCADI, 1994-II, pp. 51-99. 
«norma de conflicto» (A.-L. CALvo CARAVACA ${ }^{67}$ ). El reenvío es un puro instrumento al servicio de una mejor aplicación de las normas de conflicto. El art. 12.2 Cc. es una norma auxiliar o ancilar respecto de las normas que indican el «Derecho aplicable» (A.-L. Calvo CaravacA, A. Marín LóPeZ, H. BATIFFOL / P. LAGARDE ${ }^{68}$ ). El reenvío no puede «traicionar» el sentido de las normas de conflicto, sino facilitar su correcta aplicación. El reenvío desarrolla una «función instrumental». Esta «concepción instrumental del reenvío» no es una invención de la doctrina y/o de la jurisprudencia. Es una concepción perfectamente construida sobre diversos argumentos legales: $1 .^{\circ}$ ) el art. 12. Cc es una «norma de aplicación» y no una «norma de regulación», y es sabido que las primeras están «al servicio» de las segundas (E. VITTA ${ }^{69}$; $2 .^{\circ}$ ) se respeta la norma principal (= la norma de conflicto), lo que refuerza la seguridad jurídica; $3^{\circ}$ ) el reenvío es una «excepción» al normal funcionamiento de la norma de conflicto. Por ello, debe operar sólo en casos tasados, justificados, motivados, es decir, sólo cuando se acredita la presencia de un conjunto de circunstancias que son, precisamente las que permiten apartarse de la «regla general» (= la norma de conflicto) para acoger una solución distinta (= aplicación del Derecho sustantivo español en virtud de reenvío de retorno). Y como excepción que es, el reenvío debe interpretarse de modo restrictivo, al igual que sucede con otras excepciones contempladas en el art. 12 Cc., como el orden público internacional (art. 12.3 Cc.) o el fraude de Ley internacional (art. 12.4 Cc.).

${ }^{67}$ A.-L. Calvo Caravaca, «Art. 9.8 Cc.», Com.Cc. y Comp.For., 2. ${ }^{\text {a }}$ ed., 1995, pp. 350391, esp. p. 359, texto y nota [7]: «Finalmente, debe observarse que los principios de unidad y universalidad de la sucesión, que constituyen el eje alrededor del cual gira nuestro sistema: (...) b) Operan como un límite al reenvio de retorno del art. 12.2 del Código Civil, que no será admisible cuando conduzca a la fragmentación de la sucesión mortis causa, como sucede cuando el causante deje bienes inmuebles en España y en el extranjero, supuesto en el que habrá que estar a una sola Ley -la nacional del difunto- y no a varias leyes, según la situación de los bienes» (...) «las normas de aplicación o de funcionamiento $-y$ el art. 12.2 Cc. es una de ellas-, no pueden ser entendidas aisladamente, sino que deben ser interpretadas conjuntamente con las normas reguladoras -y el art. 9.8 Cc. es una de ellas-: es decir, sirven para resolver los problemas de aplicación que estas últimas suscitan, no para destruir los principios -como los de unidad y universalidad de la sucesión mortis causa- en ellas formulados»; ID., «Sucesión hereditaria», en J. D. GonZÁLEZ CAM-

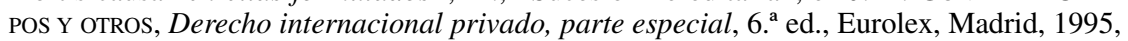
pp. 393-422; ID., «La sucesión hereditaria en el Derecho internacional privado español», $R G D, 1986$, pp. 3103-3138.

68 A.-L. Calvo Caravaca en UNED, Derecho internacional privado I, 1996, pp. $147-$ 148 y obras citadas en la nota inmediatamente anterior; A. MARín LóPEZ, Derecho internacional privado I, Granada, 1994, pp. 258-259; H. BATIFFOL / P. LAGARDE, Derecho international privé I, 1993, pp. 506-509.

${ }^{69}$ E. VITTA, Corso di Diritto internazionale privato e processuale, Torino, UTET, 3. a ed., 1989, p. 119. 
27. Esta «concepción instrumental del reenvío» comporta diversas consecuencias de extrema importancia.

1. $\left.{ }^{\circ}\right)$ El reenvío es un instrumento meramente facultativo. El reenvío que las normas de conflicto extranjeras hacen en favor de la Ley sustantiva española no debe aceptarse de manera «automática». En Derecho español, el reenvío no es obligatorio para los tribunales, sino «facultativo» ${ }^{70}$. El carácter facultativo del reenvío se deduce de dos concretas previsiones de legislador. Primera: el art. 12.2 Cc. no indica que el juez español debe «aplicar» las normas de conflicto extranjeras que remiten al Derecho español. Lo que dice el art. 12.2 Cc. es que el juez español debe «tener en cuenta» las normas de conflicto extranjeras si remiten a la Ley española. Y naturalmente, «tener en cuenta» no es lo mismo que «aplicar» las normas de conflicto extranjeras (STS 15 noviembre 1996 $6^{71}$ ). Segunda: el art. 12.6 Cc. indica que sólo las normas de conflicto «del Derecho español» son imperativas y por tanto de inexcusable aplicación por los jueces y autoridades españolas. Por tanto, a sensu contrario, las normas de conflicto «del Derecho extranjero», que son las que provocan el reenvío, nunca son de aplicación imperativa para los tribunales españoles. Éstos pueden, facultativamente, «tener en cuenta» tales normas de conflicto extranjeras, pero no están obligados a «aplicar» dichas normas» ${ }^{72}$. En suma: el reenvío no es «obligatorio».

2..$\left.^{\circ}\right)$ El reenvío debe comportar consecuencias razonables y justas. El reenvío sólo debe aceptarse si a través de él se «mejora» la aplicación de las normas de conflicto españolas y, de ese modo, se alcanzan soluciones satis-

${ }^{70}$ El carácter facultativo del reenvío fue señalado por ciertos autores antes de la STS 15 noviembre 1996. Vid. A.-L. Calvo CaravaCa, «Art. 9.8 Cc.», Com.Cc. y Comp.For., 2. a ed., 1995, pp. 350-391, esp. p. 359, texto y nota [7]; ID., «Sucesión hereditaria», en J. D. GoNZÁlez CAMPOS y OTROS, Derecho internacional privado, parte especial, 6. ${ }^{a}$ ed., Eurolex, Madrid, 1995, pp. 393-422; ID., «La sucesión hereditaria en el Derecho internacional privado español», $R G D, 1986$, pp. 3103-3138; P. RoDRÍGUEZ MATEOS, «Una perspectiva funcional del método de atribución», REDI, 1988, vol. XL, 1988, pp. 79-126; M. VIRGós SoRIANO, El comercio internacional en el nuevo Derecho español de la competencia desleal (un análisis del art.4 de la Ley española de competencia desleal de 1991), Civitas, Estudios de Derecho Mercantil, Madrid, 1993, p. 131.

${ }^{71}$ STS 15 noviembre 1996: «La frase 'tener en cuenta' no equivale a que deban aplicarse nuestras normas sucesorias de modo inexorable, puesto que en español (Diccionario de la Real Academia) 'tener en cuenta' quiere decir 'tener presente, considerar', y ello es lo que debe hacer esta Sala: considerar si el reenvio (que ya ha sido alguna vez admitido por nuestros Tribunales de instancia) ha de aceptarse en el presente caso, en virtud de lo dispuesto en la norma de conflictos del Estado de Maryland, que utiliza como punto de conexión el lugar de situación de los inmuebles para determinar la norma de derecho material por la que ha de regirse la sucesión de sus ciudadanos».

72 A.-L. Calvo Caravaca / J. Carrascosa González, Derecho internacional privado, vol. I, Granada, Ed. Comares, 8. ${ }^{a}$ ed., Granada, 2007, pp. 5-6. 
factorias, razonables y justas (STS 15 noviembre $1996^{73}$, STS 21 mayo $1999^{74}$ ). El juez debe demostrar que el reenvío conduce a resultados justos en relación con el caso concreto porque «mejora» y «perfecciona» la solución general contenida en el art. $9.8 \mathrm{Cc}$. El juez español puede emplear el reenvío de primer grado o no emplearlo. Pues bien: lo utilizará sólo y exclusivamente si dicho reenvío resulta útil para alcanzar soluciones satisfactorias, razonables y justas en el caso concreto. El operador jurídico debe demostrar que el reenvío conduce a resultados justos (= el reenvío exige un «plus de motivación» por parte del tribunal, precisamente porque su utilización es facultativa). A tal efecto, deben ponderarse los elementos del caso concreto y los resultados que comporta el reenvío en dicho caso concreto.

\section{Supuestos en los que procede acoger el reenvío}

28. Los casos en los que el reenvío resulta útil y conveniente porque «mejora» $\mathrm{y}$ «perfecciona» la solución general contenida en el art. $9.8 \mathrm{Cc}$. son aquéllos en los que se verifican, cumulativamente, estas circunstancias (A.L. Calvo Caravaca / J. CarRascosa GonZÁLeZ ${ }^{75}$ ): $1 .^{\circ}$ ) primera circunstancia: el reenvío respeta la unidad legal de la sucesión, la sucesión se rige por una sola Ley estatal; $2^{\circ}{ }^{\circ}$ ) segunda circunstancia: concurre un «índice positivo de reenvío», un conjunto de datos o circunstancias que aconsejan admitir tal reenvío porque, de tal manera, no sólo se respeta la unidad legal de la sucesión, sino que, además, se alcanzan resultados razonables y justos.

\section{A) PRIMERA CIRCUnSTANCIA: LA UNIDAD LEGAL DE LA SUCESIÓN}

29. El reenvío debe respetar los «principios básicos» de la norma principal, que es el art. $9.8 \mathrm{Cc}$., norma de conflicto que señala la Ley aplicable a la sucesión mortis causa. Es absolutamente necesario, para aceptar el reenvío de primer grado, que éste no vulnere los «principios inspiradores» de la norma de conflicto española. El art. 12.2 Cc. es una «norma instrumental» que debe respetar la «idea de Justicia» que vertebra la norma principal, que

${ }^{73}$ STS 15 noviembre 1996: «El reenvío, por último, debe entenderse como un instrumento de armonización de sistemas jurídicos de los Estados, como un instrumento respetuoso con los principios que los inspiran».

${ }^{74}$ STS 21 mayo 1999: «lo que debe añadirse que en este supuesto la solución que se alcanzaría con esa aplicación [de la Ley sustantiva española en virtud de reenvio de retorno] tampoco puede afirmarse que entrañe una mayor justicia en relación con los intereses en juego».

75 A.-L. Calvo Caravaca / J. Carrascosa González, Derecho internacional privado, vol. I, Comares, 8. ${ }^{a}$ ed., Granada, 2007, pp. 240-250; J. CARRASCOSA GonZÁLEZ, «Comentario al art. 9.8 Cc. y al art. 12.2 Cc.», en Jurisprudencia civil comentada. Código Civil (Dir. M. PASQuau Liaño), Ed. Comares, Granada, 2007, 2. ${ }^{a}$ ed. (en prensa). 
es la «norma de conflicto» española (= en este caso, el art. 9.8 Cc.). Pues bien, el principio básico que opera como columna vertebral del art. $9.8 \mathrm{Cc}$. es la «unidad y universalidad legal de la sucesión». Dicho principio significa que toda sucesión mortis causa debe quedar sujeta a una sola Ley reguladora, con independencia de la naturaleza de los bienes y de los países en los que se encuentren tales bienes. Por tanto, si el reenvío de primer grado comporta la consecuencia de que la sucesión de ciertos bienes queda sujeta al Derecho sustantivo español, pero la sucesión de otros bienes de la misma sucesión queda sujeta a un Derecho extranjero, el reenvío en favor del Derecho español no se aceptará y la sucesión quedará sujeta, enteramente, a la Ley nacional del causante (art. $9.8 \mathrm{Cc}$.). En conclusión: el reenvío nunca puede aceptarse si comporta un «fraccionamiento legal de la sucesión». Esta postura fue defendida por A.-L. CALvo CARAVACA antes de que el TS entrara en acción y la hiciera propia incluso con las mismas palabras $(=$ y con el $\mathrm{TS}$, todos los demás órganos jurisdiccionales inferiores españoles $)^{76}$.

30. Hoy día es indiscutido que el reenvío no puede aceptarse si comporta como consecuencia que la sucesión quede dividida en «segmentos de bienes» regidos por Leyes diferentes. Toda la jurisprudencia española se orienta con claridad en esta dirección. Lo dice, sin fisuras, y con contundencia el mismo TS (STS 15 noviembre 1996, Lowenthal ${ }^{77}$, STS 21 mayo 1999, Denney ${ }^{78}$, STS

76 A.-L. Calvo Caravaca, «Art. 9.8 Cc.», Com.Cc. y Comp.For., 2. a ed., 1995, pp. 350391, esp. p. 359, texto y nota [7]: «los principios de unidad y universalidad de la sucesión, que constituyen el eje alrededor del cual gira nuestro sistema: (...) b) Operan como un límite al reenvío de retorno del art. 12.2 del Código Civil, que no será admisible cuando conduzca a la fragmentación de la sucesión mortis causa, como sucede cuando el causante deje bienes inmuebles en España y en el extranjero, supuesto en el que habrá que estar a una sola Ley -la nacional del difunto- y no a varias leyes, según la situación de los bienes». Idéntica postura en J. D. GONZÁLEZ CAMPOS Y OTROS, Derecho internacional privado, parte especial, Eurolex, Madrid, 6. ${ }^{a}$ ed., 1995, pp. 393-422. El trabajo pionero que defendía la subordinación del reenvío al pleno respeto a la unidad y universalidad de la sucesión fue publicado ya en 1986: A.-L. CALVO CARAVACA, «La sucesión hereditaria en el Derecho internacional privado español», $R G D, 1986$, pp. 3103-3138. En igual sentido, también antes de la STS 15 noviembre 1996, M. MoYA ESCUDERO, «Nota a la SAT Granada 22 diciembre 1988», REDI, 1990, vol. XLII, pp. 635-637: «En ningún caso creo que la finalidad que la norma persigue, su carácter unitario en la regulación, pueda romperse por llegar a un sistema de régimen fraccionado».

77 STS 15 noviembre 1996: «El derecho español entiende preponderante la ley nacional del 'de cuius'; al propio tiempo, el sistema hereditario español es de carácter universalista, esto es, sostiene el criterio de unidad del régimen sucesorio».

${ }^{78}$ STS 21 mayo 1999: «La aplicación del reenvio en los términos pretendidos en la demanda, es contrario al principio de universalidad de la herencia que rige nuestro Derecho sucesorio e impide dar un tratamiento jurídico distinto a la sucesión mobiliaria y a la inmobiliaria». 
23 septiembre 2002, François Marie James $W^{79}$ ). La jurisprudencia de tribunales inferiores también sigue férreamente este principio: 1. ${ }^{\circ}$ ) SAP Málaga 18 diciembre 1996 [se acepta el reenvío que efectúa la Ley inglesa en favor de la Ley española pues dicho reenvío no supone ningún fraccionamiento legal de la sucesión: la sentencia fue confirmada por la STS 23 septiembre 2002]; 2. ${ }^{\circ}$ ) SAP Alicante 7 junio 2001 [se rechaza el reenvío de la Ley inglesa a la española porque provocaba un fraccionamiento legal de la sucesión, ya que existían bienes sucesorios litigiosos en Inglaterra y en España]; 3. ${ }^{\circ}$ ) SAP Asturias 1 septiembre 2005 [se acepta el reenvío en favor de la Ley española efectuado por las normas de conflicto del Estado de Pennsylvania, EE.UU., tanto porque no quedaron acreditadas tales normas de conflicto como porque el reenvío no provocaba ningún fraccionamiento de la sucesión]; $4{ }^{\circ}$ ) SAP Badajoz 11 julio 1995 [el reenvío es desaconsejable cuando comporta fraccionamiento legal de la sucesión de ciudadano británico ${ }^{80}$; 5. ${ }^{\circ}$ ) SAP Granada 19 julio 2004 [se rechaza el reenvío porque la norma de conflicto irlandesa conducía al fraccionamiento legal de la sucesión]. Y no está de más recordar que la idea de la universalidad y unidad legal de la sucesión en los casos internacionales aparece ya muy claramente en la más que centenaria pero certera STS 14 diciembre 1901 como un principio capital del DIPr. sucesorio español ${ }^{81}$.

${ }^{79}$ STS 23 septiembre 2002: «En efecto, la sentencia recurrida da como probado que los únicos bienes del causante son los inmuebles sitos en España de los cuales dispuso testamentariamente, por lo que en modo alguno se produce una fragmentación de la regulación de la herencia, en cuyo caso, la norma general (no específica para la sucesión mortis causa) del art. 12.2 Cód. civ. impondría la no aceptación del reenvío de la ley inglesa por contraria a aquellos principios. Éste es el criterio de esta Sala, y a él responden las declaraciones contenidas en su sentencia de 15 de noviembre de 1996, que no aceptó el reenvío que la ley nacional del causante hacía a la ley española en cuanto a los inmuebles por estar sitos en España, lo mismo que las contenidas en su sentencia de 21 de marzo de 1999. Por tanto, si como en este litigio ocurre, la herencia del causante se compone únicamente de bienes inmuebles sitos en España, no hay ningún inconveniente en la aceptación del reenvío de la ley inglesa, pues será la española la única que regula toda sucesión del causante (...) El motivo se desestima, pues la aplicación de la ley española, a la que se reenvía el derecho inglés, que es la ley personal del causante, respecto de los inmuebles sitos en Espa$\tilde{n} a$, no es contraria a los principios de unidad y universalidad de la sucesión, que es a lo que obedecen la regla del art. 9.1 Cód. civ.».

${ }^{80}$ SAP Badajoz 11 junio 1995: «El causante no quería dejar nada a sus hijos, con arreglo a la Ley inglesa podía hacerlo, no cabe pues nada más que formalmente en pensar en problemas de desheredación o de preterición y de aquí surge la conclusión de que no siempre el reenvío es aconsejable y de que este supuesto es uno de los que exigirían mayor meditación».

${ }^{81}$ STS 14 diciembre 1901: «...si bien la transmisión de bienes inmuebles por título singular y cuando se trata de cosas determinadas se rige por la Ley del territorio o estatuto real, al que se atiende igualmente para la determinación y clasificación de los derechos inherentes a dichos intereses, es doctrina establecida por este TS, de acuerdo con los más equitativos principios del Derecho internacional privado, inspirados en la conveniencia de la unidad de la sucesión y en la necesidad de que, a quien se concede adquirir en determinados territorios bienes raíces, se le otorga la facultad de disponer de ellos, según la Ley 
31. La unidad legal de la sucesión se refiere a la «sucesión litigiosa» en España, y no necesariamente a «toda la sucesión» (SAP Málaga 18 diciembre $1996^{82}$ ). Lo importante es que la sucesión que ha motivado el litigio ante tribunales españoles quede sujeta a una sola Ley reguladora. Cabe por tanto afirmar, al respecto, lo siguiente: $1^{\circ} .^{\circ}$ Es irrelevante que existan bienes sucesorios no litigiosos. 2. $^{\circ}$ ) Si un tribunal español conoce de un litigio relativo, exclusivamente, a la sucesión de los bienes inmuebles del causante, debe asegurarse de que la sucesión de tales inmuebles quede sujeta a una sola Ley estatal. Pero es indiferente cuál sea la Ley reguladora de la sucesión de los bienes muebles, si ésta es cuestión no litigiosa ante los tribunales españoles y/o ha sido o va ser resuelta por tribunales extranjeros (M. VIRGós SORIA$\mathrm{NO}^{83}$ ). $3 .^{\circ}$ ) Si el litigio sucesorio afecta exclusivamente a los bienes inmuebles sitos en España, es también indiferente el hecho de que existan bienes inmuebles sitos en el extranjero que no han suscitado litigio alguno ante tribunales españoles. El destino sucesorio de tales bienes bien puede resolverse ante tribunales extranjeros. En todos estos casos, la «unidad legal de la sucesión litigiosa en España» está garantizada y el reenvío es posible.

32. Algunos autores (J. L. IRIARTe Ángel, J. A. Tomás Ortiz de la TORRE, I. AyAla CARDiÑanos) han sostenido que el «fraccionamiento legal» de la sucesión, producto del reenvío de primer grado, puede admitirse ${ }^{84}$. Así lo hizo, de hecho, la SAP Granada 22 diciembre 1988 (= corregida de modo muy severo por la STS 15 noviembre 1996, que resolvió el caso en casación $^{85}$ ). Argumento: el mismo art. $9.8 \mathrm{Cc}$. admite, en ciertos supuestos, una «escisión legal» de la sucesión. Y así parece ser, porque la Ley aplicable a la sucesión es la Ley nacional del causante en el momento de su fallecimiento,

que autoriza su testamentaficación activa -derivación esta ineludible de la capacidad civil, regida siempre por el estatuto personal y doctrina ahora corroborada por el art. 10 CC».

${ }^{82}$ SAP Málaga 18 diciembre 1996, texto en REDI, 1998 II vol. L, pp. 244-248 y nota de I. Ayala CARDiÑANOS.

${ }^{83} \mathrm{M}$. VIRGÓS SORIANO, «Derecho de sucesiones y reenvío: la respuesta del sistema español», Anales de las Academia Matritense del Notariado, n. 42, 2004, pp. 181-210; M. VIRGós Soriano / E. Rodríguez Pineau, «Succession Law and Renvoi: the Spanish Solution», Festschrift Erik Jayme, vol. I, Munich, 2004, pp. 977-992.

${ }^{84}$ J. L. IRIARTE ÁNGEL, «Doble reenvío y unidad de tratamiento de las sucesiones», $R G D$, 1989, núm. 537, pp. 3561-3580; J. A. TOMÁs ORTIZ DE LA TORRE, «¿Anular por reenvío la voluntad del testador?», La Ley, núm. 5845, 9 septiembre 2003 (versión on line); ID., «El reenvío ante el Tribunal Supremo: historia y reapertura de la vieja polémica en el Derecho internacional privado español», Actualidad Civil, núm. 40, semana 1-7 noviembre 1999, pp. 1261-1295; I. AyAla CARDIÑANOS, «Nota a la SAP Málaga 18 diciembre 1996», en REDI, 1998-II vol. L, pp. 244-248. Simpatiza con tal postura también A. BORRÁs RODRÍGUEZ, «Art. 12.2 Cc.», Com.Cc. Min.Justicia, 1991, pp. 140-142.

${ }^{85}$ SAT Granada 22 diciembre 1988, RGD, núm. 543, 1989, pp. 8651-8654; M. MoYA ESCUDERO, «Nota a la SAT Granada 22 diciembre 1988», REDI, 1990, vol. XLII, pp. 635637. 
pero si el causante otorgó testamento en momento anterior con arreglo a la Ley del país cuya nacionalidad ostentaba entonces, la validez de dicho testamento se rige por la Ley nacional anterior del causante, mientras que el «resto de la sucesión» se rige por la Ley nacional posterior del causante. Ahora bien: este presunto argumento no puede compartirse. En efecto, esta previsión del art. 9.8.II Cc. es una excepción para preservar la validez del testamento. Pero con ello el art. 9.8.II Cc. no admite, realmente, una división de la herencia en «segmentos de bienes» regidos por Leyes estatales diferentes. Por tanto, el art. $9.8 \mathrm{Cc}$. no admite, en ningún supuesto, el fraccionamiento legal de la sucesión. Como se ha visto, el TS ha rechazado explícita y categóricamente, en diversas ocasiones y sin excepción alguna, que una misma sucesión litigiosa pueda quedar sujeta a varias Leyes estatales.

\section{B) Segunda Circunstancia: un ÍNDice Positivo DE REENVío}

33. Sin embargo, para aceptar el reenvío en favor del Derecho material español, no basta con que dicho reenvío respete la unidad y universalidad de la sucesión. No se trata, como se ha escrito en una inteligente «nota», de aceptar el reenvío cuando la sucesión no resulte fragmentada legalmente como consecuencia del reenvío y de no aceptarlo, sin más, en el caso contrario $^{86}$. La construcción es más sutil. En efecto, acreditado que el reenvío no rompe la unidad legal de la sucesión, es preciso que, además, concurra algún «índice positivo de reenvío», es decir, algún dato que demuestre que el reenvío es útil, en el caso concreto, para producir resultados justos. La doctrina ha discutido en profundidad en torno a los «índices» que deben ser relevantes para acoger o no el reenvío. En línea de principio, los «índices positivos de reenvío» que resultan admisibles son los siguientes.

\section{a) PRIMER ÍNDICE: EL REENVÍO COMO MECANISMO PARA RESOLVER UN «FALSO CON- FLICTO DE LEYES»}

34. Si el Derecho sucesorio material extranjero y el Derecho sucesorio material español se inspiran en los mismos principios generales, el reenvío se convierte en una herramienta que puede ser aconsejable. En tal caso, realmente, es indiferente aplicar Derecho extranjero o Derecho material español. Pues bien: el reenvío de primer grado permite aplicar el Derecho material español, lo que facilita la actividad judicial y, posiblemente, también disminuye el «nivel de litigación» de los particulares. Por tanto, el reenvío es aconsejable y positivo cuando, gracias él, se resuelve un «falso conflicto de

${ }^{86}$ I. AyAla CARDiÑAnOs, «Nota a la SAP Málaga 18 diciembre 1996», en REDI, 1998-II vol. L, pp. 244-248. 
Leyes» (False Conflict ${ }^{87}$. La jurisprudencia confirma este índice positivo de reenvío (STS 15 noviembre 1996, STS 21 mayo 1999, SAP Málaga 13 marzo 2002, SAP Alicante 10 marzo $2003^{88}$ ). Es lo que el TS llama «armonía internacional de soluciones».

35. Ahora bien, esta «armonía internacional de soluciones» se entiende, naturalmente, en un sentido «material»: el contenido material de la Ley nacional del causante y de la Ley española es muy similar. Por el contrario, cuando el Derecho sucesorio sustantivo extranjero está construido sobre principios totalmente distintos a los que inspiran el Derecho sucesorio sustantivo español, el reenvío en favor del Derecho sustantivo español podría ser contemplado como una «falta de respeto» o menosprecio al Derecho extranjero y a su modo de regular la sucesión mortis causa (J. CARRASCOSA GONZÁLEZ $\left.{ }^{89}\right)$.

36. En todo caso, hay que recordar que el TS ha admitido este índice positivo de reenvío (= el reenvío para resolver de manera sencilla un «conflicto negativo de Leyes»), pero lo ha hecho sólo obiter dicta y a sensu con-

${ }^{87}$ Los False Conflicts son muy queridos por la doctrina norteamericana, que ha teorizado muy en profundidad sobre este mecanismo (= pues se trata de una artilugio recurrente para no aplicar Derecho extranjero y dejarse caer en los cálidos brazos de la Lex Fori). Vid. ad ex., B. CurriE, Selected Essays on the Conflict of Laws, Durham, N.C., 1963, pp. 183184; ID., «Comment on Babcock v. Jackson, A Recent Development in Conflict of Laws», Columbia Law Review, vol. 63, 1963, pp. 1233 y ss., concr. p. 1242; ID., «The Disinterested Third State», Law and Contemporary Problems, vol. 28, 1963, pp. 754 y ss.; D. F. CAVERs, The Choice of Law Process, Ann Arbor, 1965, p. 75; P. KAY WeSTEN, «False Conflicts», California Law Review, vol. 99, 1967, pp. 74-122; R. A. LeFLAR, «Conflict of Laws», Annual Survey of American Law, 1968/69, p. 43.

${ }^{88}$ STS 15 noviembre 1996: «El reenvío, por último, debe entenderse como un instrumento de armonización de sistemas jurídicos de los Estados, como un instrumento respetuoso con los principios que los inspiran y si el derecho americano se apoya en una gran libertad de testar, y no reconoce las legítimas de los hijos, en nada armonizaría la coexistencia de los derechos respectivos, la aplicación por esta Sala del derecho español a la sucesión del causante de este litigio»; STS 21 mayo 1999: «Por otra parte, como señala la sentencia de esta Sala de 15 de noviembre de 1996, ante supuesto análogo al actual, la aplicación al caso del reenvío de retorno no conseguiría la finalidad que se asigna a este instrumento jurídico, de armonización de los sistemas jurídicos de los Estados, a lo que debe añadirse que en este supuesto la solución que se alcanzaría con esa aplicación tampoco puede afirmarse que entrañe una mayor justicia en relación con los intereses en juego. Por todo ello, debe concluirse que la sucesión del causante don Iván se rige por su ley nacional, es decir, por la Ley inglesa reconocedora de la libertad de testar a sus nacionales y, en consecuencia, procede la desestimación de la demanda, con revocación de la sentencia de primera instancia».

${ }^{89}$ J. Carrascosa GonzÁlez, «Comentario al art. 9.8 Cc. y art. 12.2 Cc.», en Jurisprudencia civil comentada. Código Civil (Dir. M. PASQuau Liaño), Ed. Comares, Granada, 2007, 2. ${ }^{\mathrm{a}}$ ed. (en prensa). 
trario. El TS, curiosamente, jamás ha utilizado este primer índice positivo de reenvío para solventar un litigio sucesorio internacional. Es decir, el TS jamás ha aceptado el reenvío en favor del Derecho sustantivo español sobre la base de un «falso conflicto de Leyes». En efecto, el TS aludió a este índice positivo de reenvío en la STS 15 noviembre $1996^{90}$ y en la STS 21 mayo $1999^{91}$, pero en ninguno de tales pronunciamientos el TS aceptó el reenvío en favor del Derecho material sucesorio español porque éste era «muy similar» al Derecho material sucesorio del país de la nacionalidad del causante.

37. Varios ejemplos pueden ilustrar con claridad cómo debe, o no, operar este primer índice positivo de reenvío.

Ejemplo 1: si el Derecho sucesorio extranjero correspondiente a la nacionalidad del causante está construido sobre el principio básico de «libertad absoluta de testar» sin sujeción a legítimas (= como sucede en Derecho inglés), pero el DIPr. extranjero reenvía al Derecho civil común español, que se inspira en el principio contrario (= el respeto a las legítimas), entonces no existe ningún «falso conflicto de Leyes». No concurre este índice positivo de reenvío.

Ejemplo 2: si el Derecho sucesorio extranjero correspondiente a la nacionalidad del causante se asienta en el principio básico de libertad absoluta de testar sin sujeción a legítimas, y tal DIPr. extranjero reenvía al Derecho foral navarro, en el que existe plena libertad (material) de testar, sí que existe un «falso conflicto de Leyes». Concurre este índice positivo de reenvío. El reenvío es aconsejable y la sucesión debería regirse por el Derecho navarro.

38. Este primer índice positivo de reenvío (= reenvío para solventar un falso conflicto de Leyes) responde a un principio de «facilitación» de la labor

${ }^{90}$ STS 15 noviembre 1996: «El reenvío, por último, debe entenderse como un instrumento de armonización de sistemas jurídicos de los Estados, como un instrumento respetuoso con los principios que los inspiran y, si el derecho americano se apoya en una gran libertad de testar, y no reconoce las legítimas de los hijos, en nada armonizaría la coexistencia de los derechos respectivos, la aplicación por esta Sala del derecho español a la sucesión del causante de este litigio».

${ }^{91}$ STS 21 mayo 1999: «Por otra parte, como señala la sentencia de esta Sala de 15 de noviembre de 1996, ante supuesto análogo al actual, la aplicación al caso del reenvío de retorno no conseguiría la finalidad que se asigna a este instrumento jurídico, de armonización de los sistemas jurídicos de los Estados, a lo que debe añadirse que en este supuesto la solución que se alcanzaría con esa aplicación tampoco puede afirmarse que entrañe una mayor justicia en relación con los intereses en juego. Por todo ello, debe concluirse que la sucesión del causante don Iván se rige por su ley nacional, es decir, por la Ley inglesa reconocedora de la libertad de testar a sus nacionales y, en consecuencia, procede la desestimación de la demanda, con revocación de la sentencia de primera instancia». 
judicial y de la litigación de los particulares. Es un argumento de comodidad más que de Justicia. Por eso no escapa a críticas (A.-L. Calvo CARAVACa / J. CARRASCOSA GoNZÁleZZ ${ }^{92}$ ). En efecto: en todo caso, la precisión de cuál es el Derecho estatal que debe regir y que rige la sucesión es una operación jurídica totalmente necesaria. Afirmar que es «indiferente» aplicar la Ley material sucesoria española o la Ley material sucesoria correspondiente a la nacionalidad del causante no es exacto. Así es, porque determinar qué concreto «Derecho estatal» rige el supuesto sigue siendo siempre preciso por varios motivos: $1^{\circ}{ }^{\circ}$ ) Conocer el Derecho que regula el fondo de la sucesión es un derecho subjetivo de las partes, que sólo de este modo pueden, en su caso, interponer un recurso jurídicamente bien construido (= sólo si los litigantes conocen las normas jurídicas específicas que ha aplicado un tribunal se puede recurrir contra la decisión de éste con esperanzas de éxito). 2..$\left.^{\circ}\right)$ Determinar qué concreto Derecho estatal rige una sucesión de carácter internacional es necesario para solventar problemas de formación de la jurisprudencia. Si el tribunal aplica la Ley material española, lo que exprese el tribunal se incorpora a la jurisprudencia nacional. Pero si el tribunal aplica una Ley material sucesoria extranjera, lo que diga el tribunal español no se incorpora a la jurisprudencia, porque no es «doctrina legal» en el sentido del art. 1.6 Cc. (STS 4 julio 2006) $)^{93}$. $^{\circ} .^{\circ}$ ) Precisar el concreto Derecho estatal aplicable a la sucesión mortis causa es necesario, también, porque sólo el Derecho extranjero debe ser probado (art. 281.2 LEC). 4..$^{\circ}$ ) La afirmación de que dos Derechos estatales son «idénticos» o «sustancialmente similares» raramente se verifica en la práctica. Ciertas diferencias siempre existen entre dos ordenamientos jurídicos y con mayor razón en un sector jurídico tan técnico como el Derecho sucesorio. En Derecho inglés no existen las legítimas y tampoco existen, desde un prisma material, en Derecho sucesorio navarro. Pero la regulación de la sucesión mortis causa en Derecho inglés no es «igual», ni «idéntica» a la regulación de la sucesión mortis causa en Derecho navarro. Por tanto, este índice positivo de reenvío se construye sobre una aventurada hipótesis que esconde, como antes se ha avanzado, un argumento de comodidad más que Justicia. Aunque este primer índice positivo de reenvío sea defendido a capa y espada por el TS mismo, debe recordarse que barba non facit philosophum. Por ello, si el argumento es débil, débil siempre será incluso aunque lo defienda el TS.

92 A.-L. Calvo Caravaca / J. Carrascosa González, Derecho internacional privado, vol. I, Comares, 8. ${ }^{\text {a }}$ ed., Granada, 2007, pp. 20-22.

${ }^{93}$ Art. 1.6 Cc.: «La jurisprudencia complementará el ordenamiento jurídico con la doctrina que, de modo reiterado, establezca el Tribunal Supremo al interpretar y aplicar la ley, la costumbre y los principios generales del derecho». La referencia que este precepto hace a la «Ley, la costumbre y los principios generales del Derecho» se entiende realizada en favor de la Ley «española», la costumbre vigente y observada «en «España», y los principios generales del Derecho «español». 


\section{b) SEGUNDO ÍNDICE: EL REENVÍO COMO «AJUSTE DE LA LOCALIZACIÓN»}

39. En ocasiones, la sucesión queda regulada por un Derecho extranjero porque así lo ordena el art. 9.8 Cc.: la Ley nacional del causante. Sin embargo, el juez español puede apreciar que la «conexión real» de dicha situación con tal ordenamiento extranjero es muy débil. Con otras palabras: todos los datos del supuesto lo vinculan con España, salvo el punto de conexión «nacionalidad del causante», empleado por el art. 9.8 Cc. Es un causante extranjero, pero residía habitualmente en España y todos los bienes del caudal hereditario radican y se localizan en España, los herederos habitan también en España y el causante ha testado también en España. Puede entonces afirmarse que el art. 9.8 Cc. localiza «incorrectamente» la sucesión en el marco de un Derecho extranjero, ya que éste no es el Derecho del país más vinculado con la sucesión. Y puede afirmarse también que, en dicho caso, la nacionalidad del causante en el momento de su fallecimiento se convierte en un punto de conexión «vacío de potencial localizador» ${ }^{94}$.

40. El legislador emplea, normalmente, «puntos de conexión» que conducen a una Ley cuya aplicación al caso concreto resulta perfectamente previsible para los particulares implicados en la situación privada internacional. Puntos de conexión que conducen a la Ley del país más estrechamente vinculado con la situación. Esta idea, con distintos nombres (= principio de proximidad [P. LAGARDE], centro de gravedad de la relación jurídica [jurisprudencia anglosajona], Ley propia de cada institución legal [The Proper Law Doctrine diseñada por J. WeSTLAKE], sede la relación jurídica [F. K. VON SAVIGNY]), es una constante en la Historia del DIPr. Pues bien, en el caso de la sucesión mortis causa, el legislador arranca de un presupuesto: el art. 9.8 Cc. indica que la Ley nacional del causante en el momento de su fallecimiento debe regir la sucesión porque, en la mayor parte de los casos, es la Ley del país más vinculado con la situación jurídica. En otras palabras, el legislador español arranca de la idea de que, en principio, el país más vinculado con una sucesión «internacional» es el país cuya nacionalidad ostenta el causante (= lo que no es casualidad en un país, como España, que ha sido durante muchos años, un país exportador de emigrantes deseosos de regresar a España, país donde dejaron familia y quizás bienes, aunque hoy día este escenario, como señala P. DiAGo DiAGO, ya no se corresponda con la realidad ${ }^{95}$ ).

94 J. Carrascosa González, Desarrollo judicial y Derecho internacional privado, Comares, Granada, 2004, pp. 151-156.

${ }^{95}$ P. Diago Diago, «La sucesión y el fenómeno migratorio desde la perspectiva del Derecho internacional privado español», en J. L. Collantes González / F. SERRANo Migallón, El Derecho español y europeo, Derecho civil a 200 años del Código de Napoleón, Ed. Porrúa - UNAM, México, 2005, pp. 671-692. 
41. Sin embargo, como se ha avanzado, pueden surgir casos difíciles. En relación con tales casos la «idea regulativa general» (= toda sucesión está más estrechamente vinculada con el país de la última nacionalidad del causante), puede fallar. Y puede fallar porque en ciertos casos, el país más estrechamente vinculado con una concreta sucesión internacional puede no ser el país de la nacionalidad del causante en el momento de su fallecimiento. En efecto, los casos difíciles aparecen cuando el punto de conexión no presenta un ligamen real entre el caso específico y un país concreto. Puede afirmarse que el punto de conexión pierde su «razón de ser» (= ya no proporciona «seguridad jurídica internacional» ni «previsibilidad de la Ley aplicable»). El punto de conexión se aparta de la ratio de la norma. Y se convierte en un punto de conexión «vacío de potencial localizador». Es, entonces, un punto de conexión que queda «privado de su justificación interna», como ha subrayado la doctrina (C. CAMPIGLIO ${ }^{96}$, M. Virgós SORIANO ${ }^{97}$ ).

42. En las sucesiones mortis causa en las que la nacionalidad del causante se ha convertido en un punto de conexión «vacío de potencial localizador», se aprecia que existe un «conjunto de circunstancias» que revelan un «contacto más fuerte» de la sucesión con otro país, distinto al país de la nacionalidad del causante. Por ello, el mismo causante y las demás partes implicadas en la sucesión (= herederos, terceros) prevén la aplicación de la Ley de «otro país» que no es la Ley nacional del causante (= Ley a la que conduce el art. $9.8 \mathrm{Cc}$.). En otros términos, el art. $9.8 \mathrm{Cc}$. puede, en ocasiones, apuntar en favor de una Ley que resulta imprevisible a los particulares implicados porque su aplicación depende de «hechos anecdóticos». Los particulares implicados, por ello, no pueden prever la aplicación de esa Ley indicada por el art. 9.8 Cc. Lo que suele ocurrir, realmente, es que, en ciertos supuestos sucesorios, el único vínculo de la sucesión con un país es, precisamente, el vínculo retenido como «punto de conexión» por el legislador

${ }^{96}$ C. CAmpiglio, «L'esperienza svizzera in tema di clausole d'eccezione: l'art. 14 del progetto di riforma del diritto internazionale privato», RDIPP, 1985, pp. 47-88, esp. p. 51: «in definitiva la regola ordinaria perde il proprio carattere vincolante solo qualora il risultato a cui condurrebbe la sua applicazione sia, nella fattispecie, in assoluta contraddizione con la 'ratio' della regola stessa e non rispetti in tal modo gli interessi in gioco» («la regla ordinaria pierde su propio carácter vinculante sólo cuando el resultado al que conduciría su aplicación estuviera, en el caso concreto, en absoluta contradicción con la ratio de la misma regla y no respete, por ello, los intereses en juego»).

${ }^{97}$ M. VIRGós SoRIANo, El comercio internacional en el nuevo Derecho español de la competencia desleal (un análisis del art. 4 de la Ley española de competencia desleal de 1991), Civitas, Estudios de Derecho Mercantil, Madrid, 1993, pp. 100-101: «la conexión no se ajusta a un determinado grupo de casos y la subsunción en la norma de DIPr. es formalmente posible pero contradice la propia 'ratio' que la justifica». En tal caso, «es posible hablar de una laguna legal, que consiste en la 'ausencia de restricción'. Si el juez aplicara la norma, en su decisión 'realizaría la forma' pero no el 'contenido' de la ley». 
en la norma de conflicto (= la nacionalidad del causante). Todas las demás circunstancias del caso vinculan al supuesto con otro país (= país realmente más vinculado con el supuesto internacional). Por ello, los particulares esperan ver aplicada la Ley de ese «otro país», y no la Ley nacional del causante.

43. Pues bien, en tales casos, el reenvío puede operar para «corregir», «reajustar» $\mathrm{y}$ «perfeccionar» la localización y hacer así aplicable la Ley del país más conectado con la sucesión, que es la Ley española. A tal efecto, se utiliza la norma de conflicto extranjera, que localiza la sucesión en España y ordena aplicar el Derecho sucesorio material español. La localización que lleva a cabo la norma de conflicto extranjera es más perfecta, más atinada, más exacta, que la localización que lleva a cabo el art. 9.8 Cc. Por ello es preferible.

44. Los datos que denotan una más estrecha localización del supuesto sucesorio con España que con el país de la nacionalidad del causante pueden ser de distinta naturaleza: contactos personales y territoriales. Ahora bien: debe resultar de manera muy clara y evidente la «más estrecha vinculación del supuesto con España». Y ello ocurrirá, sin duda, cuando el causante hubiera tenido su último domicilio o residencia habitual en España y cuando, además, todos los bienes inmuebles sucesorios estuvieran sitos en territorio español (A.-L. CALVO CARAVACA ${ }^{98}$ ). La mera existencia aislada de algún bien inmueble en España no parece ser un dato suficiente que denote mayor vinculación del supuesto con España, como bien señala la STS 15 noviembre 1996. Y la mera y aislada residencia habitual del sujeto en España tampoco parece reflejar una vinculación más estrecha con España. De tal

\footnotetext{
${ }^{98}$ A.-L. Calvo Caravaca, «Sucesión hereditaria», en J. D. GonZález Campos y otros,

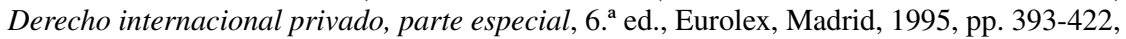
esp. p. 397: «En relación con este supuesto particular, una solución acorde con el principio que inspira el art. 9.8 Cc., podría ser la siguiente: excluir el reenvío de retorno del art. 12.2. ${ }^{\circ}$ Cc. cuando el causante fallezca domiciliado en el extranjero; acogiéndolo, en cambio, cuando tenga su domicilio en España. Así, en el primer caso, se salvaguarda la aplicación de la ley nacional, sin romper la unidad de la sucesión, aun cuando el inmueble sito en España quede regido por la ley nacional (extranjera) del causante. $Y$, en el segundo, el reenvío es utilizado, tras la referencia inicial a la ley nacional (extranjera) del causante, para afirmar el principio que inspira el art. $9.8 \mathrm{Cc}$. solución que puede justificarse, de otra parte, en atención a la más estrecha vinculación del causante con el ordenamiento español, en atención a su domicilio y al hecho de poseer inmuebles en España». Precedente muy claro en este sentido ( $=$ inmuebles en España + domicilio del causante en España, equivalen a «conexión más estrecha del caso sucesorio con España»), es el famoso y pionero Auto del Juzgado de distrito del Hospital de Barcelona de 3 agosto 1900. Como indica J. M. TRIAS DE BES, Derecho internacional privado, Madrid, Ed. Reus, 1934, Barcelona, pp. 32-34, el causante, escocés él, había vivido cincuenta años en Barcelona, hasta su fallecimiento, y todos sus bienes inmuebles, incluidas sus industrias, se hallaban en Cataluña.
} 
modo, dicho dato aislado no justifica un reenvío para «afinar» y «perfeccionar» la localización, en particular si existen inmuebles sitos fuera de España.

45. Para escapar de una «localización legal rígida» efectuada por puntos de conexión «vacíos de potencial localizador», el reenvío puede resultar muy útil. El reenvío se convierte, así, en un «elemento flexibilizador» del rígido sistema de conflicto de Leyes (P. M. PATOCChi, P. Rodríguez Mateos, C. H. Peterson, B. Audit, P. Lagarde, P. Rémy-Corlay, J. Carrascosa GonzÁ$\left.\mathrm{LEZ}^{99}\right)$.

46. El reenvío, en esta perspectiva, resulta interesante porque representa un «ejercicio de humildad» del legislador español. A la hora de precisar la Ley aplicable a la sucesión en los casos internacionales, los legisladores de los diferentes países del mundo adoptan ópticas distintas. Todos los legisladores «localizan» la sucesión en uno u otro país cuando señalan la «Ley aplicable» a la sucesión en sus normas de conflicto. El legislador inglés localiza la sucesión de los inmuebles en su país de situación, mientras que el legislador español localiza la sucesión de los inmuebles en el país de la nacionalidad del causante en el momento de su fallecimiento. Ambos «localizan». La «localización» de las situaciones privadas internacionales en un país, cuya Ley regirá el supuesto, es un arte, un ejercicio de prudencia jurídica. No es aritmética. La aritmética es igual en España, en Londres, en Sebastopol y en Vancouver. Pero la «localización» (= la determinación de la Ley aplicable a las situaciones privadas internacionales) no es una ciencia exacta. Ni es álgebra ni es geometría euclidiana. Por ello, cada legislador intenta «localizar» la sucesión del mejor modo posible y pone en movimiento, a tal efecto, no sólo un esprit de géometrie sino un esprit de finesse. Pues bien, como la localización no es una tabla de aritmética, sino un auténtico arte, es algo discutible y opinable. Puede existir una localización más correcta que otra, ya que

99 P. M. РАтосCHI, Règles de rattachement localisatrices et règles de rattachement a caractère substantiel (De quelques aspects récents de la diversification de la méthode conflictuelle en Europe), Ginebra, Georg, 1985, pp. 284-ss.; P. RODRíGUEZ MATEOS, «Una perspectiva funcional del método de atribución», REDI, 1988, vol. XL, 1988, pp. 79-126, esp. p. 100; C. H. PETERSON, «Private International Law at the End of the Twentieth Century: Progress or Regress?», AJCL, 46, 1998, pp. 197-227, esp. 219-221; B. AUDIT, «Le caractère fonctionnel de la règle de conflit (Sur la «crise» des conflits de lois)», RCADI, 1984, vol. 186, 1984, pp. 219-398, esp. pp. 326-342; P. LAGARDE, «Les principes du droit international privé hier, aujourd'hui et demain», en Principios, objetivos y métodos del DIPr. Balance y perspectivas de una década. IV jornadas DIPr., Madrid, CESSJ R.Carande, 1995, pp. 17-33, p. 24; P. RÉmY-CORLAY, «Mise en oeuvre et régime procédural de la clause d'exception dans les conflits de lois», RCDIP, 2003-I, pp. 37-76, esp. p. 40; J. CARRASCOSA GoNZÁLEZ, Desarrollo judicial y Derecho internacional privado, Comares, Granada, 2004, pp. 184-186. 
existen distintos modos de llevar a cabo la localización (= a través de puntos de conexión diferentes). Y aquí se encuentra la clave: el legislador español puede tomar conciencia de que «su» localización de la sucesión (= en las manos de la Ley nacional del causante en el momento de su fallecimiento, art. $9.8 \mathrm{Cc}$.) es «menos exacta» que la localización que realiza un legislador extranjero (= el legislador del país de la nacionalidad del causante). Y tomada conciencia del asunto, el legislador español utiliza el reenvío de primer grado y admite que la localización que realiza el legislador extranjero es «mejor» que la localización que él mismo realiza, y admite la localización que realiza la norma de conflicto extranjera.

47. Un ejemplo ilustrará este «diálogo entre localizaciones». Tómese el caso de un causante inglés cuya sucesión litigiosa se abre en España, y cuyos bienes se hallan, en tu totalidad, sitos en España, causante que tenía su residencia habitual en España desde hacía veinte años, que estaba casado con española, y que no tenía intereses económicos en Inglaterra. El legislador español localiza esta sucesión en Inglaterra, cuya Ley debe regir dicha sucesión (= art. 9.8 Cc.: Ley nacional del causante en el momento de su fallecimiento). Sin embargo, el legislador inglés localiza esta misma sucesión en España, cuya Ley debe regir, según las normas de conflicto inglesas (= normas de conflicto consuetudinarias de creación jurisprudencial), dicha sucesión (= la sucesión de los muebles se rige por el Derecho del país del último domicile del causante y la sucesión de los inmuebles se localiza en el país de situación de tales bienes). Parece evidente que, en este caso, la «localización inglesa» en favor de la Ley material sucesoria española es «más correcta»y «más precisa» que la «localización española» en favor de la Ley material sucesoria inglesa. La sucesión está más «estrechamente vinculada» con España que con Inglaterra. Precisamente por ello, todos los implicados, incluido el mismo causante, esperan ver aplicada la Ley inglesa y no la Ley española. El legislador inglés «localiza mejor» que el legislador español. El legislador español es consciente de que sus normas de conflicto son, como todas las normas de conflicto de todos los países del mundo, verdaderas «propuestas de localización» (= tentativas de señalar el país más estrechamente vinculado con la situación fáctica), más que dogmáticas localizaciones inmutables, como opina algún autor ${ }^{100}$. Por ello, el legislador español es consciente de que sus normas de conflicto son, en todo caso, normas perfectibles y mejorables en todo caso. Y por ello, acepta que la «localización inglesa» de la sucesión puede ser más exacta que la «localización española» de la sucesión contenida en el art. $9.8 \mathrm{Cc}$., y a través del reenvío de primer grado, admite la aplicación de la Ley material sucesoria española.

${ }^{100}$ Ad ex. S. SÁNCHEZ LoRENZO, «Ámbito del reenvío en la determinación de la Ley aplicable a la sucesión hereditaria», Anuario Español de Derecho internacional privado, 2004, pp. 1144-1146. 
48. Entendido como un mecanismo para «perfeccionar la localización», el reenvío de primer grado opera como una escotilla que facilita el «diálogo entre ordenamientos» (= en muy feliz expresión de A. QuiÑONES ESCÁ$\mathrm{MEZ}^{101}$ ). Dicho diálogo arranca de un dato fundamental. La localización es un arte difícil: es conveniente escuchar y tener en cuenta «cómo se practica la localización» en otros ordenamientos jurídicos para aceptar, en su caso, la localización más correcta llevada a cabo por las normas de conflicto extranjeras. Un artista aprende de otros artistas. Naturalmente, el ajuste de la localización exigiría aceptar no sólo el reenvío de primer grado, sino también el reenvío de segundo grado, como se admite en otros países (= es el caso de Francia $^{102}$ ). El legislador español no llega a tanto, y se limita a aceptar el reenvío de primer grado y prohíbe el reenvío de segundo grado.

49. El «reajuste», la «afinación» y el «perfeccionamiento» de la localización de la sucesión recogida en el art. $9.8 \mathrm{Cc}$. garantiza las expectativas de los sujetos y la seguridad jurídica. En efecto, los particulares implicados en la sucesión esperan ver aplicado el Derecho español, que es el Derecho del país más vinculado a la sucesión. España es, en dicho caso, el país donde la sucesión produce sus «efectos principales». La aplicación de la Ley española es previsible para todos los implicados en el supuesto sucesorio. Y ello por varios motivos: $1^{\circ}$ ) los datos concretos del caso lo conectan con España de modo evidente y no con el Estado del que era nacional el causante, visto que tal vínculo puede haber quedado reducido a un mero «contacto formal» (= la mera nacionalidad formalmente ostentada por el causante en el momento de su fallecimiento); 2. ${ }^{\circ}$ ) las Leyes sucesorias extranjeras suelen declarar su propia «no aplicación» a casos en los que el causante poseía bienes inmue-

${ }^{101}$ Si bien, referida a la operatividad del «orden público internacional». Vid. A. QuiÑoNES ESCÁMEZ, Derecho e inmigración: el repudio islámico en Europa, Barcelona, 2000; ID., «Limitaciones infundadas al jus nubendi: el repudio revocable. En torno a la RDGRN 14 junio 2001 sobre autorización de matrimonio civil», Homenaje R. Arroyo, Madrid, 2003, pp. 297-304.

102 Un famoso caso de reenvío de segundo es el conocido como caso Patiño, fallado por el Tribunal Civil del Sena por Sentencia de 28 junio 1950. Con ocasión de una demanda de divorcio presentada en Francia por A. Patiño, nacional boliviano, el juez francés aplicó el art. 3.3 del Código civil francés, norma de conflicto que remitía la regulación del caso a la ley boliviana. Ésta, a su vez -concretamente el art. 24 de la ley de 15 abril 1932-, establecía que la disolución del matrimonio celebrado en el extranjero puede llevarse a cabo si la ley del país en que ha sido celebrado el matrimonio admite la disolución del vínculo matrimonial. Como el matrimonio se había celebrado en España, y según la ley vigente en España en dicho momento no se permitía el divorcio, el juez francés desestimó la demanda de divorcio en virtud del mecanismo del reenvio de segundo grado (RCDIP, 1964, vol. LIII, pp. 532-543, con nota de P. LAGARDE). La doctrina francesa, no obstante, suele convenir que en el caso citado, el reenvío de segundo grado se reconoce en circunstancias equívocas, ya que la ley del tercer Estado no fue aplicada, sino simplemente tenida en consideración por el tribunal francés. Vid. P. MAYER, Droit international privé, 1994, pp. 151-152. 
bles en España y/o poseía último domicilio en España. Así lo indica la Inheritance (Provision for Family and Dependants) Act inglesa de 1975: el legislador inglés ha estipulado que dicha Ley no debe aplicarse a sujetos cuyo domicile está fuera de Inglaterra ${ }^{103}$. Aplicar dicha Ley contra lo establecido por el legislador inglés «sorprendería» a los sujetos implicados en la sucesión. Y naturalmente, comportaría una «desnaturalización de la Ley inglesa», que se haría aplicable a casos expresamente excluidos por el legislador inglés del ámbito de aplicación de la Ley inglesa relativa a las sucesiones. Es el clásico argumento de R. QUADRI en favor del unilateralismo ${ }^{104}$.

50. El TS ha aceptado expresamente este índice positivo de reenvío (STS 23 septiembre 2002 [se aplicó Derecho material español a la sucesión testada de un inglés porque el supuesto estaba más estrechamente vinculado con España que con Inglaterra ${ }^{105}$ ]) y se ha referido a él también en la STS 15 noviembre 1996 (el TS rechaza el reenvío porque el supuesto está más estrechamente vinculado con Maryland State del que era ciudadano el causante norteamericano, que con España $\left.{ }^{106}\right)$.

${ }^{103}$ Muy bien explicado por I. Ayala CARdiñanos, «Nota a la SAP Málaga 18 diciembre 1996», en REDI, 1998-II vol. L, pp. 244-248 y por J. PÉREZ MILLA, «De nuevo el TS matiza el ámbito del reenvío de retorno en materia sucesoria (nota a la STS 21 mayo 1999)», AEDIPR, 2001, pp. 1094-1097.

${ }^{104}$ R. QUADRI, Lezioni di diritto internazionale privato, 5. a ed., Nápoles, Liguori, 1969, pp. 183-203.

${ }^{105}$ En el FJ primero de la STS 23 septiembre 2002, el TS subraya, uno tras otro, los elementos fácticos del caso que ponen de relieve que el supuesto sucesorio concreto aparece más estrechamente conectado con España que con Inglaterra, a pesar de ser inglesa la ciudadanía del causante: «Son hechos básicos para la resolución de este recurso los que siguen. El ciudadano británico D. José Pedro contrajo matrimonio en 1.968 , con la española $D{ }^{a}$ Frida, del que nacieron dos hijos. Desde 1985 convivió con la española $D .{ }^{a}$ Eugenia, aunque no formalizó la separación o divorcio de su matrimonio. De esa convivencia nació Victoria el 24 de enero de 1986, reconocida por el Sr. José Pedro. Dicho Sr. residió en España en los ocho anteriores a su muerte, teniendo su domicilio en Nerja (Málaga), que ocurrió en 29 de enero de 1992. Era propietario de diversos bienes inmuebles adquiridos en España». Es decir: ciudadano británico pero casado con española, padre de hija, nacida en España, habida con otra ciudadana española y propietario de inmuebles sitos todos ellos en territorio español.

${ }^{106}$ STS 15 noviembre 1996: «El reenvío, por último, debe entenderse como un instrumento de armonización de sistemas jurídicos de los Estados, como un instrumento respetuoso con los principios que los inspiran (...) [y] en nada armonizaría la coexistencia de los derechos respectivos, la aplicación por esta Sala del derecho español a la sucesión del causante de este litigio, que no ha conservado con España ni la residencia ni el domicilio». A sensu contrario, el TS afirma que el reenvío hubiera estado perfectamente justificado en este supuesto si el causante (= que era nacional norteamericano y ciudadano del State de Maryland), hubiera tenido su domicilio «en España». Lo que no sucedía in casu. 


\section{Aspectos irrelevantes para aceptar o negar el reenvío}

A) LA «ARMONÍA INTERNACIONAL DE SOLUCIONES» EN SENTIDO CONFLICTUAL

51. Algunos autores han defendido la idea de que el reenvío podría ser aconsejable si, a través de dicho mecanismo, se logra que la Ley aplicable a la sucesión sea la misma, ya conozca del caso un tribunal español o un tribunal del Estado a cuya Ley remite el art. 9.8 Cc. Es el «reenvío-coordinación» $\left(\mathrm{H}\right.$. BATIFFOL $\left.{ }^{107}\right)$, un mecanismo que potencia la seguridad jurídica internacional y favorece el reconocimiento de sentencias españolas en el extranjero.

52. Sin embargo, este índice positivo de reenvío es criticable. Por varios motivos.

Primero: aceptar el reenvío porque conduce a una armonía internacional de soluciones es más complicado de lo que parece. En efecto, como antes se ha indicado, para que se produzca una verdadera «armonía internacional de soluciones conflictuales» (= distintos tribunales estatales potencialmente competentes pero misma Ley rectora de la sucesión), es preciso que el Derecho extranjero (= Ley nacional del causante como Lex Causae) no admita el reenvío, ya que en tal supuesto, la solución que darían al caso los tribunales extranjeros sería contraria, nuevamente, a la solución que brindarían los tribunales españoles. El tribunal español debería, por tanto, analizar en primer término, la norma de conflicto extranjera y en segundo término la postura de ese DIPr. extranjero sobre el reenvío.

Segundo: el legislador español no emplea el reenvío en el art. 12.2 Cc. como instrumento al solo servicio de la «armonía internacional de soluciones». Si así fuera, el legislador aceptaría el reenvío de segundo grado. Y es sabido que dicha modalidad de reenvío, sin embargo, está radicalmente prohibida por el art. 12.2 Cc. (E. Rodríguez Pineau, P. JimÉnez Blanco ${ }^{108}$ ). Como consecuencia de ello, el TS nada ha indicado sobre este índice positivo de reenvío basado en una armonía internacional de soluciones «conflictuales» en el ámbito de la sucesión mortis causa. Para el TS, sólo es relevante la armonía internacional de soluciones pero «de tipo material»: la Ley material nacional del causante es similar a la Ley material española y en ese caso sí es aconsejable aceptar el reenvío. Por tanto, este tercer índice positi-

${ }^{107}$ H. Batiffol / P. Lagarde, Droit international privé, t. I, 8. a ed., LGDJ, París, 1993, pp. 491-503.

108 P. JiMÉNEZ Blanco, «Nota a STS 23 septiembre 2002», REDI, 2003, pp. 4242442435; E. RodRÍGUEZ PINEAU, «Nota a STS 15 noviembre 1996», REDI, 1997, pp. 264-268; E. RodríGuez PINEAU, «Nota a STS 21 mayo 1999», REDI, 1999, pp. 7576-7760; J. PÉREZ MiLla, «De nuevo el TS matiza el ámbito del reenvío de retorno en materia sucesoria (nota a la STS 21 mayo 1999)», AEDIPR, 2001, pp. 1094-1097. 
vo de reenvío es, hasta hoy, una mera propuesta doctrinal que, además, parece poco recomendable.

\section{B) El CONTENIDO MATERIAL DE LAS LEYES EN CONFLICTO}

53. Algunos autores indican también que el reenvío podría ser aconsejable, en general, cuando conduce a resultados materiales que optimizan los valores constitucionales. Ejemplos: el reenvío debería aceptarse si a través de él se provoca la aplicación de la Ley material española, Ley que permite la determinación de la filiación del hijo (favor filii), o la disolución del matrimonio por divorcio (favor divortii). Este índice positivo de reenvío («reenvío in favorem») ha sido acogido por otros sistemas extranjeros de DIPr. (art. 13.3 LDIPr. Italia 1995 en materia de establecimiento de la filiación).

54. En este sentido, y ya en materia sucesoria, algunos autores han subrayado que el reenvío debe emplearse para potenciar una «localización centrada en valores materiales» en la regulación de la sucesión (M. GuZMÁN ZAPATER $^{109}$ ). De este modo, debe aceptarse o negarse el reenvío para lograr la aplicación a la sucesión litigiosa, de la Ley estatal cuyo «contenido material» sea más «justo». Por ejemplo, para lograr que la hija no matrimonial del causante alcance sus ansiados y presuntamente merecidos derechos sucesorios por vía de la generosa «legítima española» (I. AYALA CARDIÑANOS ${ }^{110}$ ).

55. Sin embargo, esta posición es más un coup de théâtre que un argumento sólido. No es compartible. En efecto, el contenido sustancial de una Ley sucesoria extranjera no es motivo para aceptar o negar el reenvío en favor de la Ley española. Por varias razones: $1 .^{\circ}$ ) Las Leyes sucesorias de los distintos países del mundo siguen principios muy diferentes e incluso opuestos. Todas las Leyes sucesorias del mundo representan un modo «justo» de regular el fenómeno sucesorio, salvo contradicción, naturalmente, con el orden público internacional español (art. $12.3 \mathrm{Cc}$.). ¿Es «justo» el sistema sucesorio inglés o el navarro, en los que las legítimas no existen? ¿O es más «justo» el sistema italiano en el que tales legítimas sí que existen pero son diferentes en su cuantía y características, a las legítimas «españolas»? ¿Es justo el sistema sucesorio inglés en el que se considera que existe y es válido el testamento ológrafo aunque haya sido escrito no de puño y letra del testador siempre que venga firmado por éste? ¿O es más justo el sistema sucesorio español, en cuyo contexto el art. 788.II Cc. exige que «para que sea válido este testamento [ológrafo] deberá estar escrito todo él y firmado por

${ }^{109}$ M. GuZMÁn Zapater, «Reenvío», en E. PÉrez Vera (Dir.), Derecho internacional privado, 2. ${ }^{\text {a }}$ ed. rev., Madrid, UNED, 2000, p. 153.

110 I. Ayala CARDIÑANOS, «Nota a la SAP Málaga 18 diciembre 1996», en REDI, 1998II vol. L, pp. 244-248. 
el testador (...)? Este debate, además de inútil, es improcedente. Ni el art. 9.8 Cc. entra en este debate ni el TS ha utilizado jamás el reenvío para descartar un Derecho sucesorio material, español o extranjero, porque se estimara más o menos «justo». Si así fuera, el DIPr. español operaría con un notable «menosprecio» al Derecho extranjero o con un injustificado vasallaje al Derecho material sucesorio extranjero (= que se aplicaría por ser «más justo» que el Derecho material sucesorio español, lo que resulta absurdo). $2^{\circ}$ ) Aceptar el reenvío para evitar la aplicación de una Ley extranjera de «contenido inaceptable» supone confundir reenvío con orden público internacional, lo que es improcedente e innecesario (P. JIMÉNEZ BLANCO ${ }^{111}$ ). Si la Ley extranjera presenta un contenido «inaceptable» (= contrario a principios básicos del ordenamiento jurídico español), debe entonces utilizarse el «orden público internacional», que para eso está. De ese modo se excluye la aplicación de la Ley extranjera y se provoca la aplicación de la Ley sustantiva española (Lex Fori). 3. ${ }^{\circ}$ ) Negar el reenvío porque el Derecho sucesorio material extranjero es «diferente» o incluso «opuesto» al Derecho sucesorio material español, pero más justos que éste, supone un «juicio negativo de injusticia» sobre el Derecho sucesorio español (= existirían Derechos sucesorios «más justos» que el Derecho sucesorio español), lo que no es sostenible.

\section{C) LA VOLUNTAD DEL TESTADOR}

56. Algunos autores han subrayado que el reenvío no puede emplearse en el caso de sucesión testada si el testamento es válido con arreglo a la Ley nacional del causante, pero nulo con arreglo a la Ley española. Argumento: debe respetarse la voluntad del testador (M. Virgós SORIANO, E. RODRÍGUEZ Pineau, A. Pérez Voituriez, I. Ayala Cardiñanos ${ }^{112}$ ).

57. Ahora bien, esta tesis es rechazable. El hecho de que la sucesión sea testada o intestada no debe influir para nada en la aceptación o rechazo del reenvío. Por varias razones: $\left.1^{\circ}{ }^{\circ}\right) \mathrm{El}$ art. $9.8 \mathrm{Cc}$. no acoge el punto de conexión de la «autonomía de la voluntad» del causante. Por tanto, el causante no

\footnotetext{
111 P. JimÉNEZ BlanCo, «Nota a STS 23 septiembre 2002», REDI, 2003, pp. 4242442435.

${ }^{112}$ M. ViRgós SORIANO, «Derecho de sucesiones y reenvío: la respuesta del sistema español», Anales de las Academia Matritense del Notariado, n. 42, 2004, pp. 181-210; M. VIRGós Soriano / E. RodríGUEZ PINEAU, «Succession Law and Renvoi: the Spanish Solution», Festschrift Erik Jayme, vol. I, Munich, 2004, pp. 977-992; E. RodRíGUEZ PINEAU, «Nota a STS 15 noviembre 1996», REDI, 1997, pp. 264-268; E. RodRÍGUEZ PINEAU, «Nota a STS 21 mayo 1999», REDI, 1999, pp. 7576-7760; A. PÉREZ VoITURIEZ, «El reenvío en el Derecho internacional privado español: una interpretación actualizada», Revista Jurídica del Notariado, núm.13, enero-marzo 1995, pp. 257-337. Con más matices, I. Ayala CARdiÑanos, «Nota a la SAP Málaga 18 diciembre 1996», en REDI, 1998-II vol. L, pp. 244-248.
} 
puede elegir la Ley que rige su sucesión. La existencia de testamento no significa que haya que respetar la «Ley elegida por el causante», porque, simplemente, no hay ninguna Ley elegida por el causante, ya que el art. 9.8 Cc. no concede tal facultad al de cujus $^{113}$. El TS, expresamente, ha indicado que el reenvío es perfectamente posible en el caso de sucesión testada y de testamento válido con arreglo a la Ley nacional del causante, pero inválido con arreglo a la Ley española (STS 23 septiembre 2002, François Marie James W.). 2. ${ }^{\circ}$ ) En ciertos casos, el causante otorga testamento con arreglo a su Ley material nacional, pero, en el mismo testamento, el causante indica que otorga su testamento «sin perjuicio de los derechos legitimarios que pudieran corresponder a sus descendientes», como se aprecia en el caso fallado por la STS 23 septiembre 2002, François Marie James W. Por tanto, no está tan claro que la voluntad del causante fuera testar íntegramente con arreglo a su Ley nacional $^{114} .3^{\circ}$ ) En otros casos, el causante otorga testamento pero no especifica que lo hace bajo una concreta Ley estatal. Ello revela que en muchos casos no existe, realmente, una voluntad del causante de testar con arreglo, exclusivamente, a su Ley material nacional (P. JiMÉNEZ BLANCO, E. RoDRÍGUEZ PINEAU ${ }^{115}$ ). Y por tanto, no se puede respetar una voluntad que no existe.

D) EL TIPO DE CONEXIÓN EMPLEADO POR LA NORMA DE CONFLICTO EXTRANJERA

58. Algunos autores han subrayado que el art. $9.8 \mathrm{Cc}$. aparece construido sobre una «conexión personal»: la nacionalidad del causante (M. VIRGós

${ }^{113}$ Cuando la norma de conflicto otorga a los particulares implicados la posibilidad de elegir o seleccionar la «Ley aplicable» a la situación privada internacional, es obvio que las partes elegirán o seleccionarán la Ley material que estimen pertinente. Aceptar un reenvío efectuado por la ley elegida vulneraría la directriz que sustenta la norma de conflicto, esto es, la misma autonomía de la voluntad conflictual de las partes. Así lo indica la doctrina. Ad ex.: M. Virgós Soriano en J. D. GonZÁlez CAmpos y otros, Derecho internacional privado, parte especial, 6. ${ }^{a}$ ed., 1995, p. 152; A. MARín LÓPEZ, Derecho internacional privado I, 1994, pp. 255-256; G. A. L. Droz, «Les régimes matrimoniaux en droit international privé comparé», RCADI, 1974, vol. 143, pp. 33-34; H. BATIFFOL / P. LAGARDE, Droit international privé I, 1993, p. 509. El reenvío en materia de obligaciones contractuales (= materia en la que tradicionalmente los contratantes disponen de la facultad de elegir la Ley aplicable al contrato) está hoy prohibido expresamente por el art. 15 del Convenio sobre la Ley aplicable a las obligaciones contractuales, hecho en Roma el 19 junio 1980 (versión consolidada en DOUE C 334 de 30 diciembre 2005; BOE núm. 171 de 19 julio 1993, corr. errores BOE núm. 189 de 9 agosto 1993).

${ }^{114}$ I. Ayala CARDiÑANOS, «Nota a la SAP Málaga 18 diciembre 1996», en REDI, 1998II vol. L, pp. 244-248; P. JiMÉNEZ BLANCO, «Nota a STS 23 septiembre 2002», REDI, 2003, pp. 42424-42435.

115 P. JiMÉNEZ BlAnCO, «Nota a STS 23 septiembre 2002», REDI, 2003, pp. 4242442435; E. RodríGUEZ PINEAU, «Nota a STS 15 noviembre 1996», REDI, 1997, pp. 264-268; E. RodríGUEZ PINEAU, «Nota a STS 21 mayo 1999», REDI, 1999, pp. 7576-7760. 
Soriano, E. Rodríguez Pineau $\left.{ }^{116}\right)$. Además, se dice, la nacionalidad del causante es una «conexión cultural». La sucesión se rige no por la Ley del país en cuya sociedad se halla integrado fácticamente el causante, sino por la Ley que corresponde al «ambiente cultural de origen» del causante. Por tanto, sólo será posible el reenvío cuando la norma de conflicto extranjera utilice otra conexión que sea también una «conexión cultural», como es el «domicile inglés». Pero habrá de negarse cuando la norma de conflicto extranjera utilice una «conexión social», como la residencia habitual o domicilio del causante, o una «conexión territorial», como el lugar de situación de los bienes inmuebles. La justificación de esta tesis radica en que sólo de ese modo se protegen los intereses del causante y de los derechos de los causahabientes.

59. Sin embargo, esta tesis es rechazable. El argumento clave radica en la siguiente afirmación: la norma de conflicto extranjera puede localizar el caso sucesorio de un modo más certero que la norma de conflicto española, con independencia de que las conexiones retenidas por el legislador extranjero sean de carácter «social»o «territorial». Y en este caso, todos los implicados en la sucesión se verán beneficiados por un reenvío de retorno (= la aplicación de la Ley del país más estrechamente vinculado con la sucesión comporta, para todos los particulares implicados, costes menores de información y prueba de la Ley extranjera y costes menores de adaptación a un concreto Derecho estatal). El beneficio para todos los implicados en la sucesión puede venir de la mano de una conexión «social» o de una conexión «cultural» o incluso «económica». Es irrelevante; por ello no es de extrañar que el TS no haya acogido jamás esta limitación del reenvío. Para el TS se puede aceptar el reenvío sea cual sea el «carácter de la conexión» utilizado por el legislador extranjero (STS 23 septiembre 2002, François Marie James W.).

\section{Aplicación de las normas de conflicto extranjeras en materia de sucesión mortis causa}

60. En relación con el reenvío que realizan las normas de conflicto extranjeras en favor de la Ley sustantiva española en materia sucesoria, debe tenerse presente lo siguiente.

61. Primero. La norma de conflicto extranjera en materia sucesoria y su punto de conexión debe interpretarse y aplicarse según las reglas de dicho

\footnotetext{
${ }^{116}$ M. VIRGÓs SORIANO, «Derecho de sucesiones y reenvío: la respuesta del sistema español», Anales de las Academia Matritense del Notariado, n. 42, 2004, pp. 181-210; M. VIRGós Soriano / E. Rodríguez PINEAU, «Succession Law and Renvoi: the Spanish Solution», Festschrift Erik Jayme, vol. I, Munich, 2004, pp. 977-992.
} 
ordenamiento extranjero (E. JAYMe, P. MAYER, H. BATIFfol / P. LAGARde, P. Francescakis, G. KegEL, Y. LeQuetTe ${ }^{117}$ ).

Ejemplo 1: la sucesión mobiliaria de un inglés con domicilio en España se rige por el Derecho inglés (art. $9.8 \mathrm{Cc}$.), lo que conduce al Derecho inglés. El Derecho inglés reenvía al Derecho español porque en DIPr. inglés, la sucesión mobiliaria se regula por la Ley del último domicilio del causante. Pues bien: el concepto de «domicilio» que emplea el juez español para aceptar el reenvío es el concepto de domicilio del Derecho inglés, que no coincide con el concepto «español» de domicilio, sino que es mucho más parecido al concepto español de «vecindad civil» (J. DERRUPÉ / J. P. LABORDE, M. VIRGÓS SORIANO $\left.{ }^{118}\right)$. El concepto inglés de domicile es un «concepto poético»: el lugar al que la persona, cuando está lejos de él, quisiera volver (B. BAREL / ST. ARMELlini ${ }^{119}$ ). Los anglosajones son así. Retener un «concepto español» de domicilio en la aplicación de la norma de conflicto inglesa, como hacen ciertos autores (J. A. TOMÁs ORTIZ DE LA TORRE ${ }^{120}$ ), es incorrecto, ya que «desnaturaliza» la localización llevada a cabo por el legislador inglés. Error que además resulta más profundo si el concepto «español» de domicilio que se emplea es un concepto «fiscal» y no «civil», como el haber residido en España más de 183 días, por ejemplo.

Ejemplo 2: la sucesión mobiliaria de un francés se rige por la Ley de su domicilio, «de derecho», que no tiene por qué coincidir con su domicilio «de hecho». El tribunal español que tuviera que aplicar esta norma de conflicto francesa debe apreciar el concepto «francés» de domicilio. Lo que no es sencillo y ha dado lugar a problemas complejos. Un caso célebre fue el relativo a la sucesión de la espada del Duque de Reichstadt que Napoléon llevó en la batalla de Austerlitz: el duque poseía su «domicilio de hecho» en Francia, pero tenía su «domicilio de Derecho» en Austria y la espada en cuestión se hallaba en Francia (A. LyON-CAEN, J. P. NiBOYET ${ }^{121}$ ). Otro ejemplo: la Sent.

117 P. MAYER, Droit international privé, 1994, p. 156, con apoyos en la jurisprudencia francesa; H. BATIFFOL / P. LAGARDE, Droit international privé, 1993, pp. 504-506; G. KeGEL, Die Grenze..., 1962, pp. 33-34; Y. LeQueTte, «Le renvoi de...», 1990, pp. 249-262; Рн. FRANCESCAKIS, La théorie du renvoi..., 1958, pp. 82-85.

118 J. Derrupé / J. P. Laborde, Droit international privé, Dalloz, 15. a ed., 2005, pp. 7983; M. VIRGÓs SORIANO, «Derecho de sucesiones y reenvío: la respuesta del sistema español», Anales de las Academia Matritense del Notariado, n. 42, 2004, pp. 181-210; M. VIRGÓs Soriano / E. Rodríguez Pineau, «Succession Law and Renvoi: the Spanish Solution», Festschrift Erik Jayme, vol. I, Munich, 2004, pp. 977-992.

${ }^{119}$ B. Barel / St. ARMellini, Diritto internazionale privato, 2006, p. 74.

120 J. A. TOMÁs ORTIZ DE LA TORRE, «¿Anular por reenvío la voluntad del testador?», $L a$ Ley, núm. 5845, 9 septiembre 2003; ID., «El reenvío ante el Tribunal Supremo: historia y reapertura de la vieja polémica en el Derecho internacional privado español», Actualidad Civil, núm. 40, semana 1-7 noviembre 1999, pp. 1261-1295.

121 J. P. NiBOyet, Principios de Derecho internacional privado (traducción española por

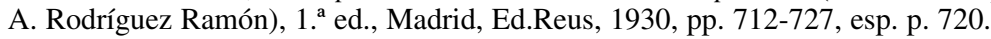


Cour Cass. Francia 7 diciembre 2005 se enfrenta al supuesto de un causante francés que habitó toda su vida en Costa de Marfil pero que regresó a Francia en 1991 para hacerse cuidar sus problemas de salud y que falleció en 1994. Su domicilio, en el «sentido francés» del término, es incierto.

62. Segundo. En relación con el DIPr. inglés, debe tenerse presente que el art. 12.2 Cc. no persigue como objetivo lograr la «armonización conflictual de soluciones». Eso importa poco al legislador español. Por ello, el tribunal español no debe operar como lo haría un juez ingles. En consecuencia, no debe tener en cuenta el famoso mecanismo del «doble reenvío» que activaría un juez inglés si conociera de primera mano del supuesto sucesorio, con el objetivo de fallar de manera idéntica a como lo hace un juez inglés ${ }^{122}$.

${ }^{122} \mathrm{El}$ «doble reenvío» (Foreign Court Theory / Total Renvoi / Double renvoi) es una construcción exclusiva del DIPr. anglosajón (muy bien explicada por J. D. FALCONBRIDGE, «Le renvoi et la loi du domicile», RCDIP, 1948, pp. 45-71). Según esta teoría, el juez anglosajón debe aplicar el Derecho material que se supone que aplicarían los tribunales del país cuya ley es declarada aplicable por su regla de conflicto. Es decir, el juez anglosajón debe decidir exactamente igual a como lo haría un juez del país cuya Ley es declarada aplicable por la norma de conflicto anglosajona. En realidad, el doble reenvío anglosajón es un remedio a la amplitud de los criterios de competencia judicial internacional de los jueces anglosajones. Ejemplo: se litiga en Inglaterra sobre la sucesión de un inglés con bienes inmuebles en España. Pues bien: el juez inglés debe fallar como lo haría un tribunal español que conoce de la sucesión de un inglés con bienes inmuebles en España. Por tanto, en primer lugar, aplicará la norma de conflicto inglesa, que le remite al Derecho español porque los inmuebles están en España; en segundo lugar, aplicará, como lo haría un juez español, el art. 9.8 Cc., que le lleva al Derecho inglés; en tercer lugar, aplicará la norma de conflicto inglesa sobre sucesiones (art. 12.2 Cc.); y en cuarto lugar, visto que la norma de conflicto inglesa remite al Derecho español (Ley de situación de los inmuebles), el juez inglés aplicará el Derecho material español. El doble reenvío plantea problemas, porque, en la práctica, los jueces ingleses no andan muy finos, ya que todavía creen (?) que el reenvío no se admite en DIPr. español, lo cual, evidentemente, no es cierto (J. PÉREZ MiLla, «De nuevo el TS matiza el ámbito del reenvío de retorno en materia sucesoria (nota a la STS 21 mayo 1999)», AEDIPR, 2001, pp. 1094-1097). Son casos de «doble reenvío»: Collier vs. Rivaz (1841), In re Annesley (1926), In re Ross (1930), In Re Askew (1930), In re O'Keefe (1944), In re Duke of Wellington (1947), In re C. W. Addams (31 julio 1985), fallado por la High Court Of Justice (Chancery Division). En torno al «doble reenvío», vid. ad ex. A. MARÍn LóPEZ, Derecho internacional privado I, 1994, pp. 264-265; J. L. IRIARTE ÁNGEL, «Doble reenvío y unidad de tratamiento de las sucesiones», $R G D$, 1989, pp. 3561-3582; J. SUAY MiLIO, «Una solución jurisprudencial inglesa: el doble reenvío», REDI, 1956, vol. IX, pp. 87-122; J. DE Yanguas Messía, Derecho internacional privado, 1970, pp. 334-336; F. Rigaux, Derecho internacional privado, 1985, pp. 309-310; H. BATIFFOL / P. LAGARDE, Droit international Privé, 1993, pp. 503-504; J. A. CARRILlo, Derecho internacional privado, 3. ${ }^{\text {a }}$ ed., Madrid, 1983, p. 212. La institución del doble reenvío se encuentra muy bien ilustrada en la SAP Badajoz 11 julio 1995 [sucesión de causante inglés con domicilio en España y bienes inmuebles en España], lo que se explica, sin duda, por la intervención en la redacción de dicha decisión, de la Profa. Dña. P. Blanco-Morales Limones, catedrática de DIPr. en la Universidad de Extramadura y posterior Directora General de los Registros y del Notariado. 
El objetivo del art. 12.2 Cc., es «tener en cuenta» el modo en que el la norma de conflicto extranjera «localiza» la situación, para aprovechar dicho modus operandi y mejorar, de tal modo, la localización del supuesto sucesorio que realiza el art. $9.8 \mathrm{Cc}$. Por todo ello, cuando la Lex Successionis es la Ley inglesa, el «doble reenvío» es un mecanismo irrelevante, ya que lo único que interesa es el punto de conexión de la norma de conflicto inglesa en relación con las sucesiones mortis causa.

63. Tercero. En la práctica española, surgen innumerables problemas en relación con causantes ingleses porque no se acredita en qué país tenía el causante su domicile. El reenvío se produce, ya que el causante está domiciliado en España a tenor del concepto inglés de domicilio (Domicile as Permanent Home). Sin embargo, el testamento que el sujeto inglés otorga ante Notario español y en cuya virtud dispone de todos sus bienes o de los bienes sitos en España se inscribe en el RAUV español sin que ninguna autoridad española compruebe si el testador tenía o no su Domicile en Españ (D. SEARL ${ }^{123}$ ). Este resultado antijurídico debe evitarse por el Notario español autorizante, que debe acreditar cuál es el país de domicilio del causante inglés y decidir si se produce o no reenvío en favor del Derecho sustantivo español. En este caso, debe advertir al testador que el testamento se rige por el Derecho sustantivo español y que, en consecuencia, no puede disponer libremente de todos sus bienes y debe respetar, en su caso, los derechos de los legitimarios recogidos en el Derecho español aplicable.

64. Cuarto. La norma de conflicto extranjera es una norma jurídica extranjera. Por tanto, debe ser probada por la parte que reclama su aplicación (art. 281.2 LEC). Para apreciar el reenvío es preciso que quede acredita en el proceso que se sigue en España la norma de conflicto extranjera. Y si ello no ocurre, el reenvío no se puede apreciar (SAP Las Palmas 28 junio 2004 [falta de prueba del Derecho inglés], RDGRN 5 febrero 2005 [falta de prueba del Derecho norteamericano]). Ahora bien: la norma de conflicto extranjera sólo debe probarse si el tribunal ignora su contenido. Por tanto, si el tribunal ya conoce de modo exacto la norma de conflicto extranjera, puede y debe aplicarla sin que sea precisa su prueba por la parte interesada. Por otra parte, en el lado opuesto, ciertas sentencias no se han pronunciado sobre el reenvío a pesar de que el Derecho extranjero fue probado (SAP Alicante 27 febrero 2004, SAP Baleares 31 marzo 2004).

65. Quinto. Si la norma de conflicto extranjera en materia sucesoria remite a la Ley de un «tercer país», dicho reenvío (= que sería un «reenvío

${ }^{123}$ D. SEARL, You and the Law in Spain, 16th ed., Santana Books, Fuengirola, 2005, pp. 243-273. 
de segundo grado») no se acepta (= art. 12.2 Cc. a contrario). La sucesión quedará en tal caso regulada por las normas materiales del Derecho extranjero que corresponde a la nacionalidad del causante en el momento de su fallecimiento (= Ley designada por la norma de conflicto española, art. 9.8 Cc.).

66. Sexto. Si la cuestión sucesoria que debe regularse por un Derecho extranjero ex art. 9.8 Cc. recibe, según tal Derecho extranjero, una calificación distinta a la que ha recibido en Derecho español, se aplicarán las normas de conflicto del Derecho extranjero correspondientes a la calificación que en tal ordenamiento recibe la institución. Es el «reenvío de calificaciones» (B. Barel / St. Armellini, G. Kegel, Y. Lequette, Ph. Francesca$\mathrm{KIS}^{124}$ ). Ejemplo: si la capacidad para testar no es una cuestión sucesoria en el Derecho de la nacionalidad del causante, sino una cuestión de «capacidad», deberán entonces tenerse en cuenta las normas de conflicto extranjeras en materia de capacidad, y no las normas de conflicto en materia de sucesión mortis causa.

67. Séptimo. Si la norma de conflicto extranjera es contraria al orden público internacional español, dicha norma no podrá «tenerse en cuenta». Resultado: el reenvío es, en tal caso, imposible y la sucesión mortis causa se regirá entonces por la Ley material extranjera designada por la norma de conflicto española. El supuesto difícilmente se producirá en el ámbito de las sucesiones. Pero es más frecuente en sectores como la filiación. Ejemplo: la filiación de un sujeto argelino se rige por el Derecho argelino (art. 9.4 Cc.), pero si el Derecho argelino «reenvía» al Derecho del país de la nacionalidad del «padre», esta norma de conflicto no puede tenerse en cuenta. Se aplicará directamente el Derecho sustantivo argelino y no habrá ningún reenvío.

\section{Reenvío y conflicto de sistemas}

68. El objetivo del art.12.2 Cc. no es resolver un «conflicto de sistemas», sino proporcionar solución al polémico asunto del reenvío. En consecuencia, los tribunales españoles deben aplicar a las situaciones privadas internacionales que se les planteen las normas de conflicto españolas (= principio de exclusividad del DIPr. del foro, deducible del art. 12.6 Cc.). El art. 12.2 Cc. no permite aplicar normas de DIPr. extranjeras «en sustitución» de las normas de conflicto españolas ${ }^{125}$. Despejada dicha cuestión, debe indicarse que,

${ }^{124}$ G. Kegel, Die Grenze..., 1962, pp. 33-34; Y. LeQuetTe, «Le renvoi de...», 1990, pp. 249-262; Ph. FrancesCAKIs, La theorie du renvoi..., 1958, pp. 82-85.

${ }^{125}$ En tal sentido, A. BorRás RodríGUEZ, «Art. 12.2 Cc...», 1991, p. 141. Un excelente estudio de las relaciones entre reenvío y conflicto de sistemas a través se encuentra en el trabajo de P. LouIs-LuCAS, «Vue simplifiée...», 1964, pp. 1-14. 
en ciertos supuestos, el art. 9.8 Cc. somete la sucesión a la Ley nacional del causante en el momento de su fallecimiento, pero resulta que el DIPr. de dicho país en materia sucesoria no contiene una «norma de conflicto de Leyes», sino una norma de «conflicto de sistemas». Así, el art. 91.1 Ley suiza DIPr. 1987 indica que la sucesión de una persona que haya tenido su último domicilio en el extranjero se rige por el Derecho que designen las normas de Derecho internacional privado de dicho Estado. En tal caso, el art. 9.8 Cc. vuelve a ser aplicable y designa la Ley sustantiva rectora de la sucesión. Ejemplo: la sucesión de causante suizo con último domicilio en España se rige, en principio, por el Derecho suizo. Pero el DIPr. suizo remite al art. 9.8 Cc., que a su vez, vuelve a remitir, ahora de modo definitivo, al Derecho sucesorio sustantivo suizo, que regirá la sucesión (SAP Barcelona 28 septiembre 2004). Dos hipótesis son posibles.

69. En primer lugar, cabe recordar al respecto que nada en el art. 12.2 Cc. se opone a aceptar la remisión que la norma suiza de «conflicto de sistemas» hace en favor del art. 9.8 Cc. El resultado final es la aplicación del Derecho material, español o extranjero, designado por las normas de conflicto españolas, esto es, por el art. $9.8 \mathrm{Cc}$. No se incumple el art. $12.2 \mathrm{Cc}$., que sólo prohíbe la remisión en favor de la Ley «de un tercer país» realizada por la norma de conflicto del Derecho del país de la nacionalidad del causante.

70. En segundo lugar, si las normas extranjeras que resuelven un «conflicto de sistemas» ordenan aplicar «normas de DIPr. de un tercer país», la cuestión cambia. Con arreglo al art. 12.2 Cc., la aplicación de las normas de conflicto de un «tercer país» no es posible, incluso si tales normas remitieran a la Ley española. Por tanto, se debe aplicar el Derecho material del país al que remite la norma de conflicto española y no se tendrá en cuenta la remisión que la norma extranjera sobre «conflicto de sistemas» hace en favor de normas de conflicto de un tercer país. Ejemplo: si el causante suizo cuya sucesión se debate en España tuvo su último domicilio en Londres y tenía bienes inmuebles en España, resultaría que el art. $9.8 \mathrm{Cc}$. haría aplicable la norma suiza de conflicto de sistemas, que a su vez remitiría la regulación del asunto al Derecho inglés, cuyas normas de conflicto remitirían al Derecho español (= lugar de situación de los bienes inmuebles). Pues bien: el art. 12.2 Cc. no admite esta compleja operación, de modo que el Derecho sucesorio material suizo regulará esta sucesión.

\section{Los tribunales españoles y el reenvío}

\section{Doctrina del Tribunal Supremo sobre el reenvío en materia sucesoria}

71. Resulta conveniente analizar, de modo sumario, la «trilogía del reenvío en materia sucesoria» generada por el TS. En este cuerpo de jurispruden- 
cia, el TS confirma varias proposiciones, ya vertidas en este estudio: $1 .^{\circ}$ ) el reenvío es una mera herramienta al servicio del art. $9.8 \mathrm{Cc} . ; 2 .^{\circ}$ ) el reenvío no puede romper, en ningún caso, la unidad legal de la sucesión (= principio impuesto de manera primordial por el art. $\left.9.8 \mathrm{Cc}.) ; 3 .^{\circ}\right)$ para aceptar el reenvío debe concurrir, además, un «índice positivo de reenvío»; $4^{\circ}$ ) tal índice positivo de reenvío puede ser, bien la existencia de un «falso conflicto material de leyes» (= similitud sustancial entre las Leyes sucesorias en conflicto), o bien la utilización del reenvío para lograr un mejor «ajuste de la localización» (= que permite aplicar a la sucesión la Ley del país más estrechamente vinculado con el supuesto sucesorio); 5. ${ }^{\circ}$ ) la «armonía internacional de soluciones» en «sentido conflictual» no es objetivo del art. $12.2 \mathrm{Cc}$.; $6^{\circ}{ }^{\circ}$ ) el contenido material de las Leyes en conflicto es irrelevante para aceptar o negar el reenvío (= salvo que se produzca, como antes se ha dicho, un falso conflicto de Leyes en sentido material); $7^{\circ}$ ) la voluntad del testador es un elemento irrelevante para aceptar o negar el reenvío; . $^{\circ}$ ) el tipo de conexión empleado por la norma de conflicto extranjera (= conexión «cultural», «social», «económica», etc.) es también irrelevante para aceptar o negar el reenvío.

72. a) STS 15 noviembre 1996, Lowenthal. Se trababa de fijar la Ley reguladora de la sucesión de un causante ciudadano del State de Maryland, EE.UU. El último domicilio del causante estuvo en Inglaterra, país en el que falleció. El causante disponía de bienes inmuebles situados en España y parece ser que también en Maryland, EE.UU. El causante otorgó testamento en cuya virtud dejó todos sus bienes, a título de heredero universal, a su hermano y a los descendientes de éste. Los hijos del causante impugnaron la validez del testamento por no respetar las legítimas del Derecho civil común español. La SAT Granada 22 diciembre 1988 falló el caso en apelación y aceptó el reenvío en favor de la Ley española en lo que se refería a los bienes inmuebles. Ello provocó la fragmentación legal de la sucesión (= la sucesión de los inmuebles regida por la Ley española y la sucesión de los muebles quedaba regida por la Ley de Maryland). Es poco conocido, pero rigurosamente cierto, que un magistrado de la Sala consultó al Prof. D. A. MARín LóPEZ sobre la procedencia del reenvío y que el citado profesor se manifestó en favor del reenvío. La STS 15 noviembre 1996 corrigió severamente lo sostenido por la SAT Granada 22 diciembre 1988. El fundamento jurídico más importante de la STS 15 noviembre 1996 en relación con el reenvío en materia sucesoria es el fundamento jurídico octavo ${ }^{126}$. El TS afirmó que no

${ }^{126}$ STS 15 noviembre 1996 FJ 8. : «El texto del artículo 12.2 del Código Civil, dice literalmente: la remisión al derecho extranjero se entenderá hecha a su ley material, sin tener en cuenta el reenvío que sus normas de conflicto puedan hacer a otra ley que no sea la española. Este precepto deja perfectamente claro que cuando el artículo 9.8 del Código Civil, declara: «la sucesión por causa de muerte se regirá por la ley nacional del causante en el 
procedía aceptar el reenvío parcial que las normas de conflicto del State de Maryland hacían en favor de la Ley española. Y ello por varias razones: 1..$\left.^{\circ}\right)$ El reenvío no es obligatorio, sino una mera facultad que el juzgador español puede «tener en cuenta» o no. $2^{\circ} .^{\circ}$ ) En este caso, no era procedente admitir el reenvío porque éste habría provocado un «fraccionamiento de la sucesión», ya que la sucesión de los bienes inmuebles sitos en Maryland habría quedado sometida a la Ley de dicho State y la sucesión de los bienes inmuebles sitos en España, habría quedado sujeta a la Ley sustantiva española, lo que hubieran vulnerado el principio básico del art. 9.8 Cc.. 3. ${ }^{\circ}$ ) El TS indica que un índice positivo que podría hacer aconsejable aceptar el reenvío es la resolución de un «falso conflicto de Leyes». Sin embargo, en este caso, no se producía ningún «falso conflicto de Leyes», pues el Derecho de Maryland admite la plena libertad de testar y el Derecho civil común español se

momento de su fallecimiento, cualesquiera que sean la naturaleza de los bienes y el país donde se encuentren», el derecho aplicable a la sucesión de autos es el del Estado de Maryland. Ahora bien, cuando la norma de conflicto de este Estado reenvía a otro Estado que no sea España, dicha remisión no ha de tenerse en cuenta (y se aplica la ley de Maryland), pero si la remisión, como en este caso, es a la legislación española, puesto que las leyes sucesorias de Maryland establecen que respecto a inmuebles la sucesión se rige por la ley del lugar donde están sitos, esta remisión sí que «debe tenerse en cuenta», pues así lo exige el texto del artículo 12.2. La frase «tener en cuenta» no equivale a que deban aplicarse nuestras normas sucesorias de modo inexorable, puesto que en español (Diccionario de la Real Academia) «tener en cuenta» quiere decir «tener presente, considerar», y ello es lo que debe hacer esta Sala: considerar si el reenvío (que ya ha sido alguna vez admitido por nuestros Tribunales de instancia) ha de aceptarse en el presente caso, en virtud de lo dispuesto en la norma de conflictos del Estado de Maryland, que utiliza como punto de conexión el lugar de situación de los inmuebles para determinar la norma de derecho material por la que ha de regirse la sucesión de sus ciudadanos. La negación del reenvío puede apoyarse en que la colisión entre el estatuto sucesorio establecido en el artículo 9.8 del Código Civil, y la que habla y permite el reenvio de retorno, como es el artículo 12.2, no existe, es más aparente que real. El artículo 12.2 contiene una norma de carácter general, de las denominadas por la doctrina «norma de aplicación o funcionamiento» que no puede interpretarse aisladamente, sino en relación con la norma específica y concreta que regula la materia de sucesiones, que en el derecho español es el 9.8, y en él se inclina por el punto de conexión de la nacionalidad para elegir la norma rectora de la sucesión, cualesquiera que sea la naturaleza de los bienes y el lugar donde se encuentren. El derecho español entiende preponderante la ley nacional del «de cuius»; al propio tiempo, el sistema hereditario español es de carácter universalista, esto es, sostiene el criterio de unidad del régimen sucesorio. A ello se puede añadir que la defensa de derechos legitimarios, hecha por los actores con apoyo en el derecho español no necesariamente ha de tener contenido real y en consecuencia no abona la tesis del reenvío en la sucesión de inmuebles radicados en España. El reenvio, por último, debe entenderse como un instrumento de armonización de sistemas jurídicos de los Estados, como un instrumento respetuoso con los principios que los inspiran y si el derecho americano se apoya en una gran libertad de testar, y no reconoce las legítimas de los hijos, en nada armonizaría la coexistencia de los derechos respectivos, la aplicación por esta Sala del derecho español a la sucesión del causante de este litigio, que no ha conservado con España ni la residencia ni el domicilio». 
inspira en el principio contrario, básico e imperativo, de respeto a las legítimas; $4^{\circ}$ ) El TS indica que otro índice positivo de reenvío es el hecho de que el supuesto sucesorio presente vínculos muy estrechos con España a pesar de la nacionalidad extranjera del causante (= test de proximidad en favor de la conexión estrecha del caso con España). Índice que, sin embargo, tampoco concurría en este supuesto, ya que el causante no tenía ni su residencia ni su domicilio en España. En conclusión, el TS niega el reenvío porque se incumple la condición básica de reenvío (= el reenvío hubiera provocado el inaceptable resultado de una sucesión regida por varias leyes), y porque, además, no hay ningún índice positivo de reenvío. Ni el caso escondía un «falso conflicto de leyes» ni la sucesión aparecía más estrechamente conectada con España que con Maryland.

73. b) STS 21 mayo 1999, Denney. Se debatió la Ley aplicable a la sucesión de un ciudadano inglés fallecido en España. El causante otorgó testamento en España y dejó todos sus bienes a su segunda esposa. Los hijos habidos por el causante con su primera esposa reclamaron su legítima a tenor de lo dispuesto por el Código Civil español. El fundamento jurídico más destacado en relación con la cuestión del reenvío es el fundamento jurídico cuarto ${ }^{127}$. El TS aplicó la Ley sustantiva inglesa y rechazó el reenvío porque cre-

${ }^{127}$ STS 21 mayo 1999 FJ 4. ${ }^{\circ}$ : «No obstante el contenido del informe sobre la jurisprudencia de los Tribunales ingleses sobre aplicación del reenvío, acompañado con la deman$d a$, lo cierto es que, como señalan los autores, tanto españoles como británicos, la jurisprudencia de ese país marca una nueva tendencia reticente a la aplicación del reenvío en materia sucesoria; postura coincidente con la que sustenta la más moderna doctrina internacionalista española en relación con el reenvío establecido en el art. 12.2 del Código Civil respecto a la norma de conflicto inglesa en materia de sucesiones inmobiliarias; así es de ver como en asunto Adams, el Juez inglés rechaza la aplicación del reenvio, entendiendo que los Tribunales españoles sólo lo aplicarían en ciertos casos y bajo determinadas condiciones, de tal manera que será aplicado cuando los Juzgadores lo estimen oportuno, o sea, que éstos sólo aceptarán el reenvío de retorno cuando éste lleve a un resultado acorde con los principios generales del Derecho español. Si bien una aplicación puramente literalista del artículo 12.2 del Código Civil conduciría a la solución defendida en la demanda, la evolución actual del Derecho Internacional Privado, tal como se manifiesta en el Derecho comparado y de manera notable en el Derecho convencional internacional, implica un tratamiento matizado del reenvío que hace imposible adoptar una actitud indiscriminada de aceptación o rechazo del mismo, sino proceder en su aplicación con un criterio flexible y de aplicación restrictiva y muy condicionada. La aplicación del reenvío en los términos pretendidos en la demanda, es contrario al principio de universalidad de la herencia que rige nuestro Derecho sucesorio e impide dar un tratamiento jurídico distinto a la sucesión mobiliaria y a la inmobiliaria; asimismo contradice y deja sin aplicación el principio rector del Derecho inglés en materia sucesoria como es de libertad de testar, manifestación de la autonomía de la voluntad. Por otra parte, como señala la sentencia de esta Sala de 15 de noviembre de 1996, ante supuesto análogo al actual, la aplicación al caso del reenvío de retorno no conseguiría la finalidad que se asigna a este instrumento jurídico, de armonización de los sistemas jurídicos de los Estados, a lo que debe añadirse que en este 
yó, erróneamente, que, en el caso concreto, de haber aceptado el reenvío, se habría producido un «fraccionamiento legal de la sucesión», de modo que la sucesión de los bienes inmuebles hubiera quedado sujeta a la Ley española ( $=$ los inmuebles litigiosos estaban sitos en España), mientras que la sucesión de otros bienes hubiera quedado sometida a otra Ley diferente, a la Ley del país de situación de los bienes muebles (= pues existían bienes muebles litigiosos sitos en Francia y España) ${ }^{128}$. Sin embargo, el reenvío, bien aplicado, habría conducido a la aplicación de la Ley española a la totalidad de la sucesión, pues la sucesión de los bienes muebles se rige, en DIPr. inglés, por la Ley del país de último domicilio del causante, que estaba en España, y no por la Ley de situación de los bienes muebles, algo que el TS no supo ver. El

supuesto la solución que se alcanzaría con esa aplicación tampoco puede afirmarse que entrañe una mayor justicia en relación con los intereses en juego. Por todo ello, debe concluirse que la sucesión del causante don Iván se rige por su ley nacional, es decir, por la Ley inglesa reconocedora de la libertad de testar a sus nacionales y, en consecuencia, procede la desestimación de la demanda, con revocación de la sentencia de primera instancia».

${ }^{128}$ Es clave el párrafo que seguidamente se reproduce y contenido en el FJ 2. ${ }^{\circ}$ de la STS 21 mayo 1999: «La aplicación del reenvío en los términos pretendidos en la demanda, es contrario al principio de universalidad de la herencia que rige nuestro Derecho sucesorio e impide dar un tratamiento jurídico distinto a la sucesión mobiliaria y a la inmobiliaria; asimismo contradice y deja sin aplicación el principio rector del Derecho inglés en materia sucesoria como es de libertad de testar, manifestación de la autonomía de la voluntad». El TS creyó que, de aceptar el reenvío de retorno, la herencia quedaría partida en dos «segmentos de bienes» regidos por Leyes distintas (= obsérvese la frase del TS: «La aplicación del reenvío en los términos pretendidos en la demanda, es contrario al principio de universalidad de la herencia que rige nuestro Derecho sucesorio e impide dar un tratamiento jurídico distinto a la sucesión mobiliaria y a la inmobiliaria...»: cursiva enfática añadida). El TS subraya que, el reenvío, en su opinión, hubiera conducido a la fragmentación legal de la sucesión en este caso concreto (= lo cual era un error: la toma en consideración de la norma de conflicto inglesa y la aplicación del Derecho sucesorio material español no hubiera producido ningún fraccionamiento legal de la sucesión). Y por eso rechazó el reenvío, porque creyó que sólo así se evitaba segmentar la herencia en grupos de bienes regidos por Leyes estatales diferentes. Aunque ciertos autores se limitan a corroborar lo que el TS, equivocadamente, afirma (= es decir, que en el supuesto de la STS 21 mayo 1999 el reenvío hubiera producido un fraccionamiento legal de la sucesión, como es el caso de S. SÁNCHEZ LORENZO, «Ámbito del reenvío en la determinación de la Ley aplicable a la sucesión hereditaria», Anuario Español de Derecho internacional privado, 2004, pp. 1144-1146), otros autores sí percibieron el desliz del TS, y subrayaron que, en este supuesto fáctico, el reenvío no producía ningún fraccionamiento legal de la sucesión y que el TS se equivocó al creer que ello era así (E. CASTELLANOS RuIZ, «Reenvío, unidad de la sucesión y armonía internacional de soluciones en el Derecho sucesorio: antes y después de la STS de 23 septiembre 2002», en A.-L. Calvo Caravaca/ E. Castellanos Ruiz (dirs.), El Derecho de familia ante el siglo XXI: aspectos internacionales, Madrid, Colex, 2004, pp. 239-269; ID., «Sucesión hereditaria» en A.-L. CAlvo CARAVACa / J. CARrascosa GonZÁlez (Directores), Derecho internacional privado, vol. II, Granada, Comares, 8. ${ }^{\text {e }}$ ed., 2007, pp. 250-299; J. PÉREZ MiLla, «De nuevo el TS matiza el ámbito del reenvío de retorno en materia sucesoria (nota a la STS 21 mayo 1999)», AEDIPR, 2001, pp. 1094-1097). 
hecho de que el Derecho sucesorio inglés esté presidido por el principio básico de la plena libertad de testar, y el Derecho español esté presidido por el principio contrario del respeto a las legítimas imperativas, fue un argumento utilizado por el TS para negar el reenvío, pero sólo ad adjuvandum, pues lo decisivo para negar el reenvío fue que, para el TS, dicho reenvío hubiera producido fraccionamiento legal de la sucesión. En conclusión: el TS negó el reenvío porque, en un profundo error, creyó que, en el supuesto concreto, dicho reenvío hubiera conducido al fraccionamiento legal de la sucesión (= faltaba, pues, según el TS, la condición básica que debe respetar todo reenvío). Y añadió que, en todo caso, el diferente e incluso opuesto contenido material del Derecho sucesorio inglés y del Derecho sucesorio español hacía que no se produjera ningún «conflicto negativo de Leyes» (= circunstancia que hubiera aconsejado aceptar el reenvío en el caso de que éste no provocase la fragmentación legal de la sucesión).

74. c) STS 23 septiembre 2002, François Marie James W. El TS aborda la Ley aplicable a la sucesión de un causante británico cuyo último domicilio estuvo en Nerja (Málaga), población donde residió los últimos ocho años de su vida. El causante había otorgado testamento en favor de su esposa española. Pero el causante era padre de una hija habida con otra mujer, de nacionalidad española. Esta mujer, en representación legal de su hija menor de edad, reclamó la legítima de su hija con arreglo al Código Civil español. Todos los bienes del caudal hereditario, bienes inmuebles todos ellos, se encontraban en España. El fundamento jurídico más relevante para la cuestión del reenvío es el segundo ${ }^{129}$. El TS indicó que el art. 9.8 Cc. remitía al

${ }^{129}$ STS 23 septiembre 2002 FJ 2. ${ }^{\circ}$ : «La fundamentación de este motivo consiste en esencia en sostener la procedencia de que la sucesión se rija por la ley nacional del causante, en este caso la inglesa, que otorga al mismo la libertad para dejar sus bienes a quien estime, no estando vinculado por legítimas ni instituciones análogas, restrictivas de la libertad de disposición 'mortis causa'. Dice la recurrente que la norma de conflicto aplicable (el art. 9.8 Cód. civ.) responde al principio de unidad y personalidad de la sucesión, incompatible con la remisión del derecho inglés en cuanto a los inmuebles a la del lugar donde estén sitos, y opera como filtro al reenvío de retorno (art. 12.2 Cód. civ.), en cuanto 'ius specialis', citando y resaltando la sentencia de esta Sala de 15 de noviembre de 1996, en un supuesto en que la norma de conflicto reenviaba al lugar de la situación de los inmuebles. Entendía la recurrente también que debía respetarse la voluntad del testador de legar a su esposa los bienes inmuebles existentes en España, manifestando en el testamento que la 'disposición es posible con arreglo a su ley personal', y ello obligaba a no aceptar el reenvío al derecho español. El motivo se desestima, pues la aplicación de la ley española a la que se reenvía el derecho inglés, que es la ley personal del causante, respecto de los inmuebles sitos en España, no es contraria a los principios de unidad y universalidad de la sucesión, que es a lo que obedecen la regla del art. 9.1 Cód. civ. En efecto, la sentencia recurrida da como probado que los únicos bienes del causante son los inmuebles sitos en España de los cuales dispuso testamentariamente, por lo que en modo alguno se produce una fragmentación de la regulación de la herencia, en cuyo caso, la norma general (no específica 
Derecho inglés, pero que la norma de conflicto inglesa afirmaba que la sucesión de los bienes inmuebles debía regirse por la Ley del país de situación de los bienes inmuebles. El TS declaró que, en consecuencia, la sucesión debía regirse por el Derecho sucesorio español en virtud de reenvío de retorno (art. $12.2 \mathrm{Cc}$.), ya que dicho reenvío no provocaba ningún fraccionamiento legal de la sucesión, puesto que la entera sucesión quedaba sujeta al Derecho sustantivo español. En consecuencia, el testamento debía reducirse para respetar la legítima de hija preterida. El TS indica que el hecho de que el Derecho inglés se base en el principio de libertad absoluta de testar y el Derecho español esté construido sobre el principio opuesto del respeto imperativo de las legitimas no debe influir en la aceptación o rechazo del reenvío. Conclusión: 1. ${ }^{\circ}$ ) en este caso, el TS acepta el reenvío porque se verifica la condición básica del reenvío ( $=$ se respeta la unidad legal de la sucesión: toda la sucesión queda regida por una sola Ley, la Ley española); $2^{\circ}$ ) el TS acepta el reenvío porque, además del respeto a la unidad legal de la sucesión, se aprecia la existencia de un «índice positivo de reenvío» (= la «vinculación más estrecha» de la sucesión con España frente a una conexión fugaz, pasajera, anecdótica y débil con Inglaterra); $3^{\circ}$ ) es irrelevante el hecho de que el contenido del Derecho sucesorio material inglés y del Derecho material sucesorio español sean completamente divergentes. Si hubieran sido contenidos materiales «similares», se habría verificado un «índice positivo de reenvío» (= el conflicto negativo de Leyes). Pero ello era ya innecesario, porque en este concreto supuesto, ya concurría otro índice positivo de reenvío (= la más estrecha vinculación del caso con España), lo que, sumado a la unidad legal de la sucesión, hicieron que el TS aceptase el reenvío.

\section{Los tribunales inferiores y el reenvío en materia sucesoria desde 1996}

75. Tras la STS 15 noviembre 1996, la «revolución del reenvío» llegó también a instancias judiciales inferiores. Las decisiones más destacables de tales tribunales relacionadas con el reenvío en materia sucesoria y posteriores a la STS 15 noviembre 1996 son las que siguen.

1. $\left.{ }^{\circ}\right)$ SAP Málaga 18 diciembre 1996: se acepta el reenvío que efectúa la Ley inglesa en favor de la Ley española pues dicho reenvío no supone nin-

para la sucesión 'mortis causa') del art. 12.2 Cód. civ. impondría la no aceptación del reenvío de la ley inglesa por contraria a aquellos principios. Éste es el criterio de esta Sala, y a él responden las declaraciones contenidas en su sentencia de 15 de noviembre de 1996, que no aceptó el reenvío que la ley nacional del causante hacía a la ley española en cuanto a los inmuebles por estar sitos en España, lo mismo que las contenidas en su sentencia de 21 de marzo de 1999. Por tanto, si como en este litigio ocurre, la herencia del causante se compone únicamente de bienes inmuebles sitos en España, no hay ningún inconveniente en la aceptación del reenvío de la ley inglesa, pues será la española la única que regula toda sucesión del causante». 
gún fraccionamiento legal de la sucesión. Esta decisión es correcta: concurría la condición básica del reenvío (= se respeta la unidad legal de la sucesión) y además se verificaba también un índice positivo de reenvío (= la sucesión estaba más estrechamente vinculada con España que con Inglaterra). Esta sentencia fue confirmada por la STS 23 septiembre 2002.

2..$\left.^{\circ}\right)$ SAP Alicante 7 junio 2001: se rechaza el reenvío de la Ley inglesa a la española porque provocaba un fraccionamiento legal de la sucesión, ya que existían bienes sucesorios litigiosos en Inglaterra y en España. Esta decisión es correcta, ya que al no concurrir la condición básica del reenvío (= la unidad legal de la sucesión), el reenvío no procede.

3. $\left.{ }^{\circ}\right)$ SAP Málaga 13 marzo 2002: se rechaza el reenvío porque el contenido del Derecho inglés y del Derecho español es muy divergente, a pesar de que el reenvío no comportaba, in casu, ningún fraccionamiento legal de la sucesión y a pesar de que ésta estaba más estrechamente vinculada con España que con Inglaterra. Esta decisión es criticable: en este caso se verificaba la condición básica del reenvío en materia sucesoria y además concurría un claro índice positivo de reenvío. El tribunal debió aceptar el reenvío de la Ley inglesa en favor de la Ley material sucesoria española.

$\left.4^{\circ}{ }^{\circ}\right)$ SAP Alicante 10 marzo 2003: se rechaza el reenvío porque el contenido del Derecho escocés y del Derecho español resulta ser muy diferente, a pesar de que el reenvío no comportaba, in casu, ningún fraccionamiento legal de la sucesión y de que ésta estaba más estrechamente vinculada con España que con Escocia. Esta decisión es también criticable: en este caso se verificaba la condición básica del reenvío en materia sucesoria y además concurría un claro índice positivo de reenvío. El tribunal debió aceptar el reenvío de la Ley escocesa en favor de la Ley material sucesoria española.

6. $\left.{ }^{\circ}\right)$ SAP Tarragona 13 mayo 2004: no se aceptó el reenvío porque no quedó probada la norma de conflicto belga en materia sucesoria.

7..$\left.^{\circ}\right)$ SAP Granada 19 julio 2004: se rechaza el reenvío porque la norma de conflicto irlandesa conducía al fraccionamiento legal de la sucesión, ya que existían bienes inmuebles sucesorios sitos en Inglaterra y en España. Esta decisión es correcta: no se verificaba la condición básica del reenvío (= la unidad legal de la sucesión), por lo que el rechazo del reenvío era obligado.

8. $\left.^{\circ}\right)$ SAP Asturias 1 septiembre 2005: se acepta el reenvío en favor de la Ley española efectuado por las normas de conflicto del Estado de Pennsylvania, EE.UU., por dos razones. Primero, porque no quedaron acreditadas las normas de conflicto del Estado de Pennsylvania. Segundo, porque el reenvío no provocaba ningún fraccionamiento de la sucesión. Naturalmente, ambos argumentos son incompatibles. Si opera el primero, el segundo no puede operar y viceversa. 


\section{Conclusión}

76. La localización de la sucesión mortis causa en un país determinado, cuya Ley debe regir tal sucesión, no es álgebra ni aritmética. Es un arte. Los legisladores de todos los países han ensayado durante siglos multitud de soluciones diferentes en el intento de alcanzar la localización perfecta en materia sucesoria. Pero en el arte, y por tanto, en los conflictos de Leyes, la perfección no existe, porque toda solución conflictual puede siempre mejorarse, afinarse, superarse. El reenvío, ese clásico inmortal de los conflictos de Leyes, se contempla hoy como un mecanismo jurídico que, utilizado en su justa medida, acompaña como siervo fiel a la norma de conflicto en materia sucesoria. Así entendido, el reenvío puede ser empleado para lograr que la localización de una sucesión en un país concreto se lleve a término con mayor Justicia. El reenvío contribuye a perfeccionar el arte de la localización, quod erat demostrandum. Como los maestros del Renacimiento italiano, los expertos en los conflictos de Leyes aprenden los unos de los otros, pues el arte es universal. En las soluciones que hoy maneja el Tribunal Supremo español se adivinan más de cien años de intentos doctrinales de utilizar el reenvío para mejorar la localización y para proporcionar una solución más justa a la cuestión de la determinación de la Ley aplicable a las sucesiones. Esos pentimenti que se adivinan tras cada sentencia y tras cada propuesta doctrinal sobre el reenvío son los restos de un pasado que recuerda a todo conflictualista que la localización perfecta no existe, es cierto, pero que la búsqueda de esa localización ideal es la que da sentido a la vida de los juristas que aman los conflictos de Leyes. 
